
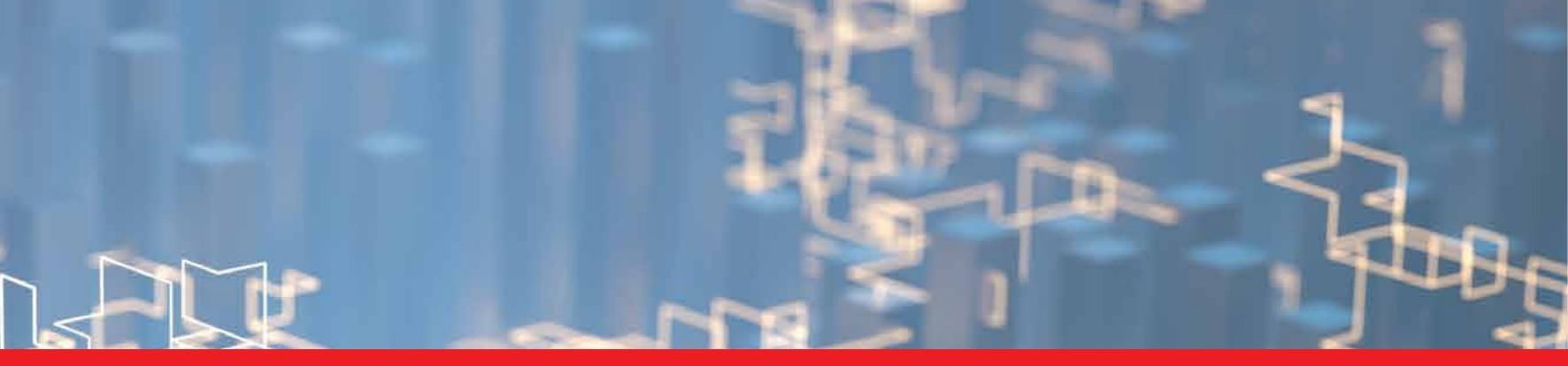

\title{
IntechOpen
}

\section{Risk Management and Assessment}

\author{
Edited by Jorge Rocha, \\ Sandra Oliveira and César Capinha
}

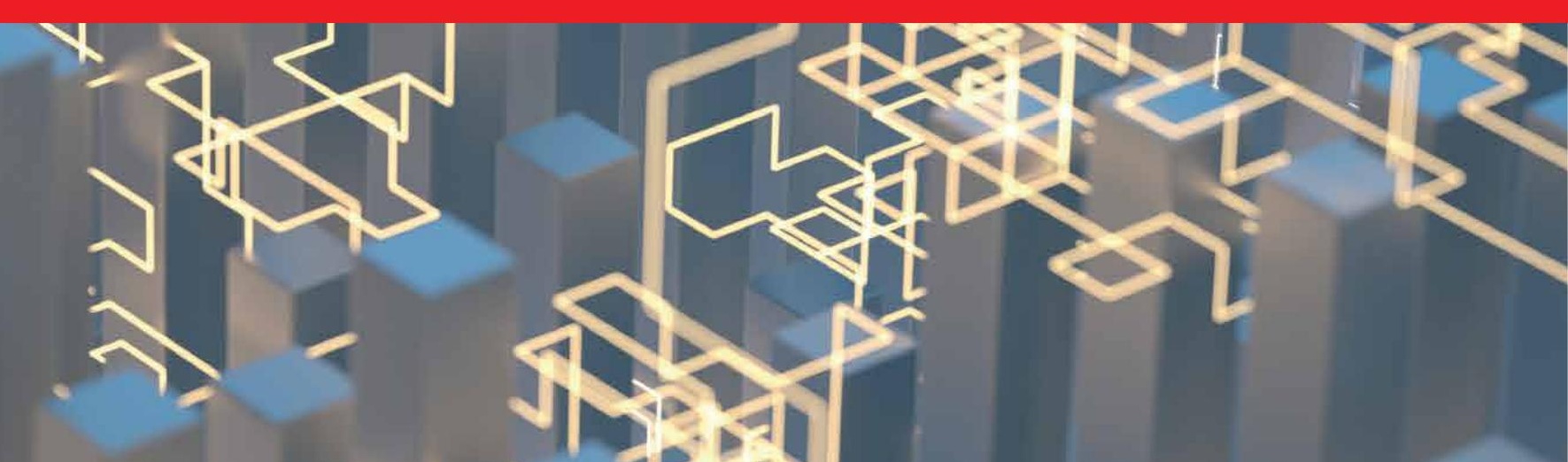





\title{
Risk Management and Assessment
}

\author{
Edited by Jorge Rocha, \\ Sandra Oliveira and César Capinha
}



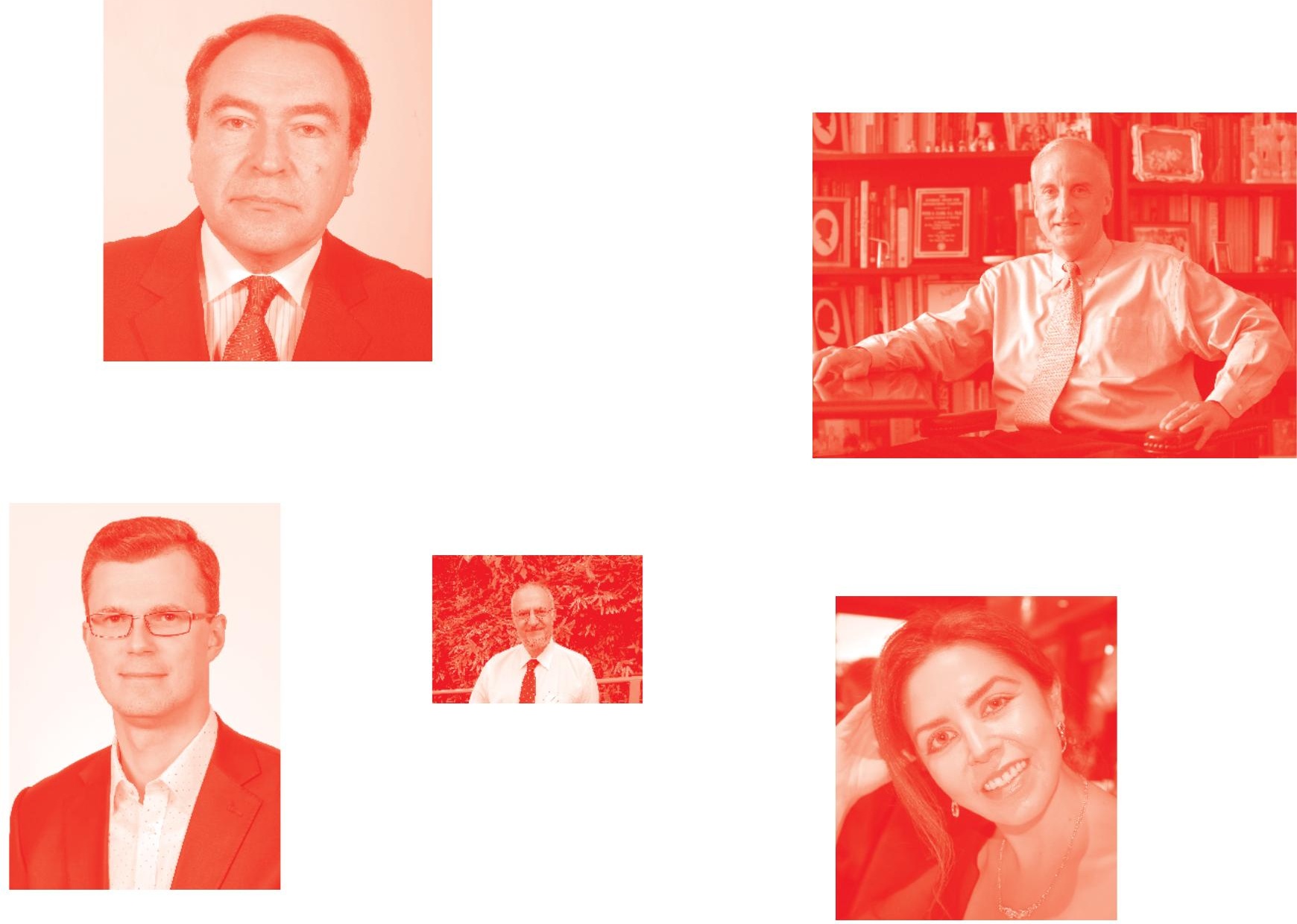

Supporting open minds since 2005
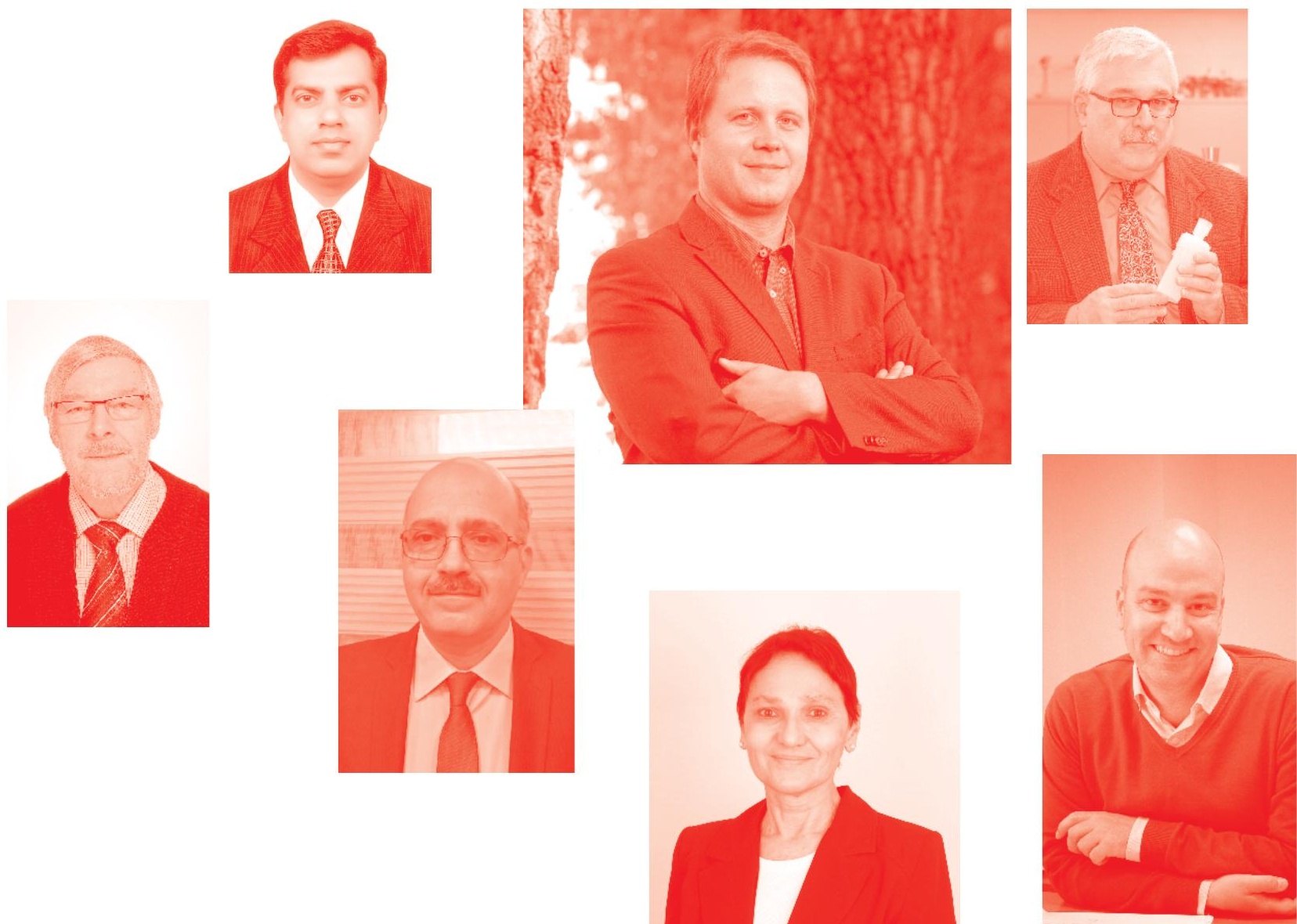
Risk Management and Assessment

http : //dx . doi. org/10.5772/intechopen. 83256

Edited by Jorge Rocha, Sandra Oliveira and César Capinha

\section{Contributors}

Karine Sargsyan, Gabriele Hartl, Brigitte Jaksa, Marek Rozycki, Ireneusz Miciuła, Sabina Irimie, Emilia Dunca, Małgorzata Dendera-Gruszka, Ewa Kulińska, Jorge Rocha, Sandra Oliveira, César Capinha, Leon Dorozik, Tomasz Strąk, Tanja Macheiner

( ) The Editor(s) and the Author(s) 2020

The rights of the editor(s) and the author(s) have been asserted in accordance with the Copyright, Designs and Patents Act 1988. All rights to the book as a whole are reserved by INTECHOPEN LIMITED. The book as a whole (compilation) cannot be reproduced, distributed or used for commercial or non-commercial purposes without INTECHOPEN LIMITED's written permission. Enquiries concerning the use of the book should be directed to INTECHOPEN LIMITED rights and permissions department (permissions@intechopen.com).

Violations are liable to prosecution under the governing Copyright Law .

\section{(cc) BY}

Individual chapters of this publication are distributed under the terms of the Creative Commons Attribution 3.๑ Unported License which permits commercial use, distribution and reproduction of the individual chapters, provided the original author(s) and source publication are appropriately acknowledged. If so indicated, certain images may not be included under the Creative Commons license. In such cases users will need to obtain permission from the license holder to reproduce the material. More details and guidelines concerning content reuse and adaptation can be found at http : //www . intechopen . com/copyright-policy. html .

Notice

Statements and opinions expressed in the chapters are these of the individual contributors and not necessarily those of the editors or publisher. No responsibility is accepted for the accuracy of information contained in the published chapters. The publisher assumes no responsibility for any damage or injury to persons or property arising out of the use of any materials, instructions, methods or ideas contained in the book.

First published in London, United Kingdom, 2020 by IntechOpen

IntechOpen is the global imprint of INTECHOPEN LIMITED, registered in England and Wales, registration number: 11086078 , 5 Princes Gate Court, London, SW7 2QJ, United Kingdom Printed in Croatia

British Library Cataloguing-in-Publication Data

A catalogue record for this book is available from the British Library

Additional hard and PDF copies can be obtained from orders@intechopen. com

Risk Management and Assessment

Edited by Jorge Rocha, Sandra Oliveira and César Capinha

p. $\mathrm{cm}$.

Print ISBN 978-1-83880-794-8

Online ISBN 978-1-83880-795-5

eBook (PDF) ISBN 978-1-83880-796-2 


\section{We are IntechOpen, \\ the world's leading publisher of Open Access books}

Built by scientists, for scientists

\section{$5,000+$ \\ $125,000+$ \\ International authors and editors \\ $140 \mathrm{M}+$ \\ Downloads}

Our authors are among the

151

Countries delivered to

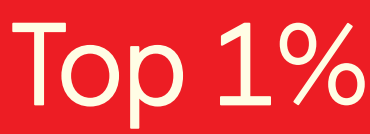

most cited scientists

Contributors from top 500 universities

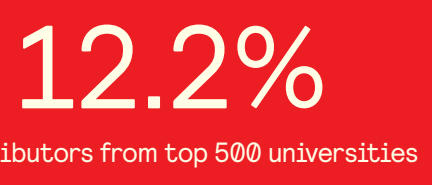

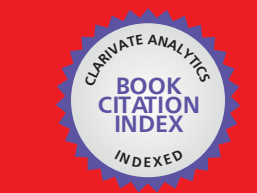

WEB OF SCIENCE ${ }^{\text {M }}$

Selection of our books indexed in the Book Citation Index

in Web of Science ${ }^{\mathrm{TM}}$ Core Collection (BKCI)

\section{Interested in publishing with us? \\ Contact book.department@intechopen.com}

Numbers displayed above are based on latest data collected.

For more information visit www.intechopen.com 



\section{Meet the editors}

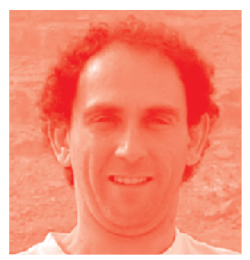

Jorge Rocha achieved his MSc in Geographic Information Systems (2003) and in Spatial Planning (2013), and PhD in Geographic Information Science (2012). He is currently an Assistant Professor of the Institute of Geography and Spatial Planning and a member of the Modelling, Urban and Regional Planning, and Environmental Hazard and Risk Assessment and Management research groups of the Centre of Geographical Studies, University of Lisbon. His field of expertise is geosimulation and geocomputation involving artificial neural networks, graphs theory, cellular automata, and multi-agent systems. Jorge's works are quite diverse, focusing mainly on, but not exclusively, in urban morphology, remote sensing, epidemiology, health geography, smart cities and big data.

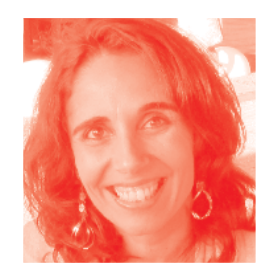

Sandra Oliveira is a researcher for the Centre for Geographical Studies, in the Institute of Geography and Spatial Planning. She graduated in Geography from the University of Coimbra and has a MSc in Environmental Sciences from the University of Wollongong (Australia) and a Ph.D. in Forest and Natural Resources Engineering at the School of Agriculture of the University of Lisbon. She started as a Scientific Officer at the Joint Research Centre-EC in Italy, working in the European Forest Fire Information System (EFFIS). She works in environmental risk assessment and geographic information systems (GIS) and her main interests are in climatic risks, wildfires, forest protection and biodiversity. She is currently focused on spatial modelling and vulnerability assessment of vector-borne diseases.

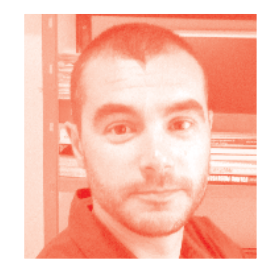

César Capinha has a PhD in Environmental Sciences, a MSc in Geographic Information Systems and Territorial Modelling Applied to Planning, and a Degree in Geography. He is a Research Fellow at the Centre for Geographical Studies (Uni. of Lisbon). César works at the interface between biogeography and biological invasions, looking into how biogeographical patterns are being modified by human-mediated dispersal of species and by other manifestations of global change, such as climate change. César is also very interested in the application and improvement of machine learning and statistical models for ecological modelling, particularly in predicting the risk of invasion by introduced species and in real-time modelling of ecological and epidemiological phenomena. 



\section{Contents}

Preface

Section 1

Risk Analysis

Chapter 1

Introductory Chapter: Risk Management

by Jorge Rocha, Sandra Oliveira and César Capinha

Chapter 2

Risk of Slipping Industrial Landfills

by Emilia-Cornelia Dunca and Sabina Irimie

Chapter 3

Supply Chain FMEA Risk Analysis for the Heavy Industry Sector by Matgorzata Dendera-Gruszka and Ewa Kulinska

\section{Section 2}

Risk Evaluation

Chapter 4

Application of Quantum Physics Assumptions for Risk Assessment by Marek Rozycki

Section 3

Risk Managment

Chapter 5

Risk Assessment Methodology in Public Financial Institutions

by Leon Dorozik, Tomasz Strąk and Ireneusz Miciuta

Chapter 6

Risk Management in Biobanks

by Karine Sargsyan, Brigitte Jaksa, Gabriele Hartl and Tanja Macheiner 



\section{Preface}

Human beings are increasingly subjected to risks and phenomena of natural or technological origin that can compromise the balance between the social and natural environments. The Knowledge Society of the 20th century is characterized by the intensification of risks associated with climate change. Potentially devastating risks are our society's biggest problem.

By definition, risk is the value obtained from the assessment of possible consequences (human losses, direct and indirect damages and costs) caused by incidents or accidents, together with the probability of occurrence of hazardous processes due to the conjunction of the factors involved. Risk is a combination of the probability of unfavorable scenarios and their consequences.

In this context, it is possible, and advisable, to evaluate the expected value of these consequences, in order to establish, based on scenarios, procedures for forecasting, preventing, controlling and mitigating the effects of these hazardous processes to people and assets, associated with both natural and technological risks.

Risk analysis, risk evaluation and risk management are the main pieces in the process known as 'Risk Assessment'. Risk assessment can be understood as the joint effort of identifying and analysing potential future events, i.e., risk analysis, and evaluating the acceptability of risk based on the risk analysis, while considering influencing factors, i.e., risk evaluation. In short, risk assessment analyses what can go wrong, how likely it is to happen and, if it happens, what are the potential consequences.

Since this is a multi-disciplinary domain involving various scientific areas, among which geography, Earth and environmental sciences, ecology, engineering, law, economics, sociology and political sciences, this book gathers contributions covering a wide spectrum of topics with regard to their theoretical background and field of application. As part of this process, the resulting assessment of risk may be expressed in both quantitative and qualitative approaches.

Vulnerability to risks varies widely, primarily depending on the capacity of societies to integrate them in the management of their activities, to mitigate their effects and to recover from the disaster. Two major parameters are decisive for ensuring the development of these capacities and the consequent reduction in vulnerability expert knowledge and planning.

It is within the first parameter that one seeks to discern the magnitude of risks and to test new technologies to support the monitoring, evaluation and communication of threats. The concept of risk has, of course, evolved over time, and is now a basic principle in decision-making by politicians, managers, entrepreneurs, builders and civil protection services, in the definition of safety and security systems, completed in safety and emergency plans, and is integrated in crisis management programs associated with accident situations. 
Risk assessment is an inherent part of an overall risk management strategy, which attempts to introduce, after a risk assessment, control measures to eliminate or reduce any potential risk-related consequences. This concept is linked today to a new paradigm, in which the technological, social and communicational aspects gain even more relevance.

Jorge Rocha, Sandra Oliveira and César Capinha Institute of Geography and Spatial Planning, University of Lisbon, Lisbon, Portugal 
Section 1

Risk Analysis 



\title{
Introductory Chapter: Risk Management
}

\author{
Jorge Rocha, Sandra Oliveira and César Capinha
}

\section{Introduction}

The notion of risk presents itself, nowadays, as one of the most dynamic scientific areas, capturing the attention of researchers from a wide group of disciplines. Studies about the probability of occurrence of an event and its possible consequences are followed by answers that guide the concerns about interventions in relation to the health and safety of populations and the environment. This is why a fundamental question, related to the human perception of risks, arises.

There is a reasonable consensus to consider the age of Renaissance, the discoveries, and the long-distance maritime trade as milestones in the initial consolidation of risk analysis. In the Modern Age, a catastrophe in a European capital, the 1755 earthquake in Lisbon, sparked a debate in Europe around ideas about providence and destiny. This event triggered, from the political power, the implementation of a set of measures to mitigate its social effects as well as protective actions against future earthquakes. The decisions that were made then are a historical example of a response to a natural disaster and an organization model of a first crisis management.

Controlling risk in its various forms, for example, management, analysis, evaluation, and mitigation or treatment, among others, has now become a normal act, almost indispensable in proper governance. In the society of risk, the greater awareness of risk inevitably leads to its assessment and a search for answers, with the objective of implementing an adequate management. Whether risks are natural, technological, or other, the inclusion of perception studies in the risk management processes has become a priority for public policies. We can already ask ourselves how we could face the challenges of the present and the future without these operational instruments.

Protection against hazards that may affect the public or the environment has become a right, recognized and demanded by the public opinion, and an indicator of the quality of life and citizenship. From the resigned acceptance of events, we have moved to a phase of intervention by citizens and states to regulate life and public and private activities in defense of public health and safety.

Increasing social responsibility allows recognizing the effects resulting from the impact of different hazards, whether they are natural or anthropogenic. Politicians also started to use the concept of risk as a support device for the control of society and as a complementary device to ensure security.

Associated with risk comes the concept of vulnerability that characterizes the potential for loss derived from the impact of hazardous events on a given asset. In certain situations and conditions of uncertainty, the credibility or validity of a quantitative risk analysis based on estimated probabilities becomes problematic. In these circumstances, the vulnerability analysis and management can be an appropriate and effective alternative. 
The concept of uncertainty, in turn, is always presented with our incomplete knowledge, namely related to successive "futures," and it has always been recognized as a permanent burden which should be avoided and that, for a long time, has been frequently ignored. Due to the object and nature of risk analysis, the uncertainty in the results and elements on which risk management decisions are based can be very significant and has important consequences. Thus, this chapter presents a summary of some relevant issues raised by the concepts of risk, vulnerability, and uncertainty.

\section{Defining risk}

Risk is increasingly present in today's society. Despite evidences that date back to several centuries, the level of risk awareness has become progressively higher since the last decades of the twentieth century. This has resulted in a higher exposure of people, built-up structures, and human activities to the potential negative effects of hazardous phenomena. In turn, the proximity of people and assets to the occurrence of hazardous events has enabled access to empirical knowledge from the population, valuable for scientific development, and the globalization processes contributed to a greater disclosure about risk from social media.

We live in a society of risk due to the difficulty in quantifying, preventing, and excluding risks from our lives due to their global nature and magnitude. Risk society refers to a type of settlement that is currently more exposed to frequent changes and uncertainty, therefore becoming more demanding and with less guarantees.

However, the attention and treatment given to the concept of risk was not always like today, having evolved over centuries. According to Covello and Mumpower [1], the first risk concerns (although it was not dealt with by this term) occurred around 3200 BC in the Tigris-Euphrates valley, where a group called Asipu practiced the analysis and advice on risk based on repeated events and motivated by divine forces, thus providing support to local populations.

The notion of risk, which is closer to the one currently used, emerged in the fourteenth century and was associated with sea expeditions and the events that could occur and jeopardize their success. In the sixteenth century, the term rischio started to be used in Roman languages to report situations of uncertainty. It was during this period, and from the seventeenth century on, that the risk concept acquired expression through Portuguese and Spanish navigators.

However, the origin of the term itself is still unknown with absolute certainty, and Proske [2] points out as possibilities the Greek word rhizia, the Persian word rozi $(k)$, or even, the Spanish and African languages with the term aresk. These terms had in common a context where life was dependent on God and on a destiny that was impossible to predict and control. According to Ewald [3], risk emerged as an act of God, a force so great that no responsibility could be attributed to humans. They could do little, either in an attempt to predict future events or to reduce its impact.

An important contribution to the evolution of the concept of risk was made by the banking sector during the seventeenth century. In the beginning of its use, the risk concept only included the notion of space, whereas from the moment it started to be used by the banking system, it was linked to the notion of time since this was also essential to determine probable consequences regarding investments, both for creditors and debtors. The emerged idea stated that, in the past, society was concerned with external risk as a result of phenomena imposed by nature, such as droughts, pests, or poor harvests. Currently, the concern lies not only on this but also on the impact that technological development has on the environment. 
During the eighteenth century, risk began to be addressed in the scientific community, especially in mathematics and probabilities. The development of the industry and its need to statistically define the degree of security of its decisions and activities have led to the use of calculus as a way to determine and even try to eliminate possible risks. According to Reddy [4], the advances observed in society over the years moved us toward the eradication of uncertainty, leaving the risk in its place. However, for Castel [5], this removal of uncertainty is not a given fact.

Risk prevention has become a fixation, yet the factor of unpredictability has continued to emerge frequently. The rational treatment given to the risk concept and the calculation carried out for its determination did not exclude completely the occurrence of unpredictable events. A clear evidence of the close relationship between unpredictability and risk can be found in the scope of activities in the insurance industry where the calculations for obtaining insurance values are based on correlative events and statistics accumulated over several years. Although the risk does not disappear, this is a way of people dealing with it and gaining a sense of control.

At the end of the last millennium, one can verify the intensification of the concerns about risk not only within the scientific community but also in the general public, creating the idea that at any moment a negative event can occur, causing disruptions at various levels and general confusion. According to Beck [6], all changes in the nature of risk made it more globalized, less identifiable, and with more serious consequences, creating anxiety in the populations. This state of greater alertness and apprehension regarding the existence of risks is a major reason for a stronger request to anticipate and warn about risk situations from those who are responsible for it. Prevention, when duly justified, can make the difference between worsening the risk or mitigating it.

The uncertainty associated with risk sometimes creates situations of alarmism, and/or of concealment of facts. When the risk is considered high and is highly publicized and when later it is found that the impacts were minimal, those involved in the prevention process are considered alarmists; on the contrary, when this risk is not properly taken care of and serious situations occur later, they are accused of underestimating the risk and of carelessness regarding the preparation to deal with it. Considering alarmism can be an instrument in favor of precaution when facing risks through the preventive action that promotes it and is instead only prized as a positive approach after the occurrence of events with negative consequences, referring to the preventive role it could have played.

In descriptive terms, the definition of risk has been the target of a disambiguation process over time. Professionals and decision-makers from the most diverse areas as well as the general public or communities in different sectors have approached this concept in an applied way, adapting it to their reality and objectives. The result of this practice is the formulation of different risk concepts. As a rule, risk is associated with the doubt about future events of a negative nature for humanity. Risk can be taken as a category of analysis associated a priori to the notions of uncertainty, exposure to danger, material damaging, economic and human life losses due to natural processes (such as exogenous and endogenous Earth processes), and/or those associated with the human actions.

In an integrated perspective, risk intends to characterize the possibility of disturbances that alter the existing or predicted balance and security state and cause negative impacts. Using mathematical concepts, risk is understood as the probability of occurrence of a specific event causing serious damage to humanity and/ or the environment in each period and under certain circumstances. According to the same authors, and in a clear reference to the importance of the concept of risk for management, risk expresses the possibility of occurrence and the respective 
quantification in terms of costs, serious damages, economic consequences, or even for the safety of people, triggered by a natural phenomenon or induced by anthropic activity. In the light of the variety of existing definitions, risk can also be seen as the probability of the occurrence of a dangerous process (or action) and the respective estimate of its consequences on people, property, or the environment, expressed in human casualties and/or material and functional damage, direct or indirect.

\section{Types of risks}

The presence of risk, or the notion of its existence, is noticed in different areas and realities. Ewald [7] referred that the notion of risk has been extended in its scope to other domains and is no longer centered solely and exclusively on nature. In fact, the globalization and scope of application of the concept of risk is felt in the daily life of modern society, being associated with work, personal security, health, housing, economy, or environment, among others.

Currently, the concept of risk applies both to uncertainties in the security of technological systems or products (technological risks) and to natural systems and catastrophes (natural risks). Technological risk does not only concern systems of technology and dangerous and manipulated products but also living beings, especially humans, either because of the direct relationship in terms of design and use or because of the exposure to a certain level of risk. An error in a design or project of an artificial or technological system created by people can bring risks and result in harmful consequences, which can become a disaster or catastrophe. Thus, technological risks are those that result from accidents, often sudden and unplanned, triggered by human activity (e.g., floods due to rupture of dams, accidents in the transport of dangerous goods, and radiological emergencies).

Advances and new approaches to science, the exploration and application of the concept of risk to different sectors of society have generated new types of risks such as social risk or environmental risk.

Social risk is related to the gaps in the life of an individual or community, restricting to some extent the access to means, goods, and basic care which provide him with the minimum acceptable level of comfort in his daily life. One can define it as the result of social needs that hinder the full human development and contribute to the degradation of living conditions. As indicators for determining the degree of social risk, one can suggest the conditions of habitability and hygiene, access to drinking water, and even in the long term, the conditions of employment, income, or technical skills. These are elements capable of demonstrating the level of dignified and sustainable human development.

As a rule, and although any individual is subject to risks, it has been verified throughout history that those who are most exposed to it are the most disadvantaged social groups. Individuals of poor financial condition, the elderly, the sick, or even children, among others, are usually the most exposed to social shortages and are most sensitive to the recovery process. We can also refer to social risk as damage caused by a society or part of it, emphasizing armed conflicts and military actions, among others. Wisner [8] approaches social risk differently, focusing on extreme natural phenomena as events that demonstrate the greater vulnerability of unprotected individuals to these occurrences.

As for the definition of the environmental component of risk, it is relatively recent, at least in the light of new theories. The definition of environmental risk, as a consequence of its designation, has been applied several times under the designation of natural risk due to the fact that the term environment is associated with nature, with all its integrated and interacting living and nonliving beings. The increasingly 
sharp and complex interaction of human activities with the functioning of natural systems led to the introduction of the concept of environmental risk, which includes phenomena such as desertification, environmental pollution, and forest fires.

Currently, the concept of environment is more complex and goes beyond the basic life support structures and living beings, encompassing as well a set of extremely diverse and interactive components. These components are connected, so even subtle modifications to one of them can generate changes in the others.

Given this change in the conceptual environment toward a reality that functions with the close relationship between complex and dependent systems, the concept of environmental risk followed the same direction, assuming itself as a risk that is a mix of several others.

The distinction between different types of risks has become increasingly fuzzy, as human influence over the natural environment has grown in association with technological development. The concepts risk and hazard are often misused as synonyms for the same definition. For Cutter et al. [9], hazard is considered as the threat to people and the things they value. The threat arises from the interaction between the social, natural, and technological systems and is often described according to its origin, although the author recognizes that this classification loses strength within the scientific community since many of these threats have a complex origin.

Social and technological hazards affect the natural environment, producing different hazards, including quasi-natural hazards, which have a dimension of the physical environment modified or determined by social or technological elements. Mixed hazards are the result of the interaction of social and technological phenomena, while environmental risks are the result of the interaction of the three elements (natural, social, and technological) in a more contemporary perspective of analysis.

\section{Risk quantification}

As expected, in concepts associated with complex entities, there are always different definitions and philosophical perspectives to characterize risk as a credible object of analysis and decision. It can be said, however, that the notion of risk is based on a subtle combination of possible knowledge and uncertainty. That is, it always involves a combination of knowledge and ignorance. This turns out to be the major practical difficulty but also the biggest interest of analysing risk as a theoretical concept.

From the point of view of the concept's intrinsic nature, there are two substantially different approaches for risk. First, risk is an objective reality that exists independently of peoples' subjective values and opinions-as in other situations, the application of a scientific methodology will allow the identification of the relationship between facts, quantification, forecasting, and control-a positivist perception of risk. Second, there is human construction in the face of uncertain events with harmful consequences. In this case, risk can even be considered as a subjective reaction to a phenomenon coming from personal and social experiences-a relativistic perspective of risk.

In both perspectives, it is interesting to define a threshold that mirrors the concept of risk and allows its quantitative analysis in a generalized way. In fact, inspired by human behavior in the face of dangers, risk analysis can be considered a construction of the human mind.

One of the difficulties in defining the magnitude of risk consists of the characterization of uncertain events that are threats to a certain objective or societal state. They are frequent future events or possibly exceptional, unique, and of great intensity, with variable, tangible, and (or) intangible consequences. Risk intends to 
measure the uncertainty of an activity and the severity of its consequences, that is, the effect of uncertainties on existing or planned conditions.

The quantification of risk could then be determined by relating hazard and consequences. For the purposes of presenting the fundamental components of natural risk, the model that follows will be a derivation of the original expression, where consequences are represented by vulnerability and exposed elements. In practical terms, the two approaches are similar. In this sense, concepts such as hazard, vulnerability, exposed elements, and consequences will be addressed, as well as other supporting concepts required for the full understanding of the components of risk and the multiple aspects it involves, such as susceptibility and severity.

Risk is a comprehensive, motivating, and ambiguous concept with different dimensions and a special potential for characterizing uncertain occurrences associated with deviations from baseline situations. Risk justifies options and actions as a decision variable in face of potential threats, encourages the protection of people and assets, and thus, improves the quality of life and enables a symbolic representation of the contemporary world.

One of the fundamental concerns of this construction, considering the decisionmaking processes, arises from the need to compare, in the present, certain effects whose future occurrences are considered with different degrees of uncertainty. The concept of probability arises, therefore, associated with the quantitative analysis of risk.

Knight [10] strongly defended the principle that risk implies knowledge with probabilities (measurable); otherwise it is ignorance or uncertainty in a restricted sense. Thus, the construction of quantitative risk analysis implies grading the plausibility of uncertain events through the assessment of probabilities. For some lines of thought, the probability of the hazardous event is so important that it is almost confused with the notion of the associated risk (probabilistic conception). In the dominant conceptual construction process, practice and reflection allowed the reduction of the three intervening factors-uncertainty, intensity, and consequence-to only probabilities and consequences.

The estimated value of the consequences is "mitigated," depending on the degree of uncertainty and by multiplying by the respective probability of occurrence. Therefore, the risk variable has a quantifiable value that can be compared with others in a quantitative assessment and decision process. Risks of a different nature (quantitative risk units indicate the type of value: victims/year or euros/year, for instance) can thus be compared by consequence classes.

It must be recognized that the solution found is simple and almost brilliant: the concept has resisted for centuries. De Moivre, in his book De Mensura Sortis, published in 1711, explains for the first time about this concept of risk: the measure of the risk of loss of an amount is the product of the amount put at stake by the probability of loss [11].

With the canonical definition, quantitative risk analysis allows the consideration and internalization of risks in cost-benefit analyses and in multi-criteria decisionmaking processes. This ability is appreciated in the design of complex technological systems or in the planning of costly protection measures against natural risks.

Regardless of the origin of the phenomenon, the concept of risk encompasses the probability of hazard. This concept is often used as synonym of the concept of risk. Therefore, it is important to add that hazard can be defined as a natural, technological, or mixed process (or action) capable of producing identified losses and damages. The United Nations definition of risk, dated of 1979, addresses this concept only in its natural aspect, describing it as the probability of the occurrence of a specific natural hazard with a specific level of severity and in a certain period [12]. The idea of associating this concept to the time and space of occurrence is evident, 
since at a more general level, danger is understood as the probability of occurrence (assessed qualitatively or quantitatively) of a phenomenon with a certain magnitude (associated to a destruction potential) in a certain period and in a given area. Hazard represents the probability that a territory will be affected by a natural or technological event or a process due to parameters such as magnitude and severity.

The exposed elements, also called elements at risk or vulnerable elements, are, according to Dilley et al. [13], the population, properties, structures, infrastructure, and economic activities, among others, exposed to a hazardous process in a certain area. The intrinsic characteristics of the exposed elements, in relation to other factors, determine whether they are predisposed to suffer impacts when affected by a certain hazard, thus contributing to the occurrence of damage or total loss.

Each type of exposed element is related to a specific set of damages and to particular factors that enhance them. The same natural phenomenon can cause different damages to people and housing or infrastructure. The outcome of the hazardous phenomenon, in complementarity with the characteristics of the elements, is influenced by factors such as the magnitude, duration, location, and time of the event. Personal and material losses always result from the interaction between the event and the characteristics of the affected elements that make them more or less susceptible to negative impacts.

It should be noted that the distinction between exposure (still undamaged or vulnerable in potential) and physical vulnerability (damage operator in action), depending on the intensity of the impact in each scenario, is of great operational efficiency and is a basis for framing mitigation measures.

\section{Risk management}

There is an old saying that states that "is better to prevent than to fix." This aphorism can be a good example of practical and popular philosophy. Almost everything that is essential for sensible human behavior is stated in this general sentence and it is applicable to all hazardous situations.

The aphorism presupposes the possibility of perceiving a hazard that can be structured and materialized in different levels of risk (hypothetically), but which can supposedly be mitigated by an anticipated action. In fact, every human being applies tactics to assess situations of risk or hazardous situations, in a more or less conscious way, in the decision-making processes associated with their survival and development.

This automatic possibility is no longer the normal feature in contemporary society. Hazards have become diffuse and are hardly perceived in a society that is heavily dependent on systems of such complexity that most citizens cannot fully understand the vulnerabilities and associated threats. It is one of the aspects of the so-called society of risk [6] and the subject of cultural analysis. Structuring the process, from identification to decision, and the implementation of measures are then necessary. This is the function of risk analysis and management.

This structure was strongly influenced by the developments in the areas of financial and insurance management during the twentieth century. As a curiosity, it should be noted that the term risk management is proposed in 1956 in the Harvard Business Review in an article by Russel Gallagher [14], and since then, a general organizational framework has been imposed, which includes risk analysis and crisis management.

According to the international standard, International Organization for Standardization (ISO) 31,000, Risk Management Guidelines [15], risk management comprises the set of activities to guide and control an organization with respect to risk. In the future behavior of a natural or built system (e.g., a technological product), we are led to admit a normal pattern of expectations, a reference, or a set 
of objectives to be fulfilled. Experience tells us that these conditions, these expectations, are not always fulfilled. Events, predictable or not, can occur in the more or less near future and cause deviations to what was expected with the consequences (positive or negative). According to this conceptual framework, the aforementioned ISO standard defines risk as the effect of uncertainty on objectives. This definition alerts us, in an elegant way, to the need to identify the objectives intended to achieve (e.g., the preservation of human life) the uncertainties to consider (epistemic and random) and the likely effects or consequences.

Risk management does not predict the future that will occur, but several possible or plausible future scenarios are considered and the respective probabilities of occurrence and the potential consequences, tangible or non-tangible, are evaluated. The risk management process comprises a set of procedures and components and a relatively consensual quantitative analysis formalism (Figure 1).

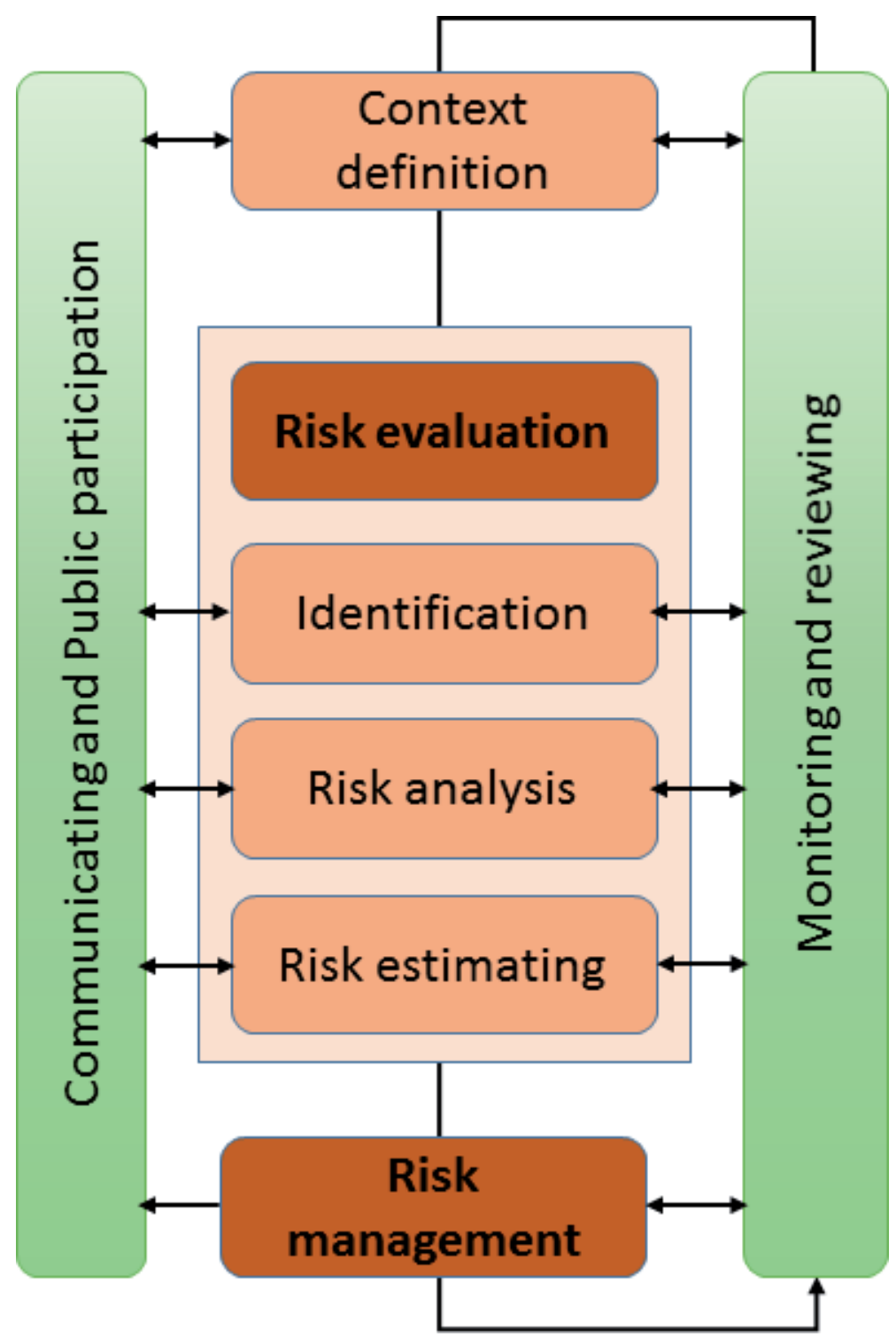

Figure 1.

General risk management process. Adapted from ISO 31000 [15]. 


\section{Conclusions}

The risk concept is based on the combination of expected consequences and probabilities/uncertainties dimensions. Quantitative risk analysis, despite the great benefits of its application in certain contexts, should not be considered as a panacea to guarantee absolute security. Qualitative or semiquantitative analyses may prove to be more appropriate in specific circumstances.

The risk management and analysis methodologies have in their favor the positive fact of placing the consequences or uncertain effects resulting from the exposure to a hazard, at the center of decisions. They can thus contribute to avoid irreparable damage or loss and, overall, improve the safety of a community, a company, or an enterprise.

Risk analysis and management should not be ruled by rigid or dogmatic methodologies and structures, which generate illusions or myths related to rationality and efficiency without limits. In some circumstances, it may be advisable to adopt the management of two of the variables that jointly provide the quantitative definition of risk in addition to the probability of the event, the exposure level, and in particular, the vulnerability. The probabilities are not always the most useful tool to characterize the uncertainties.

In any case, the characterization of the uncertainties involved in the risk assessment calculations must be carried out, considering the possibility of making more suitable decisions with the available knowledge. Without an analysis of the epistemic uncertainties embedded in the calculations, the apparent rigor of the results of a quantitative risk assessment can lead to disproportionate decisions.

\section{Acknowledgements}

This work was financed by national funds through FCT_-Portuguese Foundation for Science and Technology, I.P., under the framework of the project "TRIAD—heaLTh Risk and social vulnerability to Arboviral Diseases in mainland Portugal" [PTDC/GES_OUT/30210/2017] and by the Research Unit UIDB/00295/2020. César Capinha was funded through FCT, I.P., under the program of "Stimulus of Scientific Employment-Individual Support" within the contract “CEECIND/02037/2017."

\section{Author details}

Jorge Rocha*, Sandra Oliveira and César Capinha

Institute of Geography and Spatial Planning, University of Lisbon, Lisbon, Portugal

*Address all correspondence to: jorge.rocha@campus.ul.pt

IntechOpen

(C) 2020 The Author(s). Licensee IntechOpen. This chapter is distributed under the terms of the Creative Commons Attribution License (http://creativecommons.org/licenses/ by/3.0), which permits unrestricted use, distribution, and reproduction in any medium, provided the original work is properly cited. (cc) BY 


\section{References}

[1] Covello VT, Mumpower J. Risk analysis and risk management: An historical perspective. Risk Anal [Internet]. 1985;5(2):103-120. DOI: 10.1111/j.1539-6924.1985.tb00159.x

[2] Proske U. Catalogue of Risks. Natural, Technical, Social and Health Risks. Berlin Heidelberg: SpringerVerlag Berlin Heidelberg; 2008. p. 509

[3] Ewald F. Two infinities of risk. In: Massumi B, editor. The Politics of Everyday Fear. Minneapolis, Minnesota: University of Minnesota Press; 1993. pp. 221-228

[4] Reddy SG. Claims to expert knowledge and the subversion of democracy: The triumph of risk over uncertainty. Econ Soc [Internet]. 1996;25(2):222-254. DOI: 10.1080/03085149600000011

[5] Castel R. From dangerousness to risk. In: Burchell G, Gordon C, Miller PM, editors. The Foucault Effect: Studies in Governmentality: With Two Lectures by and an Interview with Michel Foucault.

Chicago, USA: The University of Chicago Press; 1991. pp. 281-298

[6] Beck U. Risk society revisited: Theory, politics and research programmes. In: Adam B, Beck U, van Loon J, editors. The Risk Society and beyond: Critical Issues for Social Theory. London: Sage Publications; 2000. p. 211-229

[7] Ewald F. Insurance and risk. In: Burchell G, Gordon C, Miller PM, editors. The Foucault Effect: Studies in Governmentality: With Two Lectures by and an Interview with Michel Foucault [Internet]. Chicago, USA: The University of Chicago Press; 1991. pp. 197-210.

Available from: http://www.gbv.de/dms/ bowker/toc/9780226080444.pdf

[8] Wisner B. Capitalism and the shifting spatial and social distribution of Hazard and vulnerability.
Aust J Emerg Manag [Internet]. 2001;16(2):44-50. Available from: https://search.informit.com.au/docum entSummary;dn=378174191869592;re s=E-LIBRARY\#.XvvCjAx2rlk.mendeley [cited 30 June 2020]

[9] Cutter SL, Barnes L, Berry M, Burton C, Evans E, Tate E, et al. A placebased model for understanding community resilience to natural disasters. Glob Environ Chang [Internet]. 2008;18(4):598-606. Available from: http://www.sciencedirect.com/ science/article/pii/S0959378008000666

[10] Knight FH. Risk, Uncertainty and Profit. London, UK: Pantianos Classics; 2014. p. 394

[11] Bernstein PL. Against the Gods: The Remarkable Story of Risk. New York, NY, USA: John Wiley \& Sons; 1998 p. 383

[12] Arnold M, Chen RS, Deichmann U, Dilley M, Lerner-Lam AL, Pullen RE, et al. Natural Disaster Hotspots: Case Studies [Internet]. Disaster Risk Management No. 6. World Bank: Washington, DC, USA; 2006. 184p. Available from: https://openknowledge. worldbank.org/handle/10986/7091

[13] Dilley M, Chen RS, Deichmann U, Lerner-Lam AL, Arnold M. Natural Disaster Hotspots: A Global Risk Analysis [Internet]. Washington, DC: World Bank; 2005. p. 132. Available from: https://openknowledge. worldbank.org/handle/10986/7376

[14] Gallagher RB. Risk managementnew phase of cost control. Harvard Business Review. 1956;34(5):75-86

[15] ISO. ISO 31000: Risk management-Guidelines. Geneva, Switzerland: International Organization for Standardization (ISO); 2018. Available from: https://www.iso.org/ obp/ui\#iso:std:iso:31000:ed-2:v1:en 


\title{
Chapter 2
}

\section{Risk of Slipping Industrial Landfills}

\author{
Emilia-Cornelia Dunca and Sabina Irimie
}

\begin{abstract}
Due to the high rate of industrialization, urbanization and development of the road network, hydrotechnical constructions, etc., larger areas of agricultural and arable lands are affected, some of these being removed from the economic circuit. Due to the magnitude of the involved volumes, industrial waste has lately become a threat to all the components of the environment. In Romania, 90-95\% of the total quantity of the produced industrial waste are stored, but only $24 \%$ of them have an environmental clearance certificate. The action of the climatic factors increases the risk of the occurrence of some landslides, which leads to the deterioration of the ecosystems and the risk of pollution, the loss of stability, the destruction of some historical objectives. Thus, the risk analyses represent the support for the decisionmaking process in taking solid measures, meant to lead to the limitation and diminution of the danger of slipping and losing the stability of these deposits. However, the implementation of the measures is based on a systemic model, supported by the concept of risk. This chapter presents the definition and classification of environmental risks, the risk assessment methodology and a risk analysis for waste in a mining area in Romania.
\end{abstract}

Keywords: risk, sliding risk, industrial waste, pollution risk and risk analysis, mining area

\section{Introduction}

The International Risk Institute emphasis's that "risk is part of our whole life" [1], therefore risk is a human concern, and as an object of study, it has been a component part of scientific research in various fields (socio-human, natural sciences and exact sciences). Due to this fact, the concept of risk has evolved through a variety of emerging theories. Starting from the earliest times, the representatives of different fields have tried to develop an algorithm for risk perception, assessment and management. Risk is unquestionably an ambiguous concept and very difficult to define. Up to present, there are numerous perceptions of risk, which depend on the taken perspective, context, situation, and application field.

The etymology of the term "risk" is not unambiguous either. Some authors grant it Arab roots, however most of them consider that the term comes from the Greek word-rock [2]. In French, "risqué" has two meanings: the first one is-to expose to it (the risk), and the second meaning - to bear something, to have a chance, possibility, opportunity, meaning which aims the positive favorable aspect, the possibility of success. 
Although, in the case of the ecological risk, the delimitation and assessment of the positive aspects are carried out within the programs and actions for the restoration, improvement and conservation of the natural ecosystems and habitats, for improving the ecological situation of a region, for ensuring and improving the health and life quality of the population ([3], pp. 211-212). Simultaneously, the estimation of the risk negative aspects will affect the actions which can generate a possible high risk on the environmental factors, their ecosystems and biodiversity, the health and the life quality of the population ([4], p. 83). Most of the times, the environmental risks take a negative look: natural or technogenic disasters.

For the Romanian geographers [5], the environmental risk is a category of state, designating the relational conjuncture, which results as a consequence of the hazard assumption by those components of the geo-system which possess the capacity to perceive events ([6], pp. 10-16).

The environmental risk is defined by most specialists as the probable occurrence of an unexpected effect as a result of exposure to a disturbing factor. The notion of risk is related to the probability of unforeseen results or unpredictable consequences, derived from the decisions/omissions or actions of social groups [7].

Based on the analysis of the existing specialty literature, we propose to define the environmental risk as the probability of a quantitative and/or qualitative deviation of the expected result which may occur following certain actions or inactions of the decisionmaker and the magnitude of the losses or gains resulting from this variation.

The probability of an event advancement is only a first component of the risk, the second being the size of the possible damage. Unlike danger, the risk cannot be analysed without assessing the consequences of the unwanted event occurrence. Therefore, risk represents the quantitative dimension of the danger, more precisely of the possible consequences, so the risk can be calculated by the formula:

$$
R=P x Q
$$

where $\mathrm{R}$ is the risk; $\mathrm{P}$ is the probability; and $\mathrm{Q}$ is the size of the losses, which can be of economic, social and ecological nature ([8], pp. 118-121).

Analyzing the specialized literature in this field, it can be observed that most of the classifications are made based on the criteria concerning these risk components. The existences of classifications according to the particularities of these two defining elements of risk are of great practical importance, especially for risk assessment and management.

Analyzing the criteria according to which the environmental risk classifications have been developed, one can see that they focus on the following aspects:

- The sources of risk (the subject of the action).

- Risk-generating action or inaction.

- The probability and the predictability of the risk, i.e., the occurrence of a deviant result from the expected one.

- The object of the possible impact.

- The consequences of the risk situation occurrence, which can materialize in profit or loss.

- The degree of sustainability and vulnerability to the risk (Figure 1). 


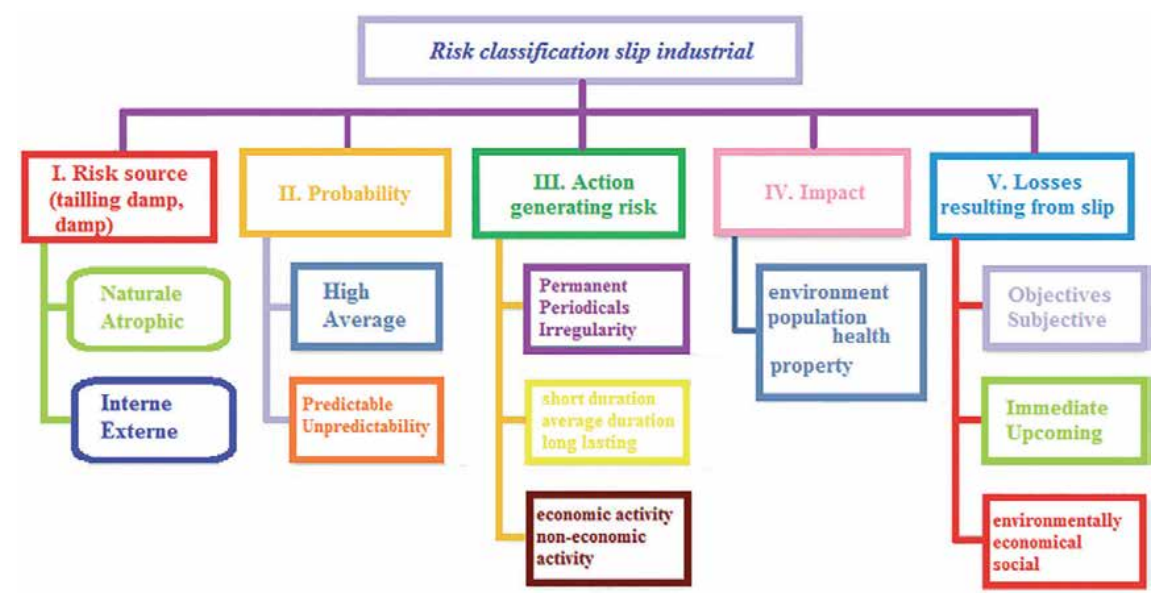

Figure 1.

Environmental risk classification. Source: authors.

In the classification regarding the sources of risk we find that depending on the type of the source of risk, there are approaches focused on the slide phenomena, which-in turn classify the risks according to their origin:

- Natural risks-generated by natural phenomena, such as earthquakes, storms, floods or droughts and so on.

- Anthropic risks-triggered by human activity.

\section{Risk assessment methodology}

In conducting risk analysis studies, reference benchmarks (indicators or indices) that can be used at different levels are required. It is obvious that the risk cannot be reduced to zero and therefore it appears as a value of the maximum importance to be the limit that can be borne by people in current activities.

Accident prevention through risk analysis involves a specific activity starting from the design stage through the application of qualitative and quantitative techniques and methods based on existing data and on systematic creative imaginative actions ([9], pp. 88-93).

The qualitative analysis has as a main objective the establishment of the list of possible hazards, and it makes possible the hierarchy of the events in the order of the risk and presents the first step in the methodology of performing the quantitative risk analysis.

There are two major categories of techniques in which a number of general components are distinguished (Table 1):

- Qualitative analysis used to identify hazards (Hazard and Operability StudyHazop). Its main objective is to establish the list of possible hazards, making possible to rank the events in the order of risk and present the first step in the methodology of performing the quantitative risk analysis $[6,10,11]$.

- Quantitative analysis used to assess hazards to decide how one should act in order to eliminate or reduce the risk (Hazard Analysis-Hazan) [12].

The order of application is from qualitative identification to quantitative analysis. 


\begin{tabular}{ll}
\hline Hazop technique & Hazan technique \\
\hline Identify hazards & Assess hazards \\
\hline $\begin{array}{l}\text { Preferred technique for use in } \\
\text { every project }\end{array}$ & $\begin{array}{l}\text { Selective technique: it is used especially for systems potentially } \\
\text { exposed to major accidents }\end{array}$ \\
\hline Qualitative & Quantitative \\
\hline Made by a team & Made by one or two experts \\
\hline Also called “But If?" & \\
\hline
\end{tabular}

Table 1.

Difference between Hazop and Hazan.

\subsection{Qualitative analysis of the consequences}

It is achieved through the classification into five levels of severity, an internationally accepted methodology and used in risk assessment studies $[2,13]$. The five levels have the following significance (Table 2):

\begin{tabular}{|c|c|c|}
\hline Crt. No. & Level & Effects \\
\hline 1 & Insignificant & $\begin{array}{l}\text { Population: insignificant injuries } \\
\text { Ecosystems: some minor adverse effects on few species or parts of } \\
\text { the ecosystem, on short term and reversible } \\
\text { Socio-political: insignificant social effects without any concern for the } \\
\text { community }\end{array}$ \\
\hline 2 & Minor & $\begin{array}{l}\text { Population: insignificant injuries } \\
\text { Ecosystems: some minor adverse effects on few species or parts of } \\
\text { the ecosystem, on short term and reversible } \\
\text { Socio-political: insignificant social effects without any concern for the } \\
\text { community }\end{array}$ \\
\hline 3 & Moderate & $\begin{array}{l}\text { Population: medical treatments are required } \\
\text { Economic: reduction of production capacity } \\
\text { Emissions: emissions within the target area withheld with external assistance } \\
\text { Ecosystems: temporary and reversible damage, damage to habitats and } \\
\text { migration of animal populations, plants unable to survive, air quality affected } \\
\text { by compounds with potential long-term health risk, possible damage to } \\
\text { aquatic life, pollution requiring physical treatments, limited contamination of } \\
\text { soil which can be remedied quickly } \\
\text { Socio-political: social effects with moderate concerns for the community }\end{array}$ \\
\hline 4 & Major & $\begin{array}{l}\text { Population: serious injuries } \\
\text { Economic: interrupting the production activity } \\
\text { Emissions: off-site emissions without harmful effects } \\
\text { Ecosystems: death of animals, large-scale damage, damage to local species } \\
\text { and destruction of large habitats, air quality requires "safe shelter" or decision } \\
\text { to evacuate, soil remediation is possible only through long-term programs } \\
\text { Socio-political: social effects with serious concerns for the community }\end{array}$ \\
\hline 5 & Catastrophic & $\begin{array}{l}\text { Population: death } \\
\text { Economic: stopping the production activity } \\
\text { Emissions: toxic emissions outside the site with harmful effects } \\
\text { Ecosystems: death of animals in large numbers, destruction of species of } \\
\text { flora, air quality requires evacuation, permanent contamination and on } \\
\text { extended areas of the soil } \\
\text { Socio-political: social effects with very high concerns for the community }\end{array}$ \\
\hline
\end{tabular}

Table 2.

Risk severity level. 


\subsection{Analysis of production probability}

It is also achieved using the five levels, internationally accepted and used in different variants (Table 3 ).

\subsubsection{Qualitative risk assessment}

The level of risk as a product between the severity level (consequence) and the probability level of the analysed event is calculated [14].

Using the information obtained from the analysis, the risk of an event is placed in a matrix (Figure 2).

The extent of the risk analysis and the intensity of the prevention and mitigation measures should be proportional to the risk involved. Simple models of hazard identification and qualitative risk analysis are not always enough and therefore it is necessary to use detailed assessments. There are several methods for performing quantitative risk assessment [15]. The choice of a particular technique is particular to the analysed accident scenario.

Those accident scenarios are analyzed more thoroughly which, as a result of the qualitative analysis, are considered as potentially major, probabilities over $10^{-6}$, i.e., they can occur earlier than 10,000 years and major consequences, so high risk above level 15.

\begin{tabular}{llll}
\hline Crt. No. & Probability & When can occur & Occurrence frequency \\
\hline 1 & Rarely & Only in exceptional conditions & Probability of occurrence in $10^{12}$ years \\
\hline 2 & Unlikely & It could sometimes occur & $\begin{array}{l}\text { Probability of occurrence between } 10^{8} \text { and } \\
10^{12} \text { years }\end{array}$ \\
\hline 3 & Possibly & It may sometimes occur & $\begin{array}{l}\text { Probability of occurrence between } 10^{6} \text { and } \\
10^{8} \text { years }\end{array}$ \\
& & It can occur in most situations & $\begin{array}{l}\text { Probability of occurrence between } 10^{4} \text { and } \\
10^{6} \text { years }\end{array}$ \\
\hline 4 & Probably & & $\begin{array}{l}\text { Probability of occurrence in a period less } \\
\text { than } 10^{4} \text { years }\end{array}$ \\
\hline \multirow{2}{*}{5} & Certainly & It is expected to happen in most \\
& situations &
\end{tabular}

Table 3 .

Levels of the probability of producing risks.

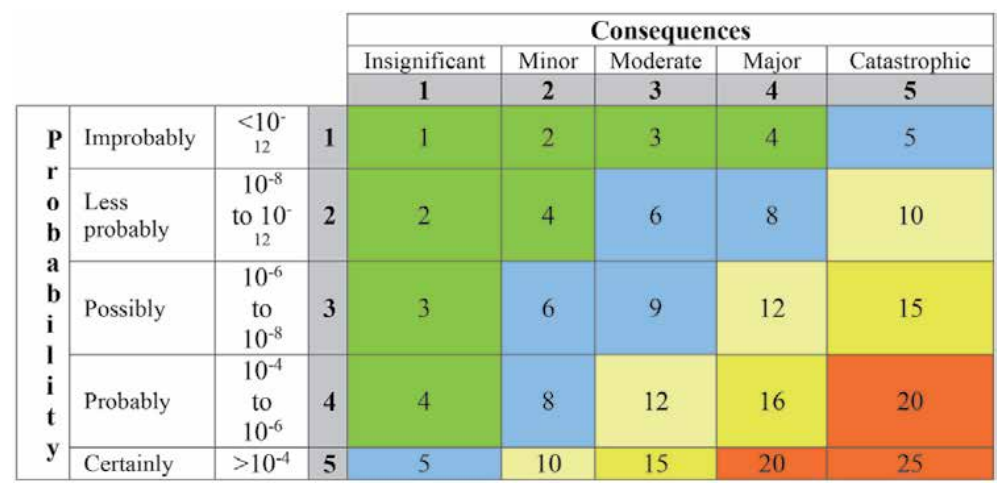

Figure 2.

The matrix of qualitative risk assessment and risk levels. 
Methods are used to estimate the accidental emissions in the atmosphere and models of simulation of the dispersion based on which the severity of the possible consequences is evaluated.

Specific simulation methods are applied to assess the consequences of possible explosions or fires. The results of some simulation studies of the formation of breaches in the body of the tailings dam and the acid water collection pond are used to assess the consequences of such events.

The frequency diagram-consequences, FN (loss of materials or number of fatalities) centralizes the result of the analyses carried out in this way and it graphically presents the social risk specific to the project in correlation with the socially acceptable level of risk.

An overall assessment of the risk associated with the sliding of industrial waste will be made using the methodology of rapid environmental and health risk assessment developed by the World Health Organization.

\section{Sliding of waste sterile dumps}

The loss of the stability of the waste sterile dumps is determined by the following factors:

- The configuration and the physical-mechanical characteristics of the founding ground.

- The hydrodynamic particularities of the waters in the area and their interaction with the material from the dump.

- The geotechnical characteristics of the waste sterile material (porosity, internal friction angle, cohesion, cracking specifies, humidity, degree of compaction, etc.).

The probability of production is average, considering the compliance with the technical design criteria for the stability of the dumps, established for the specific conditions of the site and the characteristics of the material ([7], pp. 12-13).

The dumps will be monitored continuously, through visual control, through manual and automated topographic measurements, and the tailing will be carried out in stages, with the flatting and compaction of the deposited material. The severity of the accident can be major due to the large amounts of waste resulting from and deposited on the dumps and the fact that the sliding may cause damage to buildings on the site or access roads.

Waste dumps sliding after the completion of the deposits and carrying out the rehabilitation works have low probability and moderate severity, the associated risk being much lower than in the operating phase.

Geotechnical field investigations and studies of the physico-mechanical characteristics of the boulders and of the basic land have led to the conclusion that landslides can occur through boreholes. The risk of sliding slopes occurs in areas where the slope angle exceeds the interior friction angle of the welded rocks and on or through the base terrain if its slope is greater than the interior friction angle of the rocks.

The landslides of the industrial tailings deposits are a category of natural risk phenomena, which define the process of movement, the actual movement of the rocks or deposits on the slopes, as well as the resulting form of relief.

This slip process has three phases: 
- The preparatory phase, of slow, incipient slip (preliminary processes).

- The actual slip (crossing the geomorphological threshold).

- Natural stabilization (balancing, post-processing processes).

From the geotechnical studies and the physico-mechanical characteristics of the boulders and the base terrain, they concluded that the risk of landslides may occur in areas where the slope angle exceeds the internal friction angle of the boulders and on or through the land base if its inclination is greater than the interior rubbing angle of the rocks.

As a result of the sliding large areas of agricultural land have suffered, constructions of villages or cities, roads, railways etc. are damaged, damage to industrial premises or to the area of hydrotechnical works are made. The masses of ground that can be moved can penetrate the banks of the rivers, causing the bottom to be raised or the partial or total obstruction of the drainage section.

The rocks that favor the sliding production the most are the "sensitive clays," spread in the regions that were covered with glaciers in the quaternary. They favor the movement of materials even on slopes of only $2-3^{\circ}$. That is why in the Northern countries of Europe, Alaska and so on, the landslides are frequent and large.

The most common landslides are recorded on slopes with moderate inclinations $\left(10-30^{\circ}\right)$ consisting of rocks with high shale, intensely fractured and altered.

In Romania, this type of process affected at the level of 1975 over 800,000 ha, some of which at about 250,000 ha with active landslides and 550,000 ha with stabilized landslides [16]. However, these expanded in the following years, especially until 1982. The landslides take large areas of slopes within the SubCarpathians (especially the curvature sector, where on certain areas they affect almost entirely the slopes), the Plateau of Moldova, the Transylvanian Depression, the Getic Plateau and even in the mountainous area (in the east of the Eastern Carpathians, in the sectors with high weight of clay shale, where the oil exploitation contributes to the disturbance of the slope balance by drilling, spills, vibrations. Example: the sliding in Zemes in 1992 moved out of work 47 oil wells, pipes, electrical networks, dwellings, the school).

The studies for the prevention of landslides and the fight against their negative consequences aim at the following stages:

a. Recognition of the areas affected by landslides and those susceptible to landslides.

b. Establishing the types, respectively the classification of the sliding.

c. Establishing the evolution stage.

d. Establishing the causes and mechanisms of movement in different types of rocks.

e. The mechanisms of movement in different types of rocks.

f. Knowledge of the way of intervention and of the technical works for stabilizing the lands.

(a) The recognition of the areas affected by landslides and those susceptible to landslides is facilitated by the observation of the specific micro-relief, by the mosaic 
appearance of the soils (unevolved soils) as well as by the presence of certain plant associations that indicate the varied ecological conditions determined by the newly formed soils.

The profile of the slopes has an irregular appearance, the surface deposits are kneaded in the form of sliding steps, mounds, waves, furrows, cracks, ridges, micro-depressions often occupied by water mesh or hygrophilous vegetation.

The main elements of a landslide are:

- The sliding slope or the detachment shaft, which is the area where the sliding material mass breaks.

- The body or mass of the sliding, which comprises the part of the displaced terrain, corresponding to the sector with chaotic micro relief, unfolded downstream by the detachment shaft.

- The front of the sliding, corresponding to the terminal part of the slide.

- The bed, the mirror or the sliding surface, representing the lubricated substrate, more or less smooth, on which the mass of material is moved down the slope.

(b) Establishing the types, respectively the classification of the landslides is made on the basis of several criteria: the geological structure of the slope, the way of affecting the slope, the characteristic morphology, the production time and so on. The most frequent and at the same time the most important through their consequences are the complex slidings, the interventions for their stabilization being very expensive. They are deep landslides, with generally old floods, with thicknesses exceeding $5 \mathrm{~m}$, moving slowly on slopes, generalized on important areas of slopes.

The classification according to the depth to which the deposits are disturbed is very important, from this point of view there are three important categories:

- Surface sliding, up to $2 \mathrm{~m}$ thick, with the highest frequency and which usually represent reactivations of the old surfaces with sliding, but are also present on the slopes that have undergone a single cycle of mass movement processes.

- Medium depth sliding, with thicknesses between 2 and $5 \mathrm{~m}$.

- Deep sliding, with thicknesses exceeding $5 \mathrm{~m}$, with a slightly lower frequency, but which acquire a special magnitude where they occur.

The most dangerous are those which are deep, violent and rapid (with speeds of 2-3 m per hour), with disastrous consequences when they occur in inhabited areas: cracks in the soil, mounds, slope breaks, ditches, overturned vegetation, destruction of dwellings, roads and other economic objectives, etc.

A category of catastrophic landslides is represented by the sliding-crumbling, characteristic of the areas consisting of alternations of plastic rocks (clays or marls) and relatively hard rocks (hone) and even uncemented (sand, gravel). They are the result of the erosion affecting the base of the slopes, causing the breakage and collapse of the masses without support, together with their lateral pushing on those on the intensely moistened sliding bed. Moreover, the cutting of the slopes and excavations can lead to the triggering of such sliding, thus it is necessary to take into account the limit value of the slopes in relation to the type of rock.

According to a report of the inter-ministerial commission [16] for the inventory of industrial dumps, in Romania there are 1101 waste dumps, 994 of which are 
mining targets. Most are found in Suceava (224), Maramureş (180), Caraş-Severin (78) and Alba (66) counties. The problem is that only 247 of the 1101 dumps are owned by companies, the rest reaching over the years in the custody of local administrations.

Regarding the decanting ponds, there are 108, only 15 of which are operational. Most are in the counties of Maramures (15), Hunedoara (13), Harghita and CaraşSeverin (10). Many of them present a risk of sliding, especially in the seasons with heavy rainfall. Safety and environmental works have been started in many decanting ponds, but over time they have been interrupted even for years. On the other hand, where the greening was done many years ago, and the land was subsequently relocated, no monitoring was done, so no one knows what the current situation is.

Within the 556 mining objectives approved for closure since 1998, there are 78 decanting ponds with a total stored volume of 341.31 million $\mathrm{m}^{3}$ and an area of approximately of $1770 \mathrm{ha}$, as well as 675 mining waste dumps, with a volume of 3101.92 million $\mathrm{m}^{3}$ and an area occupied by about 9260 ha [16].

In Romania, one of the worst events of this type occurred in October 1971, when the tailings dam on the outskirts of Certejul de Sus, Hunedoara County broke down and the avalanche of toxic sludge killed 89 people and injured almost 100 others, most of the victims being children. The victims were buried in the waste of decanting ponds after the dam was broken or crushed by the debris of the blocks taken by the toxic avalanche. Over the 300,000 cubic meters of tailings lapped everything in their path, in only a quarter of hour. The wave of toxic sludge covered and destroyed six blocks, a home for single people and over 50 households. Almost half of the 89 victims killed by the disaster were students and preschoolers, and almost a quarter of them were women [16].

(c) Establishing the evolution stage leads to the differentiation of the active sliding (characterised by the fact that the process of moving the materials on the slopes is in progress), semi-stabilized sliding (characterised by an obvious reactivation potential) and stabilized sliding (old sliding, which does not present conditions for the movement retake).

(d) Establishing the causes and mechanisms of movement in different types of rocks. Within the natural causes which have already been mentioned, the strength characteristics of the rocks, represented by the angle of internal friction and cohesion, are of the utmost importance in the study of the dynamics of landslides. These can be determined with the Coulomb-Terzaghi equation:

$$
\tau=(\sigma-\mathrm{u}) \operatorname{tg} \varphi+\mathrm{c}
$$

in which $\tau=$ shear strength (tangential shear stress), $\mathrm{daN} / \mathrm{cm}^{2} ; \sigma=$ normal pressure on the shear plane, $\mathrm{daN} / \mathrm{cm}^{2} ; \mathrm{u}=$ pore water pressure; $\varphi=$ internal shear angle, degrees; and $\mathrm{c}=$ cohesion, $\mathrm{daN} / \mathrm{cm}^{2}$.

The water pressure in the pore $(u)$ is determined by the formula $u=\gamma_{a} h_{a}$, in which $\gamma_{a}$ is the specific weight of the water, and ha, the equipotential height taken in point a.

(f) Knowledge of the way of intervention and of the technical works for stabilizing the lands, it is known that the stability of a slope is conditioned by the existence of a balance between the forces of movement (represented by the multiplication between the mass of the material and the gravitational acceleration) and those that are opposed to the movement (the shear strength of the rocks that make up that slope). Therefore, the triggering of a sliding will start either due to the increase of the displacement forces or due to the decrease of the resistance forces.

The movement can occur by translation or rotation, and the displaced material may retain its original structure or may be completely destroyed. 
Along with the natural causes, human activity can contribute to the triggering of sliding with disastrous effects, through improper use of the lands and carrying out works and constructions that do not take into account the degree of stability of the slopes.

\subsection{Risk matrix for sliding of the industrial waste}

The assessment of the risk of sliding of the industrial waste is a systematic technique of organizing the available information and knowledge based on a level of scientific certainty, in correlation with the necessary data and hypotheses; the technique objective is to facilitate the conclusions concerning risks, regardless of their nature ([17], pp. 73-77).

The risk assessment was carried out in accordance with "Order no. 184/1997 'regarding' the procedure for the achievement of environmental assessment" and according to which the risk is the probability of a negative effect occurring within a certain period of time ([17], pp. 73-77).

The risks of occurrence of industrial waste sliding phenomena which can have a major impact on the environment and population-for example, from the Brad mining perimeter they are:

- Loss of stability of the Cireşata Valley waste dump.

- Loss of stability of the Ribita decanting pond.

- Closure of the mining objectives in the area.

- Destruction of historical objectives.

The risk quantification is based on a simple classification system, a system in which the probability and severity of an event are classified as decreasing (Table 4).

The risk is calculated by multiplying the probability factor with the severity factor to obtain a comparative figure. This will allow comparisons between different risks. The higher the result is, the higher the priority that will need to be given in risk control.

The quantification of the relation between different economic, social, cultural and influence factors is presented in the risk matrix (Table 5).

The main purpose of assessing the risk of sliding of industrial waste is to help establish risk control. Risk assessment involves identifying the hazards and then assessing the sliding risk of the industrial waste they present, by examining the likelihood and severity of the damage that may arise from these hazards ([17], pp. 73-77).

The information regarding the assessment of the pollutants is given in the form of a checklist or matrix. The values of the sliding risk degree for the industrial waste

\begin{tabular}{lc}
\hline Probability classification & Severity classification \\
\hline $3=$ high & $3=$ high \\
\hline $2=$ average & $2=$ average \\
\hline $1=$ low & $1=$ low \\
\hline
\end{tabular}




\begin{tabular}{|c|c|c|c|c|c|}
\hline Crt. No. & Field & Influence factors & Probability & Severity & Risk \\
\hline \multirow[t]{5}{*}{1.} & Social-human & Population dependence on the objective & 3 & 2 & 6 \\
\hline & & Employment rate & 3 & 2 & 6 \\
\hline & & Health state & 3 & 3 & 9 \\
\hline & & Communications & 3 & 2 & 6 \\
\hline & & The risk of Social-human factors & & & 27 \\
\hline \multirow[t]{4}{*}{2.} & Aesthetic-cultural & Landscape effects & 2 & 2 & 4 \\
\hline & & Protected objectives & 1 & 1 & 1 \\
\hline & & Cultural settlements & 1 & 1 & 1 \\
\hline & & The risk of aesthetic-cultural factors & & & 6 \\
\hline \multirow[t]{3}{*}{3.} & Economic regional & Industrialization of the area & 2 & 2 & 4 \\
\hline & & The effect of the objective closure & 3 & 2 & 6 \\
\hline & & Current efficiency & 2 & 2 & 4 \\
\hline
\end{tabular}

Table 5.

The risk assessment matrix.

they present for the environmental, water, air and soil components are presented in matrix (Table 6). Environmental risk matrices in the mining perimeter of Brad.

The activity performed in the Brad area is $60 \%$ dependent on the mining industry. The reduction of activity in the mining industry has caused an acute shortage of jobs for the inhabitants of the area.

\begin{tabular}{|c|c|c|c|c|c|c|c|}
\hline $\begin{array}{l}\text { The } \\
\text { environ- } \\
\text { mental } \\
\text { factor }\end{array}$ & $\begin{array}{l}\text { The source } \\
\text { of pollution }\end{array}$ & Procedure & Pollutants & $\begin{array}{c}\text { Places } \\
\text { affected by } \\
\text { sliding of } \\
\text { industrial } \\
\text { waste }\end{array}$ & Probability & Degree & Risk \\
\hline \multirow[t]{12}{*}{ Water } & \multirow{5}{*}{$\begin{array}{l}\text { Water that } \\
\text { washes Morii } \\
\text { Valley Quarry } \\
\text { and Cireşata } \\
\text { waste dump }\end{array}$} & \multirow{5}{*}{$\begin{array}{l}\text { Spillage and } \\
\text { seepage } \\
\text { under } \\
\text { Cireşata } \\
\text { dump }\end{array}$} & $\mathrm{pH}$ & \multirow{8}{*}{$\begin{array}{c}\text { The wells of } \\
\text { the locals } \\
\text { from the } \\
\text { Morii Valley } \\
\text { Quarry area } \\
\text { The fauna } \\
\text { and aquatic } \\
\text { flora of the } \\
\text { streams } \\
\text { Emissary } \\
\text { Crişul Alb } \\
\text { stream by } \\
\text { disappearing } \\
\text { the aquatic } \\
\text { flora and fauna }\end{array}$} & 3 & 3 & 9 \\
\hline & & & Fixed residue & & 3 & 3 & 9 \\
\hline & & & Suspensions & & 2 & 2 & 4 \\
\hline & & & Heavy metals & & 3 & 3 & 9 \\
\hline & & & Sulphates & & 3 & 3 & 9 \\
\hline & \multirow{3}{*}{$\begin{array}{l}\text { Water of the } \\
\text { Bucureşci } \\
\text { stream }\end{array}$} & \multirow[t]{3}{*}{ Spillage } & $\mathrm{pH}$ & & 2 & 2 & 4 \\
\hline & & & Suspensions & & 2 & 1 & 2 \\
\hline & & & Heavy metals & & 3 & 3 & 9 \\
\hline & \multirow{4}{*}{$\begin{array}{l}\text { Water of the } \\
\text { Barza stream }\end{array}$} & \multirow{4}{*}{$\begin{array}{l}\text { Mine water } \\
\text { spillage }\end{array}$} & $\mathrm{pH}$ & \multirow{4}{*}{$\begin{array}{l}\text { Barza stream } \\
\text { through the } \\
\text { disappearance } \\
\text { of the aquatic } \\
\text { flora and fauna }\end{array}$} & 3 & 3 & 9 \\
\hline & & & Suspensions & & 2 & 1 & 2 \\
\hline & & & $\begin{array}{l}\text { Total ionic } \\
\quad \text { iron }\end{array}$ & & 3 & 3 & 9 \\
\hline & & & Heavy metals & & 3 & 3 & 9 \\
\hline
\end{tabular}




\begin{tabular}{|c|c|c|c|c|c|c|c|}
\hline $\begin{array}{l}\text { The } \\
\text { environ- } \\
\text { mental } \\
\text { factor }\end{array}$ & $\begin{array}{l}\text { The source } \\
\text { of pollution }\end{array}$ & Procedure & Pollutants & $\begin{array}{c}\text { Places } \\
\text { affected by } \\
\text { sliding of } \\
\text { industrial } \\
\text { waste }\end{array}$ & Probability & Degree & Risk \\
\hline \multirow[t]{6}{*}{ Soil } & $\begin{array}{c}\text { Cireşata waste } \\
\text { dump }\end{array}$ & $\begin{array}{c}\text { Dispersion } \\
\text { Exfiltration } \\
\text { Anthropic } \\
\text { Protosoil }\end{array}$ & $\begin{array}{l}\text { Sedimentable } \\
\text { powders } \\
\text { Exfiltration } \\
\text { under the } \\
\text { dump } \\
\text { Sterile }\end{array}$ & Forest fund & 3 & 2 & 6 \\
\hline & $\begin{array}{l}\text { Valea Blojului } \\
\text { waste dump }\end{array}$ & Dispersion & $\begin{array}{l}\text { Sedimentable } \\
\text { powders }\end{array}$ & Forest fund & 2 & 2 & 2 \\
\hline & $\begin{array}{l}\text { Valea Morii } \\
\text { quarry }\end{array}$ & Dispersion & $\begin{array}{l}\text { Sedimentable } \\
\text { powders }\end{array}$ & Forest fund & 3 & 2 & 6 \\
\hline & $\begin{array}{c}\text { Processing } \\
\text { plant }\end{array}$ & $\begin{array}{l}\text { Planning } \\
\text { works }\end{array}$ & $\begin{array}{c}\text { Ore } \\
\text { processing }\end{array}$ & $\begin{array}{l}\text { Agricultural } \\
\text { fund }\end{array}$ & 3 & 2 & 6 \\
\hline & $\begin{array}{l}\text { Decanting } \\
\text { pond Ribita }\end{array}$ & $\begin{array}{l}\text { Planning } \\
\text { works }\end{array}$ & $\begin{array}{l}\text { Sterile sludge } \\
\text { storage }\end{array}$ & $\begin{array}{l}\text { Forest fund } \\
\text { Agricultural } \\
\text { fund }\end{array}$ & 3 & 2 & 6 \\
\hline & \multicolumn{4}{|c|}{ Total risk for the environmental factor "soil" } & & & 26 \\
\hline \multirow[t]{5}{*}{ Air } & Crushing ore & $\begin{array}{l}\text { Dispersion } \\
\text { Propagation }\end{array}$ & $\begin{array}{c}\text { Sedimentable } \\
\text { powders } \\
\text { Noise }\end{array}$ & $\begin{array}{c}\text { Atmosphere } \\
\text { Fauna } \\
\text { Flora }\end{array}$ & 3 & 2 & 6 \\
\hline & $\begin{array}{l}\text { Ore transport } \\
\text { Sterile } \\
\text { transport } \\
\text { Gurabarza } \\
\text { processing } \\
\text { plant } \\
\text { (conveyor } \\
\text { belts) }\end{array}$ & $\begin{array}{l}\text { Dispersion } \\
\text { Propagation }\end{array}$ & $\begin{array}{c}\text { Sedimentable } \\
\text { powders } \\
\text { Noise }\end{array}$ & $\begin{array}{c}\text { Atmosphere } \\
\text { Fauna } \\
\text { Flora }\end{array}$ & 3 & 1 & 3 \\
\hline & $\begin{array}{c}\text { Ore } \\
\text { processing } \\
\text { Gurabarza }\end{array}$ & $\begin{array}{l}\text { Dispersion } \\
\text { Propagation }\end{array}$ & $\begin{array}{c}\text { Sedimentable } \\
\text { powders } \\
\text { Noise }\end{array}$ & $\begin{array}{c}\text { Atmosphere } \\
\text { Fauna } \\
\text { Flora }\end{array}$ & 3 & 1 & 3 \\
\hline & $\begin{array}{l}\text { Cireşata and } \\
\text { Valea Blojului } \\
\text { waste dumps }\end{array}$ & Dispersion & $\begin{array}{c}\text { Sedimentable } \\
\text { powders }\end{array}$ & $\begin{array}{c}\text { Atmosphere } \\
\text { Fauna } \\
\text { Flora }\end{array}$ & 1 & 1 & 1 \\
\hline & Ribita pond & Dispersion & $\begin{array}{l}\text { Sedimentable } \\
\text { powders }\end{array}$ & $\begin{array}{c}\text { Atmosphere } \\
\text { Fauna } \\
\text { Flora }\end{array}$ & 2 & 1 & 2 \\
\hline
\end{tabular}

Table 6.

Environmental risk matrices in the mining perimeter of Brad.

In conclusion, the quantification of the risk of slipping of the industrial deposits produced on the environment and the social domain was carried out through two risk matrices in which all the environmental components are analyzed.

The risk of slipping of industrial tailings deposits occurs in areas where the slope angle exceeds the internal rubbing angle of the rocky rocks and on or through the base terrain if its slope is greater than the internal rubbing angle of the rocks.

Risk assessment involves identifying the hazards and then assessing the risk of slipping the industrial deposits they present, by examining the likelihood and severity of the damage that may arise from these hazards. 


\section{Author details}

Emilia-Cornelia Dunca ${ }^{1 *}$ and Sabina Irimie ${ }^{2}$

1 Environmental Engineering and Geology Department, Faculty of Mine, University of Petrosani, Romania

2 Management and Industrial Engineering Department, Faculty of Mine, University of Petrosani, Romania

*Address all correspondence to: emydunca@gmail.com

\section{IntechOpen}

(C) 2020 The Author(s). Licensee IntechOpen. This chapter is distributed under the terms of the Creative Commons Attribution License (http://creativecommons.org/licenses/ by/3.0), which permits unrestricted use, distribution, and reproduction in any medium, provided the original work is properly cited. (c) BY 


\section{References}

[1] Council Directive 96/82/EC of 9 December 1996 on the control of majoraccident hazards involving dangerous substances

[2] Băltianu D. Natural and Anthropogenic Hazards. Bucharest: Corint; 2001. p. 110

[3] Smith K. Environmental Hazards: Assessing Risk and Reducing Disaster. London: Routledge; 2001. p. 392

[4] Grecu F. Natural Hazards and Risks. Bucharest: University; 2004. p. 168

[5] Voiculescu M. Typology of Geographical Risk Phenomena. Oradea: Publishing House Oradea University; 1995

[6] Varnes DJ. Landslide hazard zonation: A review of principles and practice. In: Natural Hazards. Vol. 3. Paris: UNESCO; 1984. p. 63

[7] Cioacă A. Vulnerability assessment of lands affected by current geomorphological processes. In: AUŞMS-Geography-Geology. Bucharest: Publishing House University of Bucharest; 1997

[8] Cheval S. The current significance of the study of natural disasters. In: The Risk in the Contemporary Economy. Galati: Academica; 2002. pp. 118-121

[9] Raboşapca I. Considerations regarding the classification of environmental risks. ASEM. 2009; 6(70):88-93

[10] Mac I, Petrea D. The Polysemy of Extreme Geographical Events, in Risks and Disasters. House of Science Book: Cluj-Napoca; 2002

[11] Stângă IC. Natural Risks. Notions and Concepts. Iasi: University Ed "Al. I. Cuza"; 2007. 112p
[12] https://www.theirm.org/what-wedo/what-is-enterprise-risk-management/

[13] Grecu F. Natural Phenomena of Risk. TUB, Bucureşti: Geology and Geomorphology; 1997

[14] Bogdan O, Niculescu E. Climate Risks in Romania. Bucharest: Romanian Academy, Institute of Geography; 1999

[15] Velcea V. Natural and Technogenic Risks. Sibiu: Faculty of Tourism Geography; 1995

[16] Report-Inventory and visual inspection of tailings dumps and tailings ponds in Romania. Ministry of Economy -Interministerial Commission for the national inventory of tailings dumps and tailings ponds. Reporting to the stage I no. $232.333 / 12.09 .2017$

[17] Dunca EC. Study on the Ecological Rehabilitation of the Affected Areas in the Brad Mining Perimeter. Petroșani: Universitas Publishing House; 2013. pp. 73-77 


\title{
Supply Chain FMEA Risk Analysis for the Heavy Industry Sector
}

\author{
Matgorzata Dendera-Gruszka and Ewa Kulińska
}

\begin{abstract}
The discussed problem is associated with the analysis of risk factors affecting supply chain management in the heavy industry sector based on the analysis of entities operating in this industry. During the research, several aspects of key importance in supply chain management in the heavy industry sector were identified. The use of the failure mode and effects analysis (FMEA) method in research has enabled the detection of defects in supply chain management and analysis of factors that may negatively affect the flow of goods. During the research, potential design flaws and the effect of these flaws were identified, indicating the class, cause, and occurrence.
\end{abstract}

Keywords: heavy industry, supply chain, risk analysis FMEA

\section{Introduction}

The need for continuous improvement of processes taking place in enterprises in order to stay on the market in the era of globalization forced on organizations is requiring cooperation. Business-to-business cooperation has evolved considerably over the past few decades. It can be safely argued that the chains of service providers from the beginning of entrepreneurship. Over time, trade has appreciated the characteristics of the supply chain and its competitive advantage. They began to create conscious networks of companies for more efficient and easier loading of goods. Services related to data flow management are most often given a competitive advantage in a given market.

The term supply chain first appeared in the 1980s. The cooperation used alone was not sufficient. In order to efficiently, dynamically, and qualitatively optimize loading of goods, such as planning, decision-making, organizing, and turning over. Over time, various concepts of supply chain management were developed toward the rapid creation, which allow the flow of goods to take place in the most efficient way $[1,2]$.

Do business, follow the constant decision-making process that is affected by a situation that requires operations. Risk management is defined as a set of activities that include planning, organizing, flipping, controlling, and making decisions.

These operations are aimed at protecting the organization against uncertain, unexpected, and dangerous events [3,4]. Risk management is a multistage process that aims to monitor business transactions against broadly understood danger. Activities included in the risk management use also the analysis of risk sources and their elimination. It should be taken into account that it does not always mean a negative 
situation and is increasingly seen as an opportunity for accessibility. Therefore, risk management may mean the elimination of the negative effects of a dangerous situation, but there may also be a chance to develop accessibility $[5,6]$. The essence of risk management determines the maximum utilization of benefits by the company while minimizing possible losses [7].

The meaning of words often raises doubts, and it is impossible to change clearly. Defining keywords on the basis of various sciences and theories, such as economics, law, psychology, statistics, probability theory, systems theory, or behavioral sciences, and then explicitly worded contents of the word risk, extremely difficult tasks.

The risk mainly applies to everyone and situations that should be avoided. It is also identified with chance, courage, and fate. It is a collection of activities that cause material losses and damage to the body or cause other losses. It is primarily associated with human activity and behavior [8]. Processing the definition of risk associated with the risk of positive or negative effects, expected values, uncertainty of achieving the goal $[9,10]$.

The failure mode and effects analysis (FMEA) method is used to identify nonconformities together with the risk of their occurrence. The method is used to determine the risk assessment arising during production, management, organization planning, etc. of given products or processes. The FMEA method works best during implementation processes, planning processes, optimization elements, or improving unstable processes. The goal of the FMEA method is to systematically identify and recognize likely product or process incompatibilities. Then, take a step that minimizes the risks associated with them, and identify the factors that most threaten the success of the product/process [11].

\section{Research goal and methodology}

The FMEA method is designed to detect defects at the earliest stages of the process. The FMEA method is based on the analysis of factors that may affect the process under investigation and relate to process methods, instrumentation, and environmental impact along with the definition of control measures $[12,13]$.

The first stage of the FMEA method concerns the selection of operations that should be analyzed along with the definition of the scope of the analysis. The number of parts and levels of the method depends on the complexity of the process [14].

The second stage consists in specifying the activities related to the FMEA analysis. First of all, potential defects that can occur in the analyzed case should be defined. After determining the sequence of events, cause-defect-effect, each defect should be assessed with an integer ranging from 1 to 10, taking into account three criteria: risk, possible occurrence of a defect, and cause [15].

The final stage of risk analysis using the FMEA method describes the elements in which changes should be made to reduce the risk of defects.

Research is based on the use of FMEA risk analysis in supply chain management in the heavy industry sector. The research lasted from 2016 to 2019. Nine business entities involved in steel production, trade, and processing were subject to examination. The entities were divided into three groups, and each group included three economic entities. The first group concerned steel companies. The headquarters of the enterprises are located in Poland, the Netherlands, and Germany. The next group concerned enterprises dealing in steel trade in Poland. The last group of enterprises is engaged in steel processing. Based on the industry analysis and intelligence in business entities, FMEA risk analysis has been developed [14]. 
In the studies presented, the FMEA analysis concerns industry analysis, not the process or product so far. This is an innovative use of FMEA risk analysis. No risk analysis has yet been developed for the industry in the context of supply chain management.

\section{FMEA risk analysis}

The FMEA analysis (Table 1) covers such areas of activity of the heavy industry sector as technological, time, location, political and legal, economic, social, and environmental area. Determinants affecting supply chains in the heavy industry sector were subjected to risk analysis.

Table 1 presents all aspects that may affect supply chain management in the heavy industry sector. In the table above, individual areas of activity of business entities involved in the flow of goods in the heavy industry sector have been analyzed. The potential type of defect was defined along with its effect. The probability of occurrence of a defect is determined on a scale of 1-10. The value of 1 is assigned to an unlikely situation, while 10 to a very likely situation. The details of the value assignment are set out in Table 2 .

The next step is to determine the cause of the defect along with determining its value. Also in this case, the cause of the defect is determined on a scale of 1-10. The value of 1 is assigned to an improbable situation and 10 to a very likely situation. The details of the value assignment are set out in Table 3.

In the next step, you need to specify preventive measures and estimate the detection parameters, based on Table 4.

The final stage of FMEA analysis is the assignment of the RPN parameter. Assigning the above parameters to the FMEA spreadsheet allows you to specify the priority number of RPN risk, which is calculated according to the following formula:

$$
\mathrm{RPN}=\text { Meaning }(\mathrm{I}) \times \text { Occurrence }(\mathrm{P}) \times \text { Detection }(\mathrm{D})
$$

RPN makes it possible to determine which threats carry the highest risk and the hierarchy in which order preventive actions should start.

FMEA analysis is a method of identifying and preventing problems related to the analyzed process before its implementation. It is focused on preventing process or product defects, increasing process security, financial security of the project, work safety, and environmental protection [14]. FMEA analysis is carried out at the design stage of the process or product to avoid the biggest threats and flaws in the implementation phase. This is an important technique for identifying and eliminating potential defects and errors in processes and products.

\section{Conclusion}

The research aimed to show the sources of risk in supply chain management in the heavy industry sector. During the analysis, RPN = 100 was determined below which the impact of factors on supply chain management is insignificant. For the industry studied, the greatest impact of risk on supply chain management has social aspects, primarily related to the lack of qualified staff, an increase in labor costs and social benefits, and the need to meet staffing needs with foreign personnel. Further aspects affecting supply chain risk management include an increase in energy and raw material prices, business relationships with customers, expansion of emerging markets, and reduction of spatial barriers. 


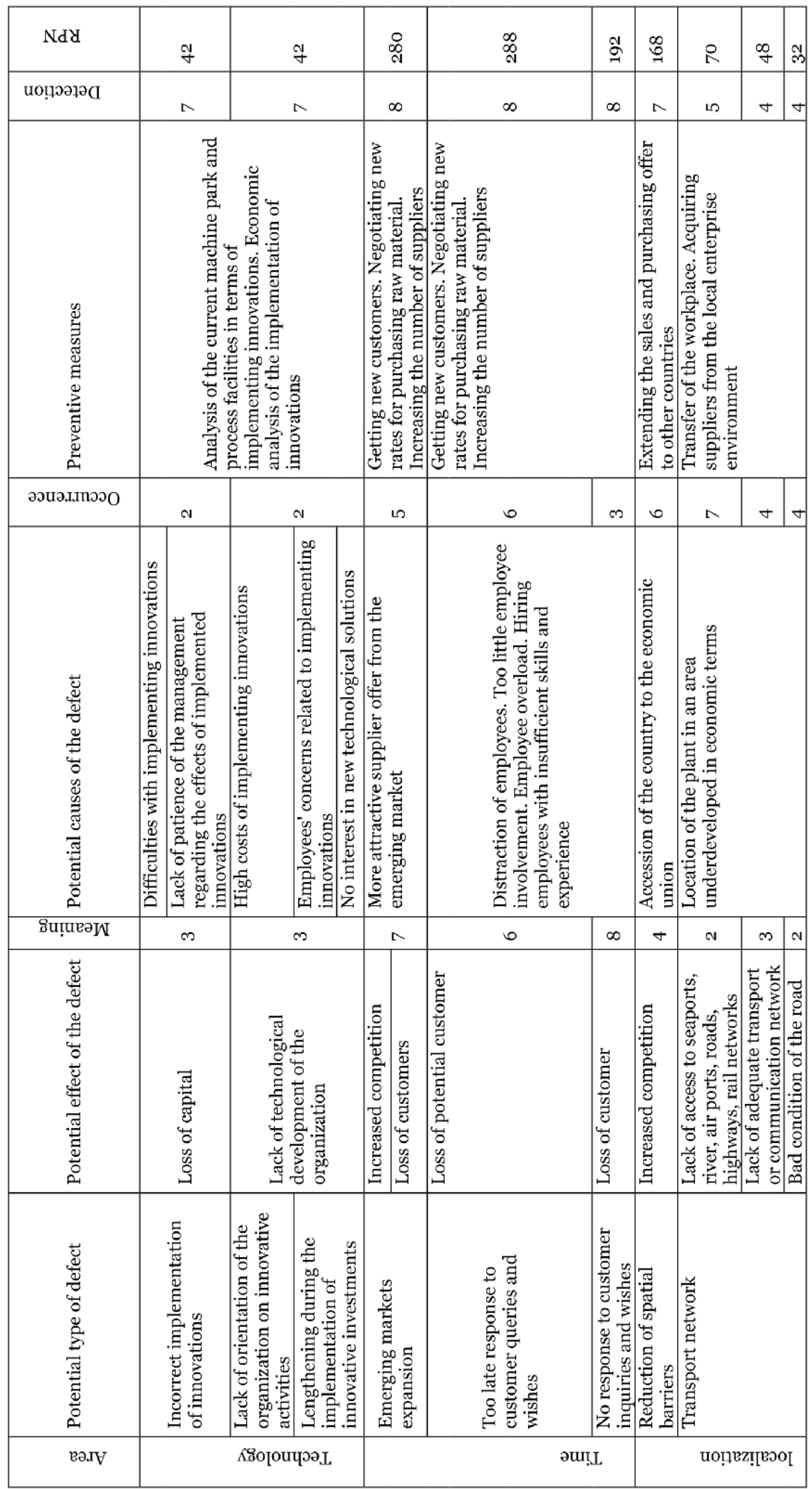




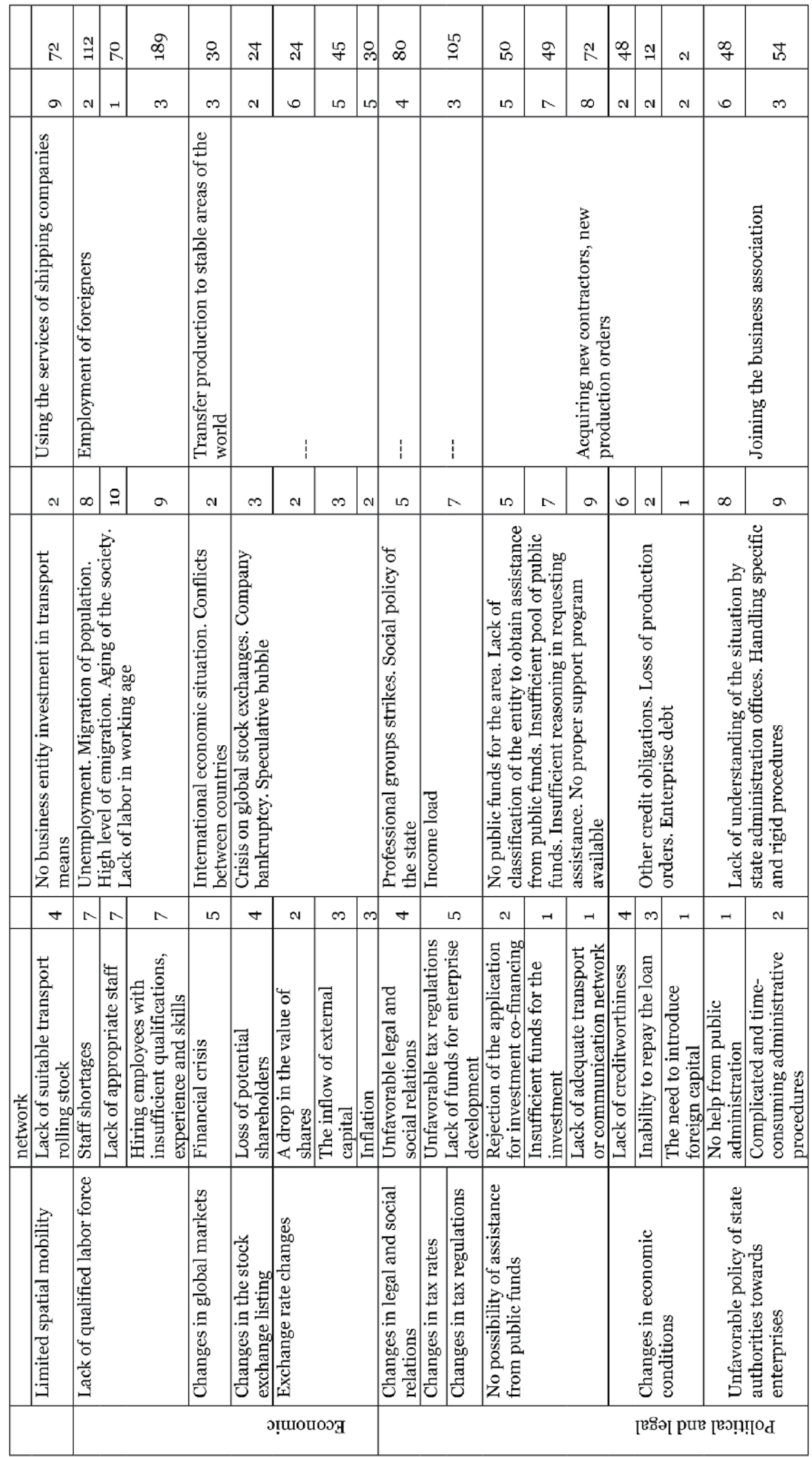




\begin{tabular}{|c|c|c|c|c|c|c|c|c|c|c|c|c|c|}
\hline बू & $\stackrel{\infty}{+}$ & ה & ম্র & N & $\stackrel{\circ}{\circ}$ & 寸 & $\begin{array}{l}\infty \\
\text { 心 } \\
\text { N }\end{array}$ & \& & స్త్ & & \& & $\stackrel{m}{\circ}$ & $\stackrel{\wp}{\varrho}$ \\
\hline$\Lambda$ & a & N & -1 & $m$ & 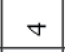 & $\nabla$ & $a$ & N & $n$ & & $m$ & $\infty$ & ما \\
\hline 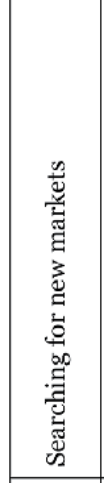 & 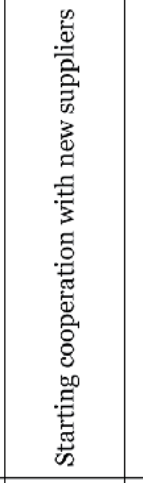 & 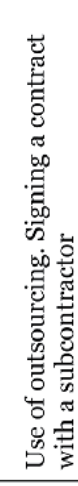 & $\vdots$ & 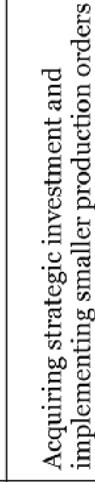 & $i$ & 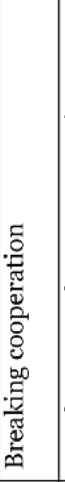 & 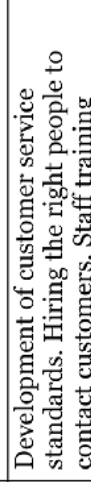 & 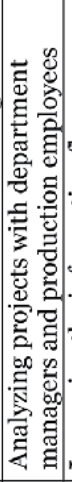 & 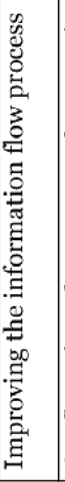 & 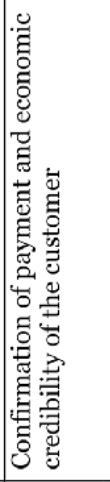 & & 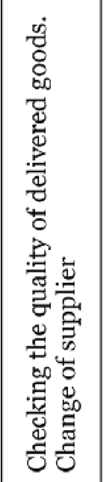 & 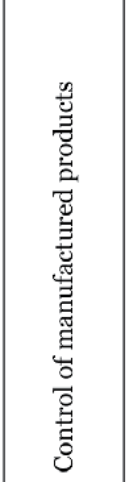 \\
\hline$\Lambda$ & 0 & $\nabla$ & t & $N$ & 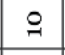 & $a$ & $\infty$ & $n$ & $\Lambda$ & & \llcorner & $\sigma$ & $m$ \\
\hline 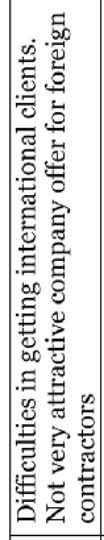 & 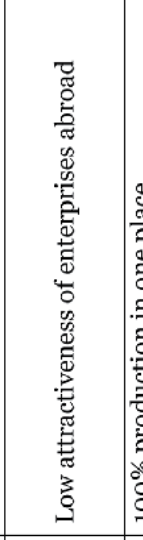 & 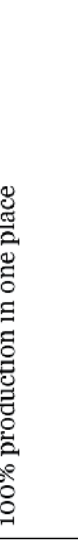 & 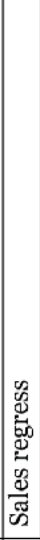 & 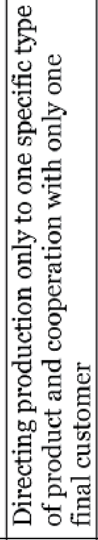 & 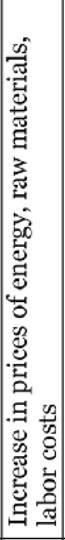 & 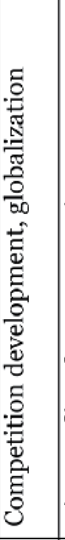 & 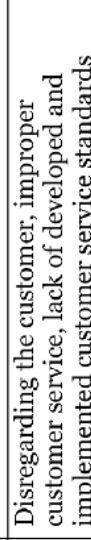 & 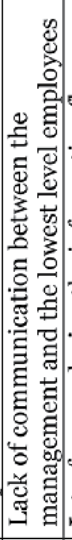 & 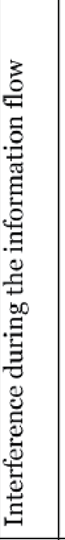 & & 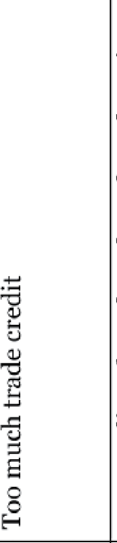 & 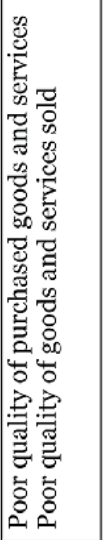 & 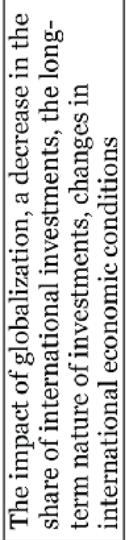 \\
\hline$\infty$ & + & $m$ & 0 & N & $a$ & $\nabla$ & + & $\Lambda$ & 0 & & $m$ & $\infty$ & 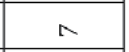 \\
\hline 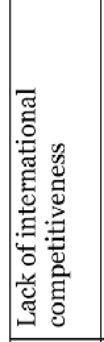 & 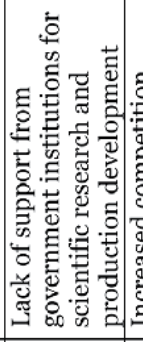 & 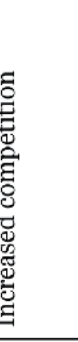 & $\begin{array}{l}\text { 苟 } \\
\text { 范 }\end{array}$ & 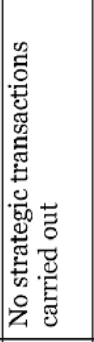 & 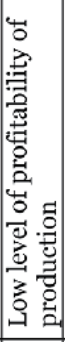 & 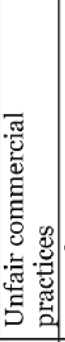 & 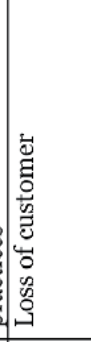 & 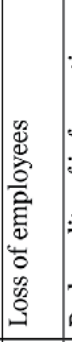 & 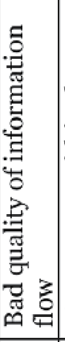 & 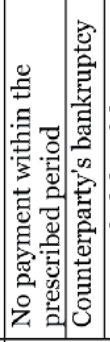 & 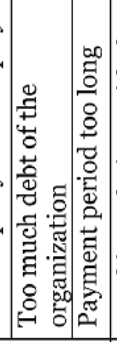 & 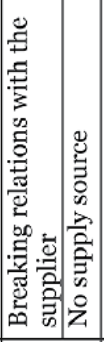 & 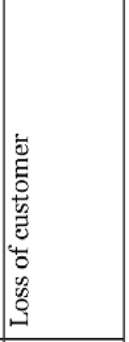 \\
\hline 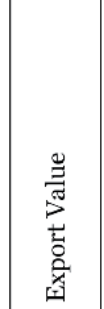 & 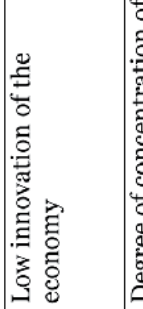 & 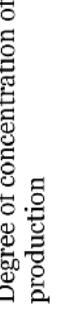 & 4 & 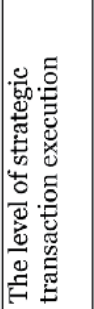 & 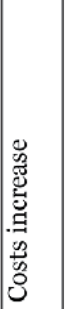 & 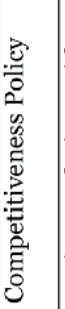 & 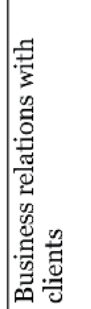 & 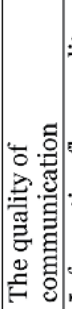 & 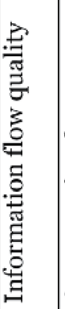 & 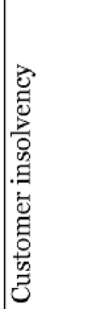 & & 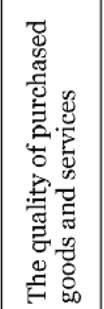 & 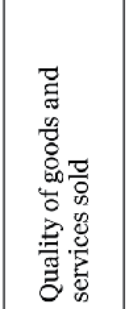 \\
\hline
\end{tabular}




\begin{tabular}{|c|c|c|c|c|c|c|c|c|c|c|c|c|}
\hline สั & $\stackrel{\infty}{+}$ & $\ddot{~}$ & \& & 品 & 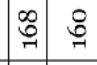 & स & $\%$ & $m:$ & $₫ \mid \infty$ & t & 8 & $\begin{array}{lll}\infty \\
\end{array}$ \\
\hline L & t & $\nabla$ & ه & 0 & 4 & a & $\sigma$ & $\infty$. & $\infty$ & a & N & $\infty$ \\
\hline 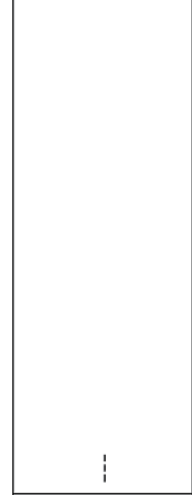 & & 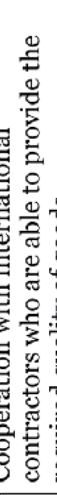 & & & 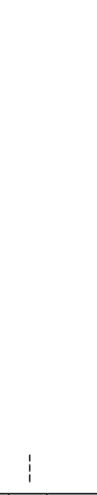 & 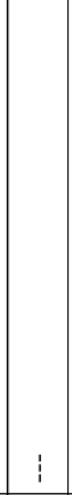 & 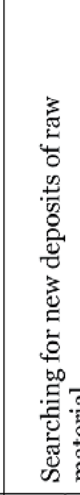 & & 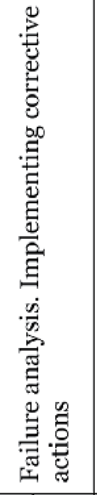 & & 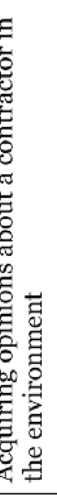 & \\
\hline n & t & a & ص & $n$ & $0 \%$ & 0 & $\infty$ & $\rightarrow 0$ & \begin{tabular}{l|l} 
N & ה
\end{tabular} & t & 0 & $\wedge \infty$ \\
\hline 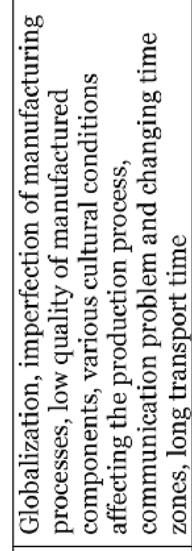 & 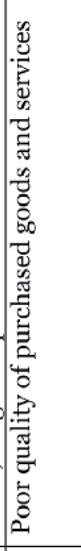 & & & & 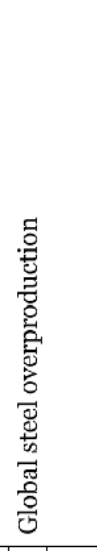 & 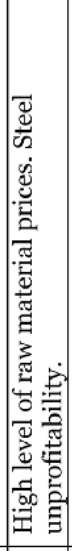 & 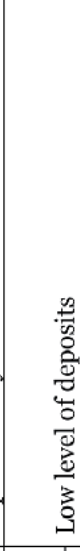 & 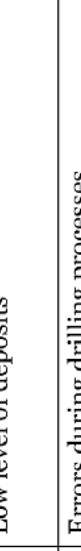 & 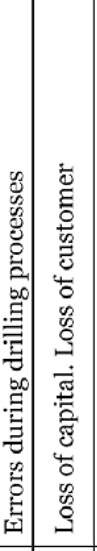 & & 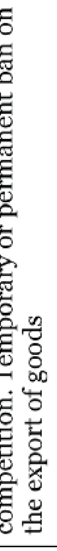 & 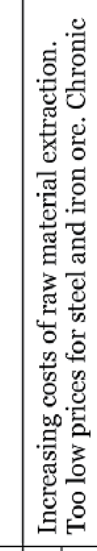 \\
\hline 0 & $\infty$ & $\theta$ & 0 & $\infty$ & $\therefore \infty$ & a & $\infty$ & \begin{tabular}{l|l}
$\rightarrow$ & 0
\end{tabular} & \begin{tabular}{l|l|} 
& $N$ \\
\end{tabular} & $\infty$ & in & $+\infty$ \\
\hline 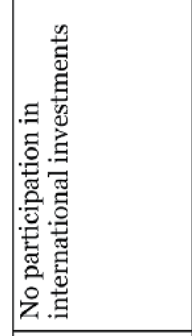 & 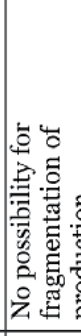 & 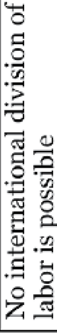 & 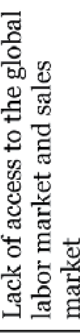 & 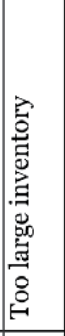 & 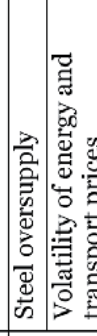 & 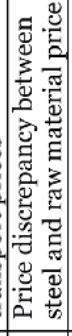 & 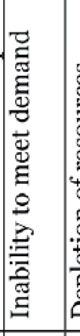 & 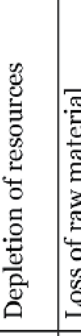 & 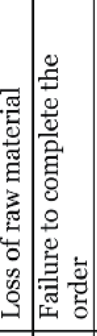 & 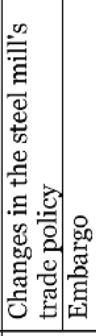 & & 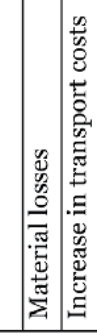 \\
\hline 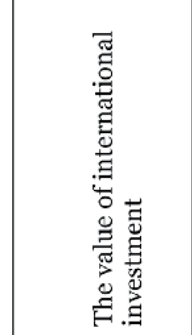 & 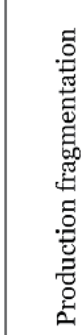 & & 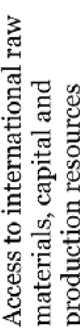 & 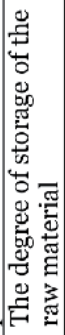 & 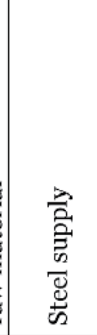 & 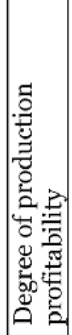 & 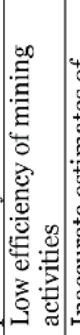 & 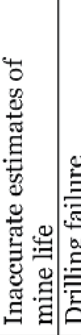 & 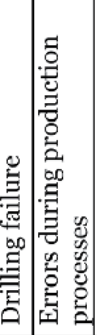 & 剂 & & $\begin{array}{l}\text { 总 } \\
\text { 兽 } \\
\text { 总 }\end{array}$ \\
\hline
\end{tabular}




\begin{tabular}{|c|c|c|c|c|c|c|c|c|c|}
\hline $\mid$\begin{tabular}{l}
$\infty$ \\
0 \\
\hdashline
\end{tabular} & 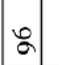 & 寺 & & 号 & $\mathbb{N}$ & $\stackrel{\infty}{\sim}$ & त्ञ & 号 & $\stackrel{\varphi}{\circ}$ \\
\hline$\infty$ & a & a & & ـ & + & 0 & \begin{tabular}{l|l|l|}
4 & 4 & $\infty$ \\
\end{tabular} & 0 & $\infty$ \\
\hline \multicolumn{4}{|c|}{ 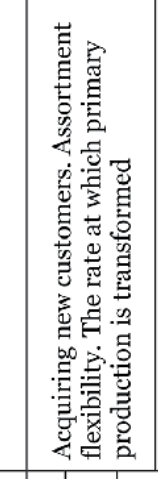 } & 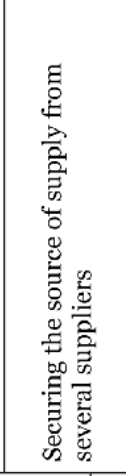 & & i & 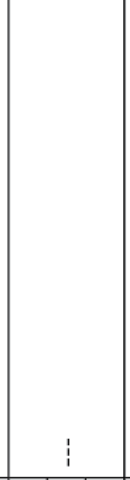 & 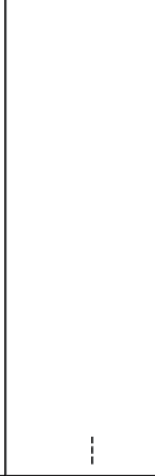 & 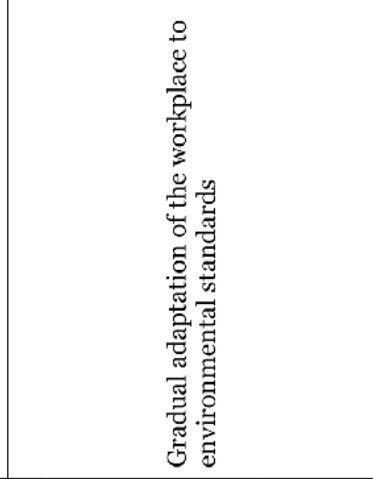 \\
\hline a & $\infty$ & $\infty$ & & $\Lambda$ & $\infty$ & H & \begin{tabular}{c|c|c|}
4 & 4 \\
\end{tabular} & $\stackrel{ }{ }$ & 0 \\
\hline & \multicolumn{2}{|c|}{ 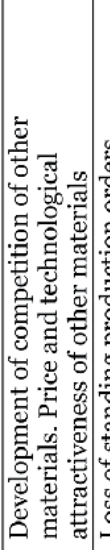 } & \multicolumn{2}{|c|}{ 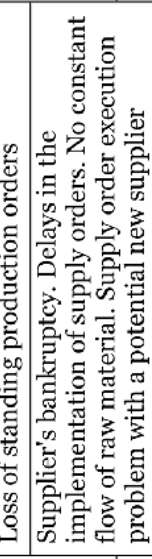 } & 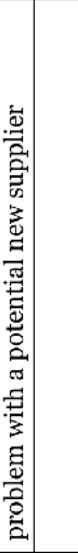 & 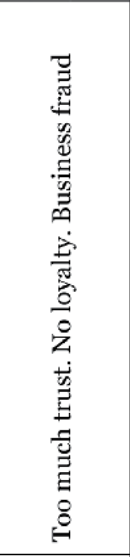 & 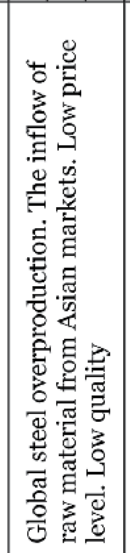 & 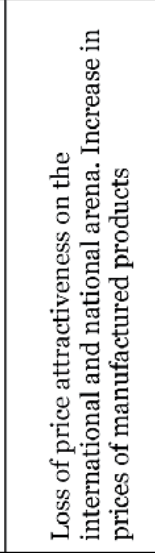 & 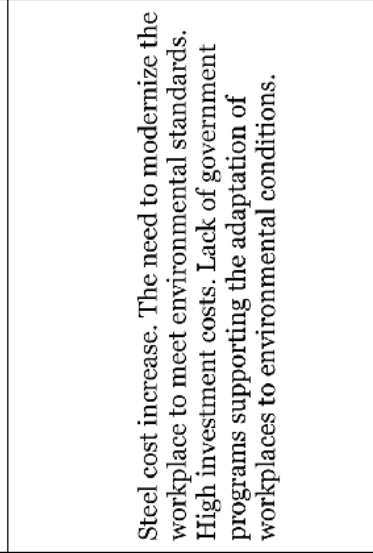 \\
\hline+ & 0 & $a$ & & - & -4 & $m$ & \begin{tabular}{l|l|l|}
$\circ$ & $N$ & $m$ \\
\end{tabular} & $a$ & a \\
\hline 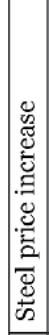 & 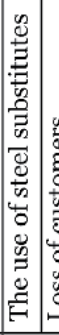 & 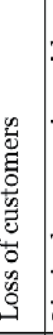 & 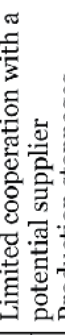 & 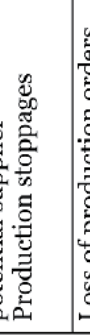 & 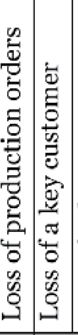 & 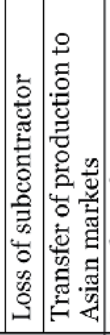 & 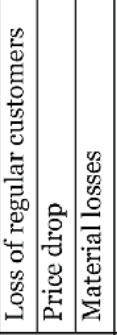 & 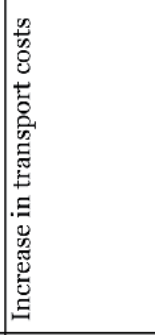 & 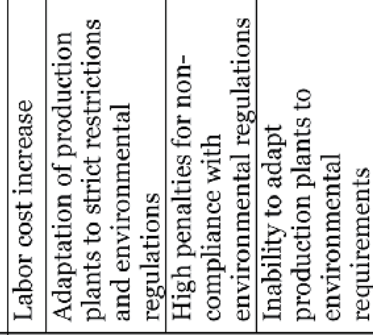 \\
\hline & 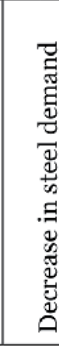 & 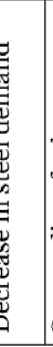 & 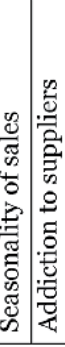 & 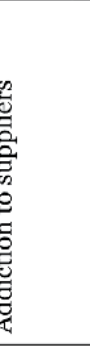 & & 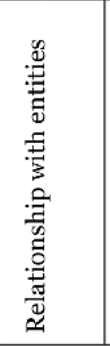 & 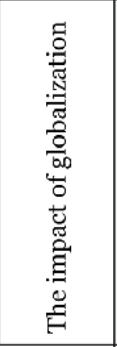 & 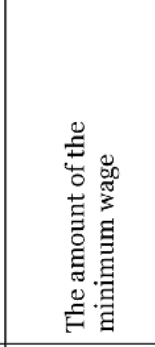 & 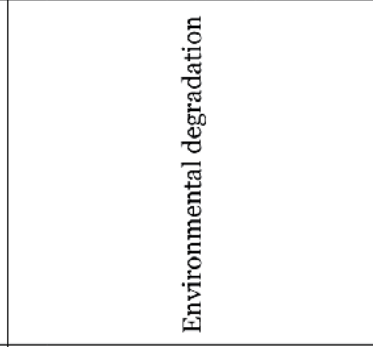 \\
\hline & & & & & & & & [Еழ๐OS & 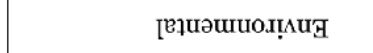 \\
\hline
\end{tabular}

है 


\begin{tabular}{lll}
\hline I & Importance & FMEA services/constructions \\
\hline 1 & Unbelievable & An imperceptible impact on the service \\
\hline $2-3$ & Little & The defect is small and has little impact on customer satisfaction \\
\hline $4-6$ & Average & Average defect, felt customer dissatisfaction \\
\hline $7-8$ & Important & $\begin{array}{l}\text { The defect happens cyclically and has a big impact on customer } \\
\text { dissatisfaction }\end{array}$ \\
\hline 9-10 & $\begin{array}{l}\text { Extremely } \\
\text { important }\end{array}$ & $\begin{array}{l}\text { An extremely important defect, which affects further work, safety and is } \\
\text { contrary to the law }\end{array}$ \\
\hline
\end{tabular}

Table 2.

Determining the significance of the occurrence of a defect [own study].

\begin{tabular}{cll}
\hline $\mathbf{P}$ & $\begin{array}{l}\text { Probability of occurrence } \\
\text { of a defect }\end{array}$ & FMEA service/construction/process \\
\hline 1 & Unbelievable & No defect can occur \\
\hline 2 & Very low & $\begin{array}{l}\text { Very low probability of occurrence of a defect. Defects occur } \\
\text { individually and very rarely }\end{array}$ \\
\hline 3 & Low & Low probability of occurrence of individual defects \\
\hline $4-6$ & Average & Defects occur on average in small quantities \\
\hline $7-8$ & High & Disadvantages occur very often \\
\hline $9-10$ & Very high & Very high probability of a defect \\
\hline
\end{tabular}

Table 3.

Determining the probability of occurrence of a defect [own study].

\begin{tabular}{lll}
\hline D & Detection & FMEA service/construction/process \\
\hline $1-2$ & Very big & Some defect detection \\
\hline $3-4$ & Large & The chances of detecting a defect are high, a test or functional check is used \\
\hline $5-6$ & Average & Defect control can detect average detectability \\
\hline $7-8$ & Small & Defect detection difficult \\
\hline $9-10$ & Very small & Detection of a defect is difficult or impossible to detect \\
\hline
\end{tabular}

Table 4

Determining the probability of detection [own study].

Risk analysis has been created for a specific industry. Based on the analysis, the values included in Table 1 have emerged. The RPN value presented in Table 1 identifies the greatest threats to the process under study. A detailed analysis of all RPN values above 100 identifies the greatest threat to supply chain management in the heavy industry sector. At the same time, analyzing the results contained in Table 1, you can simultaneously create and implement appropriate preventive measures described in the column "Current preventive measures in the process." Disregarding the results of risk analysis using the FMEA method may lead to negative effects on the functioning of enterprises operating within the analyzed supply chain.

The FMEA risk analysis itself can be used for different cases. The studied problem concerns threats and uncertainty in the supply chain in the heavy industry sector. Each risk analysis based on a given problem is individual. Risk factors may vary on each enterprise that is technologically similar, and it is not possible to use risk analysis prepared for entity A for entity B. Even more, the risk analysis 
considered in the context of one industry may differ for other industries. The impact of risk factors may be the same in some respects, but it will be different even if it is personal or environmental. Risk analysis is always created with a specific enterprise, process, product, or industry in mind. The scheme of risk analysis using the FMEA method can be used for each individual problem.

\section{Fundings}

Research financed by a research project NCN nr UMO-12/05/B/HS4/04139.

\section{Author details}

Małgorzata Dendera-Gruszka* and Ewa Kulińska

Faculty of Production Engineering and Logistics, Opole University of Technology, Poland

*Address all correspondence to: m.dendera-gruszka@po.edu.pl

\section{IntechOpen}

(C) 2020 The Author(s). Licensee IntechOpen. This chapter is distributed under the terms of the Creative Commons Attribution License (http://creativecommons.org/licenses/ by/3.0), which permits unrestricted use, distribution, and reproduction in any medium, provided the original work is properly cited. (cc) BY 


\section{References}

[1] Tarasewicz R. Jak mierzyć efektywność łańcuchów dostaw?

Warszawa: Oficyna Wydawnicza Szkoły Głównej Handlowej w Warszawie; 2014. pp. 11-14

[2] Rogowski W, Michalczewski A. Zarządzanie ryzykiem w przedsiębiorstwach inwestycyjnych. Kraków: Wyd. Oficyna Ekonomiczna; 2005. p. 7

[3] Kulińska E, Dornfeld A. Zarządzanie ryzykiem procesów, identyfikacjamodelowanie-zastosowanie. Opole: Oficyna Wydawnicza Politechniki Opolskiej; 2009. p. 9

[4] Dendera-Gruszka M, Kulińska E, Masłowski D. Mapa ryzyka jako narzędzie analityczne wspomagające zarządzanie ryzykiem. In: Studia i Materiały Wydziału Zarządzania i Administracji Wyższej Szkoły Pedagogicznej im. Jana Kochanowskiego w Kielcach. Zarządzanie kryzysowe i bezpieczeństwo, 21. 2017;1(4): 533-546

[5] Kulińska E. Metody analizy ryzyka w procesach logistycznych. Logistyka. 2011;2:385-390

[6] Szymonik A. Logistyka w bezpieczeństwie-bezpieczeństwo w logistyce. Wybrane zagadnienia, Innowacje w zarządzaniu i inżynierii produkcji, T. I, red. R. Knosala. Oficyna Opole: wydawnicza PTZP; 2016. pp. 1033-1044

[7] Dendera-Gruszka M, Kulińska E, Masłowski D. Mapa ryzyka jako narzędzie analityczne wspomagające zarządzanie ryzykiem. Zarządzanie kryzysowe i bezpieczeństwo: Studia i Materiały, R. 21 Wydziału Zarządzania i Administracji Wyższej Szkoły Pedagogicznej im. Jana Kochanowskiego w Kielcach. 2017;1(4):533-546
[8] Kaczmarek TT. Ryzyko i zarządzanie ryzykiem, ujęcie interdyscyplinarne.

Warszawa: Wyd. Difin; 2008. pp. 51-53

[9] Šotić A, Rajić R. The review of the definition of risk. Online Journal of Applied Knowledge Management. 2015; 3(3):17-19

[10] Dendera-Gruszka M, Kulińska E, Wojtynek L. Analiza ryzyka usług logistycznych w oparciu o audyt logistyczny na podstawie wybranego przedsiębiorstwa. Zeszyty Naukowe SGGW. 2017;2(1):17-30

[11] Rusecki A. Praktyczne zastosowanie metody FMEA na przykładzie produkcji koła pasowego w wybranym przedsiębiorstwie. Quality Production Improvement. 2018;8(1):7-18

[12] Folejewska A. Analiza FMEA zasady, komentarze, arkusze, Wyd. Warszawa: Verlag Dashofer; 2010

[13] Pałubicki S, Kukiełka K. Zarządzanie jakością w wybranym procesie produkcyjnym $\mathrm{z}$ zastosowaniem metody FMEA. Autobusy. 2017;7-8:90-96

[14] Wyrębek H. Znaczenie metody FMEA w zarządzaniu jakością w przedsiębiorstwach. Zeszyty Naukowe Uniwersytetu Przyrodniczo -

Humanistycznego w Siedlcach. 2012;92: 151-165

[15] Huber Z. Analiza FMEA procesu. Gliwice: Wyd. Złote Myśli; 2007. pp. 11-32 

Section 2

Risk Evaluation 



\title{
Application of Quantum Physics Assumptions for Risk Assessment
}

\author{
Marek Rozycki
}

\begin{abstract}
Risk assessment is the result of assumptions of people performing it. Therefore, its use may be limited, because in principle it is difficult to predict events that we are not aware of. A certain solution to this problem seems to be the application of inception theory and quantum physics assumptions to describe future phenomena. The aim of the study will be to demonstrate the experience of risk assessment attempts using quantum physics assumptions. The current application of new assumptions for risk assessment in the case of road infrastructure allows for the thesis that a change in the approach to risk assessment is necessary in all areas related to human activity.
\end{abstract}

Keywords: risk assessment, quantum physics assumptions

\section{Introduction}

With the formulation of the theory of relativity, we gained a new tool with which to explain the world. It appears that the laws of quantum mechanics explain the processes governing the deepest layers of reality, operating at the levels of the smallest particles of our world. Through experiments and analyses, we can assume that these laws explain phenomena both on the micro- and macroscale. Rules different from classical physics explain the heretofore unexplained and, crucially, allow us to design new experiments within a world entirely unavailable to our senses. The analyses of the visible outcomes of interactions between componentsthat is to say, events in the real world-return little information about the structure of the observed reality. By interpreting outcomes (events), instead of images of detailed relations, we project our expectations; the mathematical structures we use to explain outcomes are merely an attempt to fit our model to reality, and we can only determine the model's applicability when, and insofar as, the observable reality confirms our reasoning. Nevertheless, the fact remains that mathematics allows us to draw conclusions as to the rules governing the functioning of the world. The more appropriate the model we use, the better will be our results. If reality is like music, then the tools of analysis are our music score [1]. The notes we use will be the substance of music, but not the music itself. Similarly with analyses, a model of reality used for analysis is the score whose reality is created with many unspecified or loosely defined components. This may lead us to conclude that reality can only perform a score once it has been written. Such an anthropocentric approach leads us to believe that we can influence and shape events. This is especially clear in analysing risk. We usurp the right to assess risk and event probability and expect 
that reality will perform our freshly composed score. We must, however, allow that mathematical analysis may try to impose its assumptions on reality, which may or may not succeed (e.g. in management methods used in banks and insurance companies).

The job of the risk assessor at such institutions is to draw conclusions about the structure of the world based on mathematical structures. In this context, the ideas of quantum physics - in particular, the concept of the state of an object in a Hilbert space [2], the phase space and the quantum system-may help our analyses, allowing a fuller understanding of reality.

In light of the present investigation, we can conclude that quantum mechanics does not apply to individual events but is a theory of interactions between groups of events (composition series) whose behaviour observably conforms to the laws of statistics. All measurement attempts made within a quantum system will, in essence, be performed on groups of identically prepared objects. These objects may realise every possible state. The results of these measurement attempts come in the form of probability distribution of all possible measurement results. In line with this interpretation, we can focus strictly on looking for the probability distribution and ignore individual events.

Risk assessors have been using this interpretation for some time now. The theory of inertia [3], as an example, asserts that the probabilities of a given state occurring and not occurring are equal. This means that at any given moment a given event may occur or not. If we assign a value of 1 to the state occurring, and a value of 0 to the state not occurring, the distribution will result in a mean of 0 and standard deviation of 1 . The potential of the event occurring has equal probability, which means that at any given moment we can expect a given state to occur and not occur-just as described by Schrödinger in his famous 1935 experiment [4]. Each object interacts with its environment, and at the quantum level this interaction can be described as consistent with the second law of thermodynamics, i.e. with quantum decoherence, where every system moves towards increased entropy if it is devoid of energy needed to preserve its current state. The identified risk potential is an expression of quantum entanglement and exhibits a tendency to equalisation (entanglement reduction), towards irreversible change of interference between the system and the environment. Risk, therefore, should be understood as the measurement of loss of information about a given system, as a result of its interaction with the environment. In this context, it is imperative to attempt a quantum-mechanical analysis of risk.

\section{Quantum mechanics in interpretation of phenomena}

The desire to understand the world and to describe it in terms of mathematical formulae is as old as the human desire to dominate it. Each age has tried to explain observable correlations as causes and effects, in a manner peculiar to itself. In ancient Greece, atomistic theories of the likes of Democritus, according to which matter consisted of final, eternal, unchanging and indivisible atoms, clashed with continuous theories of Aristotle and others, who believed that matter was fluid and ever-changing. Such theoretical clashes across the ages have always encouraged further investigations into our questions about the world, leading to new questions, new theories and new clashes. This progress of human knowledge sped up with the industrial revolution and the creation of more efficient tools of observation. When electrons were discovered, the structure of previously indivisible atoms was called into question. The discovery of the atomic nucleus led to the formulation of the planetary model of the atom, according to which nearly all the mass and positive 
charge are concentrated in the nucleus, around which negatively charged electrons orbit. During his work on black-body radiation, Max Plank formulated the hypothesis of quanta of energy, when existing analyses based on classical physics proved ineffectual. Further discoveries and ideas followed; one of which was the waveparticle duality, which posits that the entire universe behaves consistently with laws governing either the behaviour of waves or that of particles. This idea, and the results of many experiments which it enabled (including the work of Wheeler [5]), suggests that the observed structures change as the result of observation. So, it is probable that a given event's result, which we wish to observe, will occur depending on whether and how we observe the event. The manner in which we choose to measure the "present moment" will influence that which caused the present event. Ideas like these are far removed from those of Aristotle and Democritus and require a completely fresh gaze. The premises of quantum physics appear to be verifiable both on micro and macro level, which begs the question: if quantum physics applies to the level of elementary particles, will they apply to modelling real events? If the answer is yes, there should be no objection to the use of analytical tools proper to quantum physics in analysing events such as those which risk analysts are concerned with. The language of mathematics seems to be the only tool precise enough to describe the subtle and rich structures of reality. Structures transparent to human senses are revealed in mathematics, and numbers allow the identification of their states and properties (e.g. their minima, maxima or functions). Let us attempt a certain simplification. The classical, Newtonian understanding of phenomena is determined by the notions of motion, point particle and rigid body. Classical mechanics relies on the premise that there exist objective, quantifiable objects, in motion along specific trajectories, possessing other specific properties, such as position, mass or charge. Elements of a system interact, as do point particles, in strictly defined ways. Contacts and collisions occur, whether directly or indirectly through fields (e.g. of energy, temperature, etc.). These observations lead to the conclusion that the properties of a physical situation can be defined by absolute terms and numbers. We identify laws of cause and effect and conjecture that, under identical conditions, objects will behave identically. We conclude that all objects in the world are determinate and their behaviour is strictly defined and uniform. In the standard (classical) probability measure of a given state occurring, a family of events is characterised as follows:

There exists a sample space $\Omega$ and a family $\mathrm{Z}$ of subsets of the sample space $\Omega$, called events. The following premises are true:

1. $\varnothing$ (empty set) and $\Omega$ (sample space) are events.

2. If $\mathrm{A}$ is an event, then $\mathrm{A}^{\prime}=\Omega-\mathrm{A}$ also is an event.

3. If $A$ and $B$ are events, the sum of sets $A \cup B$ is also an event.

Probability is the function $P: Z \rightarrow\langle 0,1\rangle$ where:

4.P $(\Omega)=1$.

5. If $\mathrm{A}$ and $\mathrm{B}$ are events and the product of sets $A \cap B=\varnothing$, then

$$
P(A \cup B)=P(A)+P(B) .
$$

It follows from premises (1), (2) and (3) that if A and B are events, $A \cap B$ is also an event. 
This model works in general but fails in particular, detailed analyses where it turns out that it is impossible to define generic behaviours of such elementary particles as electrons.

We would reach similar conclusions in analysing human behaviours. We cannot predict human reactions to specific stimuli; we can only predict the probability that the person will behave in this or that specific way. In creating models of reality, we try to describe complicated reactions which consist both of defined and undefined situations. In effect, individual points of such a system become a blur. They become less sharply defined as discrete entities and tend towards the state which is the result of our analyses. Whilst we can define, as an example, the length of a road tunnel using classical physics, the result of the measurement of the total velocity of the motion of vehicles in the tunnel, or the time needed to evacuate people from the tunnel in an emergency, will depend on the chosen method of measurement. Defining the method of measurement is key in assessing the safety of a tunnel, both for particular tunnels and all tunnels in general. This in turn creates the risk that, in defining an object, one can describe its properties so that the correct (i.e. well defined) response to the question about its state will be elicited only if the object is in the ground state (assumed by the analysis operator). To return to the example of a road tunnel, the very question whether the tunnel is "safe" is, in effect, a question not about the state of the object but the properties of the analysis operator. The response to such a question will be incidental and unreliable. The basic problem here appears to be expressing the measurement numerically. If we do not use a precise measurement method, the result will always be a blur.

It remains a fact that there are such values, or their relations, which can never be specified precisely (expressed as discrete numbers) at the same time, for example, the number of people at risk in a particular road tunnel emergency. We can assume the minimum, maximum or mean (expected) value, but we can only arrive at a probability of the value of our prediction.

It could be argued that an object in a particular state has the unique ability to respond to the demands of its environment and display a particular property. When its state conforms with the state expected by the operator, the object can return an unambiguous response to the operator's "question". In the case of the road tunnel, its state usually does not conform with the state expected by the operator (questioning the tunnel's safety), and as a result the question generates a random response out of a set of the operator's ground states. Of the many states identified by the analysis operator, the current state of the object may be constructed, but each of these states may reveal itself as the response to the operator's question, without the possibility of predicting which. In other words, the complete state of the object fractures into multiple ground states of the operator, and the object picks a state haphazardly and returns it to the operator as its response.

These observations are consistent with the tenets of the Copenhagen interpretation of quantum mechanics. Accordingly, we can set forth the following theses:

1. Every system is fully described by the wave function $\mathrm{Y}$ which fully describes the observer's understanding of the system (Heisenberg).

2. A description of nature is probabilistic. The probability of an event is the squared modulus of the wave function associated with the event (Max Born).

3. We cannot know the values of all properties of a system at a given time; imprecise properties may be expressed as probabilities (Heisenberg's uncertainty principle). 
4. When the size of the system approaches macroscale, the quantum-mechanical description ought to yield results consistent with the results from a classical treatment (Bohr's and Heisenberg's correspondence principle).

An attempt to model future events within a given system consistent with the classical probability modelling must result in producing questions inadequate to the possibility of eliciting responses, as we are unable to predict all variants of events and correlations. Classical probability attempts to ignore reality and proceeds against logic, which allows us to accept the instances of "black swans". Meanwhile, if we accept that the real-life result is a wave function of the relations between the preparation of the system and its measurement and that it has an operational character inextricable from the observer, we can attempt to identify the final states and define the occurrence probability of the elements leading up to these final states.

Let us consider the following model. Let us suppose, in accordance with the above premises, that the probability $\boldsymbol{p}$ is described as the squared modulus of a certain complex number $\mathrm{A}$, which is the amplitude of probability:

$$
\boldsymbol{p}=|\mathrm{A}|^{2}
$$

This pattern has been confirmed in multiple experiments, of which the most representative is the one using a quantum gun.

Let us consider an electron gun (although it could equally well be a ball launcher or traffic organisation in a tunnel). Let us launch electrons towards screen $\mathrm{E}$ through an obstacle with two apertures $\mathrm{S}_{1,2}$ and define the variable $\boldsymbol{x}$ (probability) along the screen $\mathbf{E}$. The number of apertures may be greater. The screen is positioned at the distance L. The system may be illustrated as shown in Figure 1.

Let us assume that the passage of an electron through the apertures can happen in two distinct ways, $\left(\boldsymbol{S}_{1}\right)$ and $\left(\boldsymbol{S}_{2}\right)$, each of which is described by the probability amplitude $\boldsymbol{A}\left(\boldsymbol{S}_{1}\right)$ and $\boldsymbol{A}\left(\boldsymbol{S}_{2}\right)$.

In classical reasoning, the launched electron can reach the screen either through aperture $\left(S_{1}\right)$ (trajectory $S_{1}$ ) or aperture $\left(S_{2}\right)$ (trajectory $S_{2}$ ). This level will result in flares on the screen appropriate to the location of the apertures, which is illustrated below (Figure 2). The position of the flares conforms to Gaussian (normal) distribution.

In practice, such an ideal model cannot occur. This is because it is also probable that the electron will not pass through the aperture, or that events will suffer from

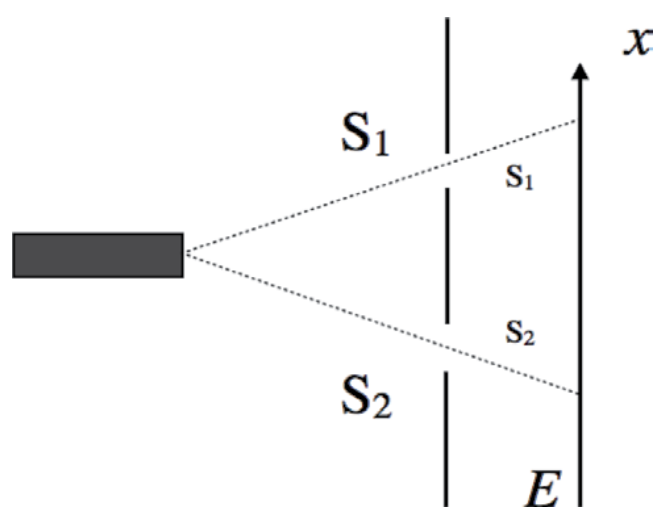

Figure 1.

Aperture experiment. 


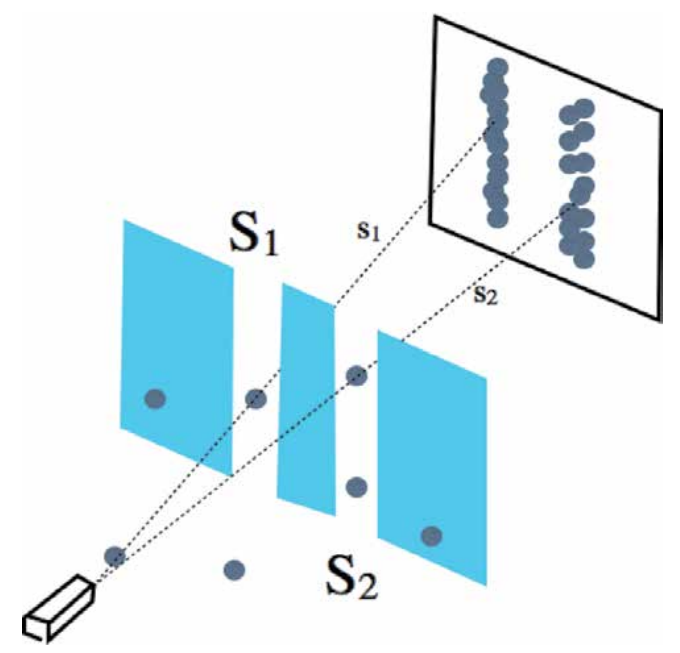

Figure 2.

Probability distribution for positions of electrons hitting the screen, consistent with the tenets of classical physics.

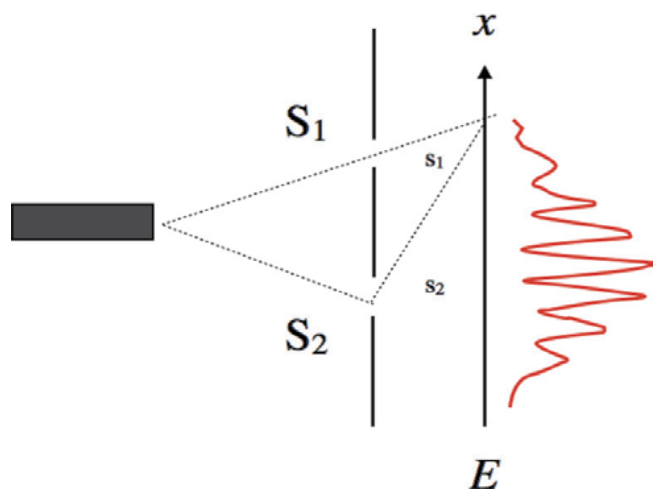

Figure 3 .

Probability distribution for locations of electrons hitting the screen, accounting for possible interferences.

mutual interference. In effect, there will be areas of maximum likelihood of the electron hitting the screen, as well as areas which will never be hit by the electron (under constant conditions of the experiment). This situation will result in a probability amplitude which can be formulated as

$$
A\left(S_{1} \text { or } S_{2}\right)=A\left(S_{1}\right)+A\left(S_{2}\right) .
$$

This observation replaces the practice of adding up probabilities of classical physics: the final result is not a sum of probabilities of the electron passing through the aperture. It can be illustrated as shown in Figure 3 above.

The following equation is, therefore, true:

$$
\boldsymbol{p}_{\left(\boldsymbol{S}_{1} \text { or } S_{2}\right)}=\mid\left.\boldsymbol{A}\left(\boldsymbol{S}_{\mathbf{1}} \text { or } \boldsymbol{S}_{\mathbf{2}}\right)\right|^{2}=\left|\boldsymbol{A}\left(\boldsymbol{S}_{\mathbf{1}}\right)+\boldsymbol{A}\left(\boldsymbol{S}_{\mathbf{2}}\right)\right|^{2}=\left|\boldsymbol{A}\left(\boldsymbol{S}_{\mathbf{1}}\right)^{2}\right|+\left|\boldsymbol{A}\left(\boldsymbol{S}_{\mathbf{2}}\right)^{2}\right|
$$

The probability depends on the relative phase of the amplitudes $A\left(S_{1}\right)$ and $A\left(S_{2}\right)$, whilst in $\boldsymbol{p}_{\left(S_{1}\right)}$ and $\boldsymbol{p}_{\left(S_{2}\right)}$ such phases do not occur. Consequently, event probabilities transfer onto the amplitudes, and this results in the occurrence of new phenomena, unaccounted for by classical physics. Let us assume, for the purposes of our argument, that a given phenomenon can occur in two distinct ways, $S_{1}$ and $S_{2}$, each of 
which is described by the probability amplitude $\boldsymbol{A}\left(\boldsymbol{S}_{\mathbf{1}}\right)$ and $\boldsymbol{A}\left(\boldsymbol{S}_{2}\right)$. The influence of an interference must be considered if we cannot identify the aperture through which the electron will travel. If we define the phenomenon occurrence probability as $=p_{1} 1(\mathrm{x})+p_{2}(\mathrm{x})+I(\mathrm{x})$,

where $I(\mathrm{x})$ denotes the influence of interference calculated as:

$$
I(x)=2 \sqrt{p_{1}(x) p_{2}(x)} \cos \left(\varphi_{1}(x)-\varphi_{2}(x)\right)
$$

and we must define values for the correlation $\varphi 1 ; 2$ of $\mathrm{x}$, then in the particle behaviour analysis we can assume that the correlation is linear and can be expressed with the equation

$$
I(x)=2 \sqrt{p_{1}(x) p_{2}(x)} \cos (\alpha x)
$$

where the constant $\alpha$ depends on the mass and energy of the launched particles, distance of screen from apertures and other conditions. To consider questions other than the particles, we need to define the influence of interference as a corrective.

Probability calculations informed by quantum physics can be defined as follows. There exists a sample space $\Omega$ and a family Zk of subsets of $\Omega$, called k-events. The following premises are true:

(1) $\varnothing$ (empty set) and $\Omega$ (sample space) are k-events.

(2) If $A$ is a k-event, then $A^{\prime}$ also is a k-event.

(3K) If $\mathrm{A}$ and $\mathrm{B}$ are k-events and the product of sets $A \cap B=\varnothing$, then $A \cup B$ is also a k-event.

Probability if the function $P: Z_{k} \rightarrow\langle 0,1\rangle$, so.

(4) $P(Q)=1$.

(5) If $\mathrm{A}$ and $\mathrm{B}$ are k-events and the product of sets $A \cap B=\varnothing$, then $P(A \cap B)=$ $P(A)+P(B)$.

The difference between the two approaches hinges on exchanging premise (3), considered earlier, with premise $(3 \mathrm{~K})$, which prevents us from considering alternatives for the k-events whose conjunction is not itself a k-event.

It follows from premises (1), (2) and (3K) that if A and B are k-events, the product $A \cap B$ is a k-event if and only if the sum $A \cup B$ is a k-event.

This condition is met when considering random variables which are significant in analysing possible real events.

The function $X: \Omega \rightarrow \mathbb{R}$ is a random variable if for each interval $\langle a, b\rangle \subset \mathbb{R}$ the set $\{\omega \epsilon \Omega \mathrm{X}(\omega) \epsilon\langle a, b\rangle\}$ is an event.

A random variable will be continuous if the function $\int: \mathbb{R} \rightarrow \mathbb{R}$ is nonnegative and for each interval $\langle a, b\rangle, P(\{\omega \epsilon \Omega: \mathrm{X}(\omega) \epsilon\langle a, b\rangle\})=\int_{a}^{b} f(x) d x$.

The function $f$ will be the distribution density of the variable $X$. So if for each particle $\psi(q)$ is a wave function which we can define as $f(q)=\psi(q)^{2}$, that is the distribution density for the position of the particle along a straight line, then $\int_{a}^{b}|\psi(q)|^{2} \mathrm{~d} q$ defines the probability that the particle will be within the interval $\langle a, b\rangle$. 
In probability theory, the pair of random variables $(X, Y)$ is called a twodimensional (bivariate) variable. A nonnegative function $h(x, y)$ is called the distribution density of a bivariate random variable $(X, Y)$, if for any numbers $a<b$ and $c<d$ there is equality:

$$
P\left(\left\{\omega \epsilon \Omega:(\mathrm{X}(\omega) \epsilon\langle a, b\rangle i(Y(\omega) \epsilon\langle c, d\rangle\})=\int_{a}^{b} \int_{c}^{d} h(x, y) d y d x\right.\right.
$$

We can also demonstrate that

$$
\mathrm{f}(\mathrm{x})=\int_{-\infty}^{+\infty} \mathrm{h}(\mathrm{x}, \mathrm{y}) \mathrm{dy}
$$

is the distribution density of the variable $X$ and $g(x)=\int_{-\infty}^{+\infty} h(x, y) d x$ is the distribution density of the variable $Y$.

If instead of classical probability we employ quantum-mechanical density amplitude probability, we arrive at a correct definition. This leads us to conclusively abandon the "objective realism" which determines classical probability and replace it with quantum probability. To examine our reasoning, we shall consider the following example. A pair of random variables (q, p) are given, with known distribution densities. We need to establish the distribution density of the bivariate random variable $(q, p)$ as a nonnegative function $h(q, p)$ such that

1. $\int_{-\infty}^{+\infty} h(q, p) d p=|\psi(q)|^{2}$ and $\int_{-\infty}^{+\infty} h(q, p) d p=|\phi(p)|^{2}$.

2. The above relation between $\phi$ and $\psi$, as well as the uncertainty principle, is realised.

3. The expected values of the observable quantum random variables, calculated according to the definition of expected value in probability theory, are equal to the expected values of the same variables, calculated according to quantum operation formalism.

Following Leon Cohen's interpretation, there exist functions fulfilling conditions (1) and (2), but a function fulfilling all three conditions does not exist. Consequently, we cannot go too far in probabilistic interpretations of quantum mechanics.

Even so, we can treat both $\boldsymbol{p}$ and $\boldsymbol{q}$ as random variables, but if we consider $\boldsymbol{p}$ and $\boldsymbol{q}$ jointly, we are leaving probability theory behind: the pair $(\boldsymbol{p}, \boldsymbol{q})$ is not a random variable. Instead, we must broaden the applicability of probability theory. None of the above premises contradict our knowledge of real-life phenomena inside road tunnels so it seems justifiable to use quantum probability in risk assessment calculation models. Quantum physics focuses primarily on an object's state which may, for its final manifestation, depend on the tools of analysis we use. The state of the object at a given moment is represented by the direction (radius) in the Hilbert space. A Hilbert space illustrates the type of phase space in which referring to real numbers alone is incomplete. A given state should be treated as a superposition of all possible states at every moment, and quantum mechanics typically deals with complex vector spaces. The resultant model of reality is very rich and composed of many interconnected structures whose states are synchronised and the probability of any state's occurrence at any given moment is always the same. 
The conclusion to which quantum physics points us is that event occurrence or nonoccurrence probability is always the same at $50 \%$, and the certainty of this result will be the derivative of the set probability distribution.

\section{Risk identification}

If we want to apply mathematical models to risk analysis, we must clarify our premises and definitions. Risk, in popular understanding, measures the possibility of loss of a given state and may be positive (profit) and negative (loss). Most commonly, "risk" is applied in the context of safety. Most people identify safety as a primary need, without which they experience anxiety and insecurity. It is psychological needs like these that cause individuals, societies, states and organisations to act on their environments in order to remove or reduce factors which increase anxiety, fear, uncertainty or insecurity. As a result, no matter how we define safety, it will ultimately remain an individual interpretation of a given phenomenon. For some people dangerous actions which, if successful, will make them a hero seem right, and their evaluation of possible consequences does not stop them from taking such actions, which would cause fear and inaction in another person. In this context, the security of larger organisations should not rely solely on such subjective assessments. State security is not the same as the sum total of individual securities of each of the state's citizens, and the safety of an organisation is not tantamount to the safety of each of its stakeholders. In the aftermath of the financial crash which bankrupted many companies in 2008, renewed efforts were undertaken to clarify safety for use both in financial management and in other areas of life. In line with the proposed guidelines, safety must be defined as freedom from unacceptable risk. In process safety procedures used in chemical process facilities, "safety" is understood as the absence of unacceptable risk to health, life, property or environment, whereas risk is the product of probability (frequency of occurrence) of a given phenomenon and the scale of losses (size of undesired results) formulated as

$$
\text { risk }=\text { probability } \times \text { results }
$$

The use of this formula is, however, vitiated by the cognitive determinism of the person identifying the probability and the results. With the 2009 ISO 31000 standard, a new understanding of risk has been proposed. Both the standard and the UN Recommendations on the Transport of Dangerous Goods [6] redefine "risk" as the "effect of uncertainty on objectives". The standard is a collection of frameworks, processes and rules which ought to be complied with during the risk assessment process in every organisation, commercial and otherwise. Building on the earlier considerations, we can reformulate risk as follows:

$$
\text { Risk - |uncertainty|objective }
$$

where "uncertainty" is defined as blurred probability of an event, which cannot be foreseen with absolute certainty, and all the related possibilities and probabilities are variable and possible.

In using measurement instruments (in this context, mathematical analysis) to measure a quantum state, a certain aspect of this state must be adjusted to the state of the instrument used. This is called an observable. In accordance with quantum mechanics' second postulate, each observable is represented by the linear map (vector-Hermitian operator) acting in a Hilbert space, and the eigenvalues of this 
operator present all possible results of its measurements. The third postulate proposes that the likelihood, that the measurement of the measurable magnitude of observation A will return a k eigenvalue of the Hermitian operator, equals $|\lambda \boldsymbol{k}|^{2}$, thus confirming the aptness of the risk assessment method, but does not bring us any closer to calculating the actual risk in a particular situation. Real-life events, even in their vector manifestation, do not allow the prediction of the direction of change. It follows that we should limit ourselves to identifying the possibility of each state occurring, based on their probability as derived from probability distribution.

\section{Example application}

Risk analyses are typically related to incident analyses. Let us consider the risk of an incident inside a road tunnel. Real data is available: over the last few years, the number of traffic incidents (traffic jams, attempts to reverse, collisions and fires) averages 340 per annum. We can further identify the likely rate of each type of incident within the total number. Let us conduct an analysis of the risk of change to the state of safety, based on the above-discussed postulates.

\section{Step 1. Identify the objective}

Accepting the definition of risk as the effect of uncertainty on objectives, we must first identify the objectives. This will be the number of incidents acceptable under the circumstances. Let us assume that the current state is acceptable, which means that we expect 340 incidents in the coming year. Let us take the year to be 365 days. The expected value (objective) will be 381 over the course of the year. Let us now attempt to measure the influence of uncertainty (i.e. the likelihood of a particular distribution) on the objective, i.e. the given annual number of incidents.

\section{Step 2. Identify the event distribution}

Let us assume that incidents occur according to normal distribution.

Traffic intensity is constant. There are no planned maintenance works.

For a given tunnel, the number of incidents (vehicles stopped) has been calculated, at certain traffic intensity, as 340 per year.

Calculating the uncertainty of 340 incidents per year (Table 1).

\begin{tabular}{|c|c|c|c|}
\hline Parameter & Equation/symbol & Value & Comments \\
\hline Expected mean & $\lambda$ & 340.000 & \\
\hline Median & $\begin{array}{l}M e \approx \lambda+1 / \\
3+0.02 / \lambda\end{array}$ & 340.333 & \\
\hline Mode & & 340.000 & $\begin{array}{c}\text { Equals the greatest integer lesser } \\
\text { than } \lambda\end{array}$ \\
\hline Kurtosis & $1 / \lambda$ & 0.003 & \\
\hline Cumulative probability & & 0.514 & \\
\hline $\begin{array}{l}\text { Probability mass function for the } \\
\text { Poisson distribution }\end{array}$ & & 0.0216 & \\
\hline Skewness & $\sqrt{ } \lambda$ & 18.439 & $\begin{array}{l}\text { Measures the asymmetry of the } \\
\text { distribution about its mean }\end{array}$ \\
\hline
\end{tabular}

Table 1.

Uncertainty parameters for the presumed outcome. 


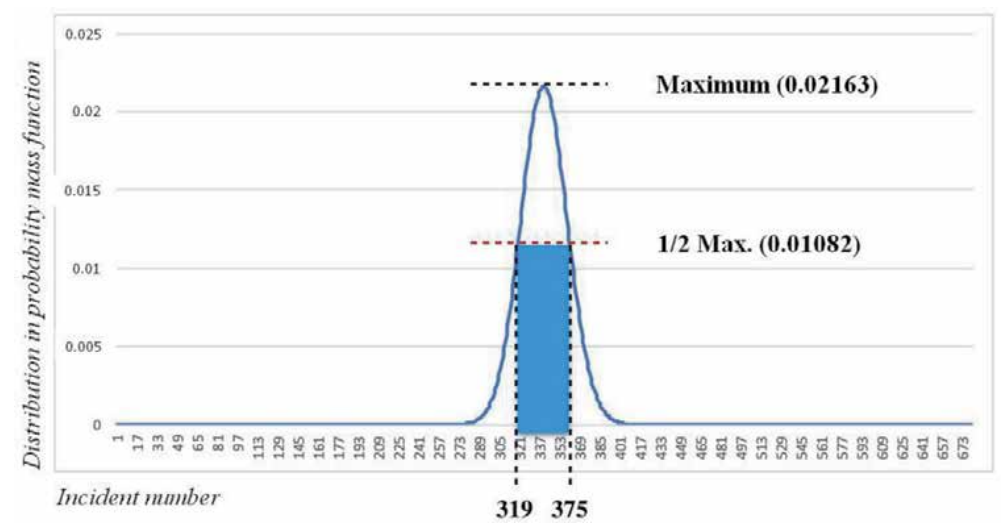

Figure 4.

Representation of uncertainty of 340 incidents occurring.

Graphic representation of uncertainty of incident estimate as shown in Figure 4 above.

Conclusion: For the analysed tunnel, there is a $50 \%$ uncertainty that the number of incidents (vehicles stopped) in the year will be between 319 and 375 .

The analysis leads to the following conclusions:

1. We do not know if the number of incidents will equal to 0 .

2. It is likely that at least 289 incidents will occur.

3. We must be prepared for no fewer than 319 but ideally 375 incidents.

4. We do not know if the number of incidents will exceed 401.

The analysis allows conclusions which will enable a better preparation for incidents than would have been the case using the standard method, which assumes that the risk of incident equals the product of its value and the probability of its occurrence.

\section{Conclusion}

We ought to understand risk management process as actions coordinated towards the achievement of a predefined state of acceptability. Acceptance of a state, that is to say preparation for it, is the key process in ensuring that an organisation may continue functioning. Risk management process comprises the following stages [7]:

- Risk recognition, including identification of objectives

- Risk identification, including possible consequences

- Risk analysis, or risk magnitude estimation, i.e. quantification of uncertainty in attaining objectives

- Risk evaluation, i.e. comparison of results with objectives 
Risk analysis is, in this process, just one of the stages and ought not to be conducted apart from the other elements. Aside from describing dangers and consequences, the process will result in identification of conditions for decision-taking regarding actions which consider the uncertainties of danger and dangerous events occurring, as well as identification of possibilities for avoiding or limiting losses.

Therefore, the full process ought to comprise calculations of the influence of uncertainty on our objectives and evaluation of results, including the evaluation whether occurrences of motion deviation are counterbalanced by solutions used.

Risk analysis will be most fully realised when we assume that to identify the level of attainment of objectives (i.e. identification of possible risk), we must first identify the probability of each possible state's occurrence, based on probability distribution.

\section{Author details}

Marek Rozycki

m/d/r/k Trusted Adviser Group Sp z o.o., Poland

*Address all correspondence to: m.rozycki@mdrk.eu

\section{IntechOpen}

(C) 2020 The Author(s). Licensee IntechOpen. This chapter is distributed under the terms of the Creative Commons Attribution License (http://creativecommons.org/licenses/ by/3.0), which permits unrestricted use, distribution, and reproduction in any medium, provided the original work is properly cited. (cc) BY 
Application of Quantum Physics Assumptions for Risk Assessment

DOI: http://dx.doi.org/10.5772/intechopen.90825

\section{References}

[1] Heller M. Elementy mechaniki kwantowej dla filozofów. Kraków: Copernicus Center Press; 2017. p. 17

[2] Hilbert D. Grundlagen der Geometrie. Leipzig: Teubner; 1899 $(1903,1977)$

[3] Różycki M. Inertia in procurement risk management. In: Sustainability and Scalability of Business: Theory and Practice. New York: Nova Science Publishers; 2018. pp. 237-245

[4] Schrödinger E. Die gegenwärtige Situation in der Quantenmechanik. Die Naturwissenschaften. 1935;23(50): 844-849

[5] Wheeler JA. Delayed choice experiments and the Bohr-Einstein dialog. The American Philosophical Society and the Royal Society: papers read at a meeting, June 5, 1980. Physical Review Letters. 1981;84(1):1-5

[6] Joint ADR, ADN agreement and the RID Regulations

[7] ISO/IEC Guide 51: 2014(en). Safety aspects-Guidelines for their inclusion in standards. Available at: https://www. iso.org/iso-31000-risk-management. html 

Section 3

Risk Managment 



\title{
Risk Assessment Methodology in Public Financial Institutions
}

\author{
Leon Dorozik, Tomasz Strąk and Ireneusz Miciuta
}

\begin{abstract}
This chapter classifies the risk and fundamental elements necessary to manage it. It presents the individual stages of the procedure and standards of conduct in risk management. In accordance with the EU accession agreement, Poland has developed and implemented a system of financial management and control standards in public finance sector units. This chapter presents the risk assessment tools that can be customized to the needs of a specific organization, including public sector entities. Information about how to manage risk in each EU country are made available because of the desire to show the stability and proper monitoring of the risks in order to fulfil the given tasks. This affects the perception of stability in the country, which has a direct impact on the economic effects.
\end{abstract}

Keywords: risk management, score-based risk assessment, management control, public institutions, finance

\section{Introduction}

Risk management concerns both public and private organizations. Recent failures in companies from the public and private sector all around the world resulted in an increased interest in effective risk identification and, most importantly, risk management. In many companies there are regular processes related to risk management, including periodic (e.g. monthly) reports for regulatory bodies. However, it turns out that such periodic reports are not sufficient for management bodies to prevent risk effectively. This is of particular importance in the public finance sector, where there is a high degree of legislation and hierarchy. Now, given the changeability of the economic situation caused by globalization processes, among other reasons, this method is no longer sufficient [1]. This method of management can be applied only in units which do not take numerous activities or when such activities do not generate unacceptable risk which may significantly deteriorate the situation. This is why risk should be considered in the tasks performed by units from the public finance sector. The possibilities of a public finance unit in terms of risk management in the course of its activities should be defined. Knowledge on how to use risk management tools will contribute to effectiveness in achieving goals, i.e. higher and more secure financial results [2]. Positive effects (opportunities) of risk management, which citizens and the administration can enjoy, are perceived by the Polish government as an added value. Thus, efforts should be made so that all employees in a public administration unit could fully understand the idea of risk management, which is not fighting risk or using it to achieve better results but managing it in line with the policy pursued by the management. It is, therefore, necessary for managers 
of public administration units to learn appropriate risk management methodology. The aim of the article is to analyse the process of risk management and the role of internal control in quick decision-making in public sector units. In order to achieve this aim, particular stages of risk identification and management were analysed, and the score-based risk assessment method was presented.

\section{Notion of risk: definition and classification}

Risk is an objectively existing possibility of failure, loss or damage as a result of an activity. As a consequence of making wrong economic decisions, there might be a decrease in potential profits, loss of financial liquidity, bankruptcy of an organization (an enterprise or a public institution) and even huge debt which entails legal liability. Risk cannot be eliminated; it can only be limited by appropriate economic, legal, organizational and HR-related prevention. The size of risk depends on numerous interrelated factors, the majority of which is independent of the activity of an organization. These include general economic, social, political, demographic and technical factors.

Financial institution risk is a danger which results from making a profit whose amount is different than expected. In terms of the main sources of risk, Jachowicz points to the following: "the lack of possibility to perfectly anticipate future states and the possibility of occurrence of unexpected states", i.e. the undisputed impossibility to predict all determinants of the future in a particular economic situation and consequences following a given activity [3]. Risk is, therefore, inherent to each and every economic activity. Moreover, risk is taken intentionally in order to make a higher profit because there is a close link between the level of income and risk [4]. A higher risk gives the possibility to achieve a higher return on investment. Taking risks, we expose ourselves to bigger losses, but at the same time, we have a chance to make a higher profit, so the spectrum of both advantages and disadvantages is wider. Risk is defined as a negative deviation of the achieved result from the previously planned figure [5]. Therefore, when striving to optimize profit, it is unavoidable to accept certain levels of risk, which are usually related to an increase in the volume of income. Each organization operates in a state of uncertainty of future events [6]. Information which is available when making a decision is usually incomplete and inaccurate, and predicting how events will unfold is not always possible.

In general terms, it is impossible to avoid risk. This results from the fact that within the general approach, the term risk refers to everything that is uncertain [7]. It is beyond any doubt that life was, is and will be unpredictable as far as future events are concerned, i.e. risky. This is why the aim of this chapter is to present new suggestions in terms of risk management and to identify deterministic activities, i.e. activities which enable determination of the consequences and scope of risk. Each activity involves risk, which is to a large extent undefined, is complex and undergoes dynamic changes. The term "risk" is ambiguous and defies a clear and synthetic definition. Risk itself follows from the very fact of making decisions concerning the future. This is because it refers to situations in which a company does not have a $100 \%$ certainty as to the course and final results of its activity. Phenomena which influence an entity's operating business activity but which are beyond the scope of its will are usually referred to as uncertainty. Risk, however, is defined as merely a possibility of failure, in particular a possibility of occurrence of events which are beyond the control of an entity and which are impossible to predict and prevent. As a consequence, a particular activity may turn out to be less effective or less beneficial. Both notions, i.e. "risk" and "uncertainty", are often treated as equivalent although they denote something entirely different. One could quote a number of definitions which define mutual relations between these categories. According to Willet "risk is the objectified uncertainty 
concerning the occurrence of an undesirable event. Risk changes together with uncertainty and not with the level of probability" [8]. Braig et al. define risk as a combination of elements of hazard and it is measured with probability, whereas uncertainty is measured with the level of faith. "Risk is a state of the world and uncertainty is a state of the mind" [9]. Being convinced of the result of an action, one can decide not to perform such action and not to take a risk. In order to specify a general and universal definition of risk, one can refer to the PWN dictionary of foreign terms, according to which risk is an undertaking whose result is unknown, the possibility that something either works or not as well as the decision to conduct such undertaking [10]. The meaning of the word "risk" is derived from the Italian word "risco", which means reef, which ships should stay away from. The notion of risk is frequently and incorrectly equated with danger. There is a significant difference between these two terms, which should be taken into consideration. Danger is rather a direct threat, whereas risk occurs in a situation when the consequences are uncertain. Within this meaning, a certain loss is not a risk. There are many other definitions of risk as well. The approach to the category of risk varies depending on the author, and it proves how complex phenomenon it is and how difficult it is to define and measure it.

As it is the case with defining risk, classifying it is also very problematic. Current categories are not unanimous and disjunctive, which means that one type of risk can be a specific example of another risk [11]. Generally, there are the following basic types of risk [12]:

1. Commercial risk: risk following directly from a commercial activity. It comprises

a. Liquidity risk - manifests itself in the necessity to adjust maturities of assets and liabilities to make sure an entity is able to meet its obligations.

b. Credit risk-related to the failure on the part of a business partner to meet their liabilities towards a particular entity. Currently, over $80 \%$ of global trade is conducted with a deferred payment term. The term of trade credit depends on the type of goods. It is shortest for consumer goods (ca. 30 days), whereas investment goods are at the other end of the scale with payment terms of at least 1 year. Due to an increasing competition and the need to fight for clients, companies will extend the terms even more.

2. Market risk: concerns the probability of changes in the value of market instruments, i.e. the possibility of change of financial conditions as a result of changes in market prices, including

a. Interest rate risk-results from the fact that the value of a part of assets and liabilities depends on interest rate changes (e.g. a loan bearing a variable interest rate). This results from interest rate fluctuations.

b. Foreign exchange risk-related to an unsecured open foreign currency position and unfavorable movements in exchange rates.

There also exists a market risk, which exerts indirect impact on financial results, i.e. resource risk, price risk, business cycle risk and technological risk.

3. Operational risk-danger of failure to achieve objectives due to mistakes in an IT system or mistakes made by employees or inappropriate internal control of the enterprise. 
4. Social risk-related to the way people in a particular country behave, religion, political regime, culture and tradition.

5. Risk of contingent events-e.g. natural disasters and calamities (flood, earthquake), accidents caused by social conflicts and prohibited acts (strike, arson).

6. Political risk-concerns the possibility of intervention on the part of state authorities in particular countries or on an international scale, both for the entire economy and in selected sectors.

7. Economic risk-related to the possibility of a change in a country's economic policy and legal regulations concerning, e.g. tax or foreign exchange law.

8. Risk of events-resulting from unexpected events which influence a particular entity or investment but without influence on the entire market.

9. Transfer risk-concerns situations in which there are obstacles in transferring funds abroad or changing the currency of such funds.

10. Legal risk-risk of loss due to a failure to conduct transactions due to a lack of legal regulations or insufficient documentation and lack of financial reliability of a partner.

More specific areas of risk are identified depending on the specific nature of a particular business activity. The following conclusions can be drawn from the general classification:

- Lack of a criterion which would unanimously identify risk.

- Strong and bidirectional relations among factors which cause risk.

- Strong relations among particular types of risk.

- Risk is determined by external and internal factors at the same time.

- Risk is inherent to the financial market.

The list of types of risk presented above is not an exhaustive one. Given the complexity of business activity, managers of public organizations are constantly exposed to various forms of this phenomenon [7]. Although not all of the risks enumerated above can be predicted or controlled, one should be aware of their existence and limit their occurrence and impact on organization to the greatest extent possible. Since there are so many factors causing risk, it is simply impossible to avoid it. Moreover, some of these factors are beyond the control of an enterprise. There are two main groups of factors which influence risk [13]:

\section{External factors}

- General economic factors following from a country's economic policy and condition of the economy (economic growth or downturn, changes in the level of inflation, significant changes in the central bank's policy, budget deficit)

- Political factors which consist in a change of relations and direction taken by the country 
- Social factors (change in the tendency to save, customer behaviour, level of unemployment)

- Demographic factors (structure of population)

- Technological factors (technological progress)

\section{Internal factors}

- Structure of assets and liabilities (level of high-risk assets)

- Human resources policy and qualifications (risk management)

- Company strategy

- Internal control system (efficiency of operation)

- Criminal activities

\section{Internal control as an element of the risk management process}

Risk management is one of the basic elements (processes) of managing a unit. Its primary aim is to increase the probability of achieving goals. In order to manage risk successfully, one should establish and adopt objectives which are to be achieved in a particular time and specific objectives of particular organizational departments. Defining objectives allows for identification of risk which can endanger the achievement of goals. In the process of risk management, it is important to take measures to reduce risk to an acceptable level. Risk management undertaken by the management of a unit is a continuous process. To emphasize the importance of risk management, three standards of financial control announced in a communication from the Minister of Finance in January 2003 [14] were introduced:

- The head of a unit conducts day-to-day assessment (monitoring) of the completion of tasks with the use of quantifiable indicators or precisely defined criteria.

- The head of a unit systematically identifies external and internal risk related to the achievement of the unit's objectives, concerning both the entire unit's operations and particular schemes, projects or tasks undertaken by the unit. In the event of a change of conditions in which a unit operates, identification of risk should be resumed.

- The head of a unit guarantees systematic analysis of the identified risk in order to define potential consequences and the probability of the occurrence of a particular risk. The head of a unit defines the acceptable level of risk and measures which are to be taken in order to reduce a particular risk to the acceptable level.

Effective risk management is one of the elements of effective management of a public administration unit [15]. The Act on public finance has been in force as of 1 January 2010, with the exception of regulations concerning the obligation to plan and implement budgets in a task-based manner, which are effective as of 1 January 2012 [16]. One of the significant changes with respect to the previous Act of 30 June 2005 is the implementation of regulations concerning internal control and its coordination in units from the public finance sector and local government units. Pursuant to the Act on public finance (Article 68), internal control is a set of measures taken 
in order to guarantee achievement of objectives and completion of tasks in a legal, effective, economical and timely manner. The aim of such control is to ensure:

- Conformity of activity with provisions of law and internal procedures

- Effectiveness and efficiency of action

- Reliability of reports and protection of resources

- Complying with and promoting rules of ethical conduct

- Effective and efficient flow of information

- Informed risk management

Standards of internal control drawn up by the Minister of Finance and currently subject to consultation constitute an attempt to arrange this type of control. It has been primarily emphasized that it is necessary to organize such control at two levels [17]. The basic level of internal control is a unit from the public finance sector (first level of internal control). It is the head of the unit who is responsible for the functioning of internal control. There should be internal control in government and self-government administration at the level of a government administration department as a whole (second level of internal control). Mayors of villages, towns and cities, province governors or marshals are responsible for the functioning of internal control at this level [18]. There is a project on standards of internal control which includes five areas:

1. Internal environment which constitutes the basis for the remaining elements of control because it concerns the management system of a unit and includes professional competences (level of expertise, skills and experience) of the management and employees and their scope of duties, authorization and responsibility in particular organizational departments.

2. Risk management whose aim is to increase the probability of achieving goals by defining objectives and monitoring completion of tasks, identifying and analysing risk and taking preventive measures.

3. Control mechanisms which constitute the answer to a particular risk. The unit wants to reduce by documentation, registration and confirmation (authorization) of commercial operations, division of key responsibilities, verification, supervision under company hierarchy, registration of deviations from procedures, maintenance of operational continuity, controlled access to financial, material and information resources (protection of resources) and IT system control mechanisms. Example includes control of access to IT resources and system software.

4. Information and communication standards provide employees with access to information which is necessary for the performance of their duties and maintain effectiveness of internal and external communication systems.

5. Monitoring and assessment of control system by ongoing assessment of the efficiency of the control system and its components and day-to-day problemsolving by all employees depending on their competences, including by selfassessment and internal audit. 


\section{Risk management in the public sector}

Risk management is an implemented system of procedures and rules, which is used to identify, analyse, assess and monitor risk. It allows not only to reduce risk but also to take advantages of any opportunities that may appear [19]. A correct system is supposed to improve results in the future and support decision-making on an ongoing basis. Therefore, it should comprise a planned, logical, comprehensive and documented strategy [20]. Such strategy includes instructions, plans and procedures which will function in everyday work of a particular office or its organizational units in order to manage risk. In local government units, risk can be considered in the following areas: finance (e.g. income from tax on real estate is lower than expected), human resources (e.g. mistakes made by employees when making various decisions), IT (e.g. faulty software) and other areas which influence the risk of failure to achieve established objectives and results. Therefore, risk management in local government units should be subject to a strictly defined process which comprises the following elements:

1. Establishing objectives and understanding the context of a particular field

2. Identifying risk

3. Analysing risk:

- Probability of the occurrence of risk

- Consequences of certain events

4. Estimating and prioritizing risk (high and low risk)

5. Assessing risk (whether it is acceptable or not)

6. Methods of dealing with risk:

- Acceptance of risk (resulting from the fact that costs of prevention exceed potential losses related to the occurrence of a particular phenomenon)

- Withdrawing from certain activities

- Counteracting risk (creating and implementing action plans)

- Transfer of risk (e.g. taking out insurance policies, relying on guarantees of correct performance of contracts)

Governments and public services in European Union (EU) countries often make available information on the nature and scope of investment in risk management because stakeholders want to be sure that risk is adequately supervised and resources are adequately protected [21]. If Poland wants to be perceived as a country where investments pay off, it should implement a risk management system which will meet relevant standards established by the European Commission. In the administrative system, senior management is responsible for risk management whose objectives are the following [22]:

- Achievement of goals

- Protection of assets

- Efficient, economical and effective use of resources 
A risk management system is of particular importance in this process. Risk management in the public sector can be defined as a logical and systematic method of creating context; identifying, analysing and assessing risk, action and supervision and informing about risk in a way which enables an organization to minimize loss and maximize opportunities [23]. Thus, the process of risk management includes:

- Identifying risks related to operational activities as soon as possible

- Assessing the degree of influence of risk on a particular organization's results and objectives

- Implementing adequate risk control measures

- Risk management structures, including organizational plans, policies and procedures concerning risk management, data on all teams and individuals responsible for risk and documentation concerning risk

Risk management is one of the basic processes (elements of managing a unit), and its primary aim is to increase the probability of achieving objectives. In order to manage risk successfully, objectives of particular units should be established in order to identify risks which may prevent from achieving them. Risk management is a continuous process. According to financial control standards, the head of a unit systematically identifies both internal and external risk related to the achievement of the unit's objectives, concerning the whole unit as well as particular programmes, projects or tasks separately [24]. When there is a change of conditions in which a unit operates, identification of risk should be performed again. Each identification of risk should be analysed in terms of potential consequences and the probability of their occurrence. A manager will perform ongoing assessment of task completion with the use of qualitative and quantitative indicators or with the use of other established criteria. Each sector of public finance should develop and implement a method of identifying and analysing risk. The implemented programme must enable identification and understanding of all types of risk which a unit is exposed to when providing services and achieving its goals.

\section{Score-based risk assessment in public financial institutions}

Score-based risk assessment is one of the methods of internal control mechanisms which enable risk detection. It includes the definition of risk for various levels of impact and probabilities of occurrence. This method prioritizes risk (increases transparency) and enables assessment of the identified risk in terms of its impact on the achievement of goals (Tables 1-3).

\begin{tabular}{lccccc}
\hline Score & $\mathbf{1}$ & $\mathbf{2}$ & $\mathbf{3}$ & $\mathbf{4}$ & $\mathbf{5}$ \\
\hline Description & Infrequent & Unlikely & Average & High probable & Almost certain \\
\hline Probability & $0-10 \%$ & $11-30 \%$ & $31-49 \%$ & $50-75 \%$ & $76-100 \%$ \\
\hline Source: own work based on [25]. & & & &
\end{tabular}

Table 1.

Score-based probab ility of the occurrence of risk. 
Risk Assessment Methodology in Public Financial Institutions DOI: http://dx.doi.org/10.5772/intechopen.91152

\begin{tabular}{|c|c|c|c|c|c|}
\hline \multirow[t]{2}{*}{ Score } & \multirow[t]{2}{*}{ Description } & \multicolumn{4}{|l|}{ Criteria } \\
\hline & & Financial & Organizational & $\begin{array}{l}\text { Health } \\
\text { and } \\
\text { safety }\end{array}$ & Reputation \\
\hline 5 & Catastrophic & $\begin{array}{l}\text { Financial } \\
\text { loss }>\text { PLN } \\
500,000\end{array}$ & $\begin{array}{l}\text { Failure to } \\
\text { achieve key } \\
\text { objectives }\end{array}$ & Death & $\begin{array}{l}\text { Media coverage in } \\
\text { the entire country }\end{array}$ \\
\hline 4 & Serious & $\begin{array}{l}\text { Financial loss PLN } \\
100,000<\text { PLN } \\
500,000\end{array}$ & $\begin{array}{l}\text { Failure to } \\
\text { achieve the key } \\
\text { objective }\end{array}$ & $\begin{array}{l}\text { Serious } \\
\text { injuries }\end{array}$ & $\begin{array}{l}\text { Some information } \\
\text { in national media }\end{array}$ \\
\hline 3 & Moderate & $\begin{array}{l}\text { Financial loss PLN } \\
10,000<\text { PLN } \\
100,000\end{array}$ & $\begin{array}{l}\text { Disturbances in } \\
\text { activity }\end{array}$ & $\begin{array}{l}\text { Some } \\
\text { injuries }\end{array}$ & $\begin{array}{l}\text { Some information } \\
\text { in local or } \\
\text { regional media }\end{array}$ \\
\hline 2 & Small & $\begin{array}{l}\text { Financial loss PLN } \\
100<\text { PLN } 1000\end{array}$ & $\begin{array}{l}\text { Small } \\
\text { disturbances in } \\
\text { activity }\end{array}$ & $\begin{array}{l}\text { Small } \\
\text { injuries }\end{array}$ & $\begin{array}{l}\text { Limited } \\
\text { information } \\
\text { in local or } \\
\text { regional media }\end{array}$ \\
\hline 1 & Insignificant & $\begin{array}{l}\text { Small financial } \\
\text { loss }<\text { PLN } 100\end{array}$ & $\begin{array}{l}\text { Short-term } \\
\text { disturbance in } \\
\text { activity }\end{array}$ & $\begin{array}{l}\text { Small } \\
\text { injuries }\end{array}$ & $\begin{array}{l}\text { Scarce } \\
\text { information } \\
\text { in local or } \\
\text { regional media }\end{array}$ \\
\hline
\end{tabular}

Table 2.

Score-based impact of risk.

\begin{tabular}{lccccc}
\hline Impact & \multicolumn{1}{l}{} & & \\
\hline Catastrophic & 5 & 10 & 15 & 20 & 25 \\
\hline Serious & 4 & 8 & 12 & 16 & 20 \\
\hline Average & 3 & 6 & 9 & 12 & 15 \\
\hline Small & 2 & 4 & 6 & 8 & 10 \\
\hline Insignificant & 1 & 2 & 3 & 4 & 5 \\
\hline Frequency of occurrence & Infrequent & Unlikely & Average & Likely & Almost certain \\
\hline Source: [25]. & & & & \\
\hline
\end{tabular}

Table 3.

Matrix of score-based risk assessment.

Of course, the number of probability levels for different risk events for an organization may vary. It will be adjusted depending on the state, ownership, sector and industry in which the organization operates. In the further methodology, it will translate into the level of economic effects having a certain impact on the functioning of the organization. In this chapter we have to deal with the public organization concerning the implementation of budgetary tasks in Poland.

In this method, the scores describing the impact and probability are multiplied to calculate a total score-based risk assessment. Tables presenting the assessment of impact and probability of risk are adjusted depending on the entity under analysis. This chapter presents an example of a matrix of risk management in public administration developed for the Ministry of Finance, which was an EU requirement. This enables to identify risk early enough and take decisions to counteract negative consequences. 
Score-based risk analysis enables to prioritize actions, and its aim is to reduce risk:

- Risks in the top right corner (almost certain, score above 16, catastrophic impact) require immediate actions to be taken.

- Risks in the middle of the matrix (score between 10 and 15) should be addressed and monitored; action should be taken in some cases.

- Risks in the bottom left corner (below nine points) pose the smallest threat to an organization and frequently do not require any reaction.

After ranking risks, an organization must agree on actions to take in order to control particular risks. How they proceed depends on the level of acceptance of risk and the possibility to control it as well as the relation between the cost of reducing or eliminating it and possible negative consequences of such risk.

\section{Conclusions}

An organization should have a process of supervising the probability of the occurrence of risk. The manager should receive reports from a register of risk to be able to react to various levels of risk. Reporting on risk should be integrated into currently existing processes of internal reporting. Frequency of reporting should be adjusted to the organization, and measures related to high risk should be monitored on an ongoing basis [26]. The importance of risk management in the public sector is due to the requirement of the European Union to implement risk management systems in units from the public finance sector. During talks on EU accession, one of the requirements was to develop and implement financial management systems and control in units from the public finance sector and develop standards of financial control in self-government units. Controls are performed by an internal auditor and concern risks involved in raising and using public funds. Risk management standards are based on the COSO (Committee of Sponsoring Organizations of the Treadway Commission) model. In this way the legislator obliged units from the public sector to analyse and manage risk pertaining to completing public tasks. This results from the intention to provide citizens with services they need because risk management can streamline processes of making reasonable decisions. It is not the aim of the process to avoid risk but to increase the probability of achieving success in particular areas of operation of the public sector. This also results from the intention to manifest stability and adequate supervision of risk in order to complete tasks assigned by the public sector. Strengthening the function of internal control and risk management in the new Act on public finance, the Polish government follows other European Union countries. Risk management helps to protect the population and ensure efficiency of public administration in the event of a financial crisis or other threats. Changes which are increasingly visible in many Polish institutions are the components of a bureaucratic change in administration towards an effectively managed organization. The aim of this change is to increase the effectiveness of the public sector. Thanks to such an approach, the system of procedures in an organization is adequate to its current needs. The article described the particular stages in risk identification and a score-based risk assessment method, which shows the importance of risk management in units from the public sector for ensuring the possibility to make management decisions early enough. 


\section{Acknowledgements}

The project is financed within the framework of the programme of the Minister of Science and Higher Education in Poland under the name "Regional Excellence Initiative" in the years 2019-2022, project number 001/RID/2018/19, the amount of financing PLN 10,684,000.00.

\section{Conflict of interest}

The authors declare no conflict of interest.

\section{Author details}

Leon Dorozik, Tomasz Strąk and Ireneusz Miciuła*

Faculty of Economics, Finance and Management, University of Szczecin, Poland

*Address all correspondence to: irekmic@wp.pl; ireneusz.miciula@usz.edu.pl

\section{IntechOpen}

(C) 2020 The Author(s). Licensee IntechOpen. This chapter is distributed under the terms of the Creative Commons Attribution License (http://creativecommons.org/licenses/ by/3.0), which permits unrestricted use, distribution, and reproduction in any medium, provided the original work is properly cited. (cc) BY 


\section{References}

[1] Ziółkowska W. Public Finance, Theory and Application. Poznań: WSB; 2000

[2] Almqvist R, Catasús B, Skoog M. Towards the next generation of public management: A study of management control and communication in the Swedish armed forces. International Journal of Public Sector Management. 2011;24(2):122145. DOI: $10.1108 / 09513551111109035$

[3] Jachowicz K. Interest Rate Risk Management. Warsaw: PWN; 1999

[4] Begg D, Fischer S, Dornbusch R. Macroeconomics. Warsaw: PWE; 2007

[5] Best P. Value at Risk. Cracow: House Printer ABC; 2004

[6] Bovaird T, Loffler E, editors. Public Management and Governance. London: Routledge; 2003

[7] Bożek S. Integrated risk management in units from the public finance sector on the example of tax offices. Scientific Notebooks. Silesian University of Technology Organization and Management. 2014;1921(74):289-304

[8] Willett A. The Economic Theory of Risk and Insurance (Reprint). New York: Columbia University Press; 1901

[9] Braig S, Gebre B, Sellgren A. Strengthening Risk Management in the US Public Sector. New York: McKinsey \& Company; 2011

[10] Risk management-general information [Internet]. 2011. Available from: http://www.mf.gov.pl [Accessed: 21 September 2018]

[11] Public finance [Internet]. 2018. Available from: http://finansepubliczne.bdo.pl/biuletyn/70/ finanse-z-odpowiedzialnoscia/ kontrola-zarzadcza-w-jednostkachsektora-finansow-publicznych.html [Accessed: 11 July 2019]

[12] Jajuga K, editor. Theoretical basis for risk management. In: Risk Management. Warsaw: PWN; 2007

[13] Miciuła I. The universal elements of strategic management of risks in contemporary enterprises, entrepreneurship and management. Entrepreneurship and Management. 2015;8(3):313-323

[14] Szemrej M. Risk Management in Units from the Public Finance Sector. Warsaw: Polish Academy of Accountancy; 2010

[15] Sławińska-Tomtała E. Internal Control in the Public Sector. Practical Recommendations on System Implementation. Warsaw: C.H. Beck; 2010

[16] Act on public finance of 27 August 2009. Journal of Laws of 2009. No. 157, Item 1240

[17] Kosikowski C. Public Finance Sector in Poland. Warsaw: House Publishing ABC; 2013

[18] Klimczak K, Pikos A. Risk-based management control in the public sector in Poland. Theoretical Notebooks of Accounting. 2013;72:63-77

[19] Miciuła I. Financial innovations on the currency market as new instruments to risk management. Journal of International Studies. 2015;8(1):138-149. DOI: $10.14254 / 2071-8330.2015 / 8-1 / 12$

[20] Tarczyński W, Mojsiewicz M. Risk Management. Warsaw: PWE; 2001

[21] Pikos A. Introduction of risk management into municipal offices across Poland as an example of organizational change. Journal 
of Management and Business

Administration. Central Europe.

2015;4:74-97. DOI: $10.7206 / \mathrm{mba}$.

ce.2084-3356.158

[22] Staniec I, Klimczak K.

M. panorama of risk. In: Staniec I, Zawiła-Niedźwiecki J, editors.

Operational Risk Management.

C.H. Beck: Warsaw; 2008

[23] European Union. Orange Book, Risk Management_Principles and Concepts.

2004

[24] Stępień P, Miciuła I. General principles of financial risk management in business organizations. World Scientific News. 2017;89:252-259

[25] Ministry of Finance of the Republic of Poland. Manual on the Implementation of a Risk Management System in Public Administration in Poland. Warsaw: Bentley Jennison; 2007

[26] Kazojć K, Miciuła I. Current trends in currency risk management by polish shipbuilding enterprises. Research Papers of Wrocław University of Economics. 2019;63(2):165-182. DOI: 10.15611/pn.2019.2.15 



\title{
Chapter 6
}

\section{Risk Management in Biobanks}

\author{
Karine Sargsyan, Brigitte Jaksa, Gabriele Hartl \\ and Tanja Macheiner
}

\begin{abstract}
The administration of risks is usually an important corner stone of professional operations. Nevertheless, specifically for biobanking organizations, risk recognition, control, management, and easing are inevitably extremely critical elements of everyday operations. The costly kind of unique samples/cell lines, data and also other high-pitched value biobanking products and services such as cell-based drugs, and biologically active pharmaceutical materials call for tremendously precise planning-including the full spectrum of risks. In this chapter, we have included the common risks in biobanking and the management way and methods of risks in a biobanking institution.
\end{abstract}

Keywords: risk management, special risks, strategic risks, physical and chemical risks, biobanks

\section{Introduction}

What can biobankers do to ensure that their biobank does not have to struggle in case of an emergency? The best activity plan could be as follows:

Implement risk assessment and risk determination processes specifically designed to address the needs of your biobank, come up with risk management and action strategies, and teach and train your staff in all these matters!

The management of risks is part of all business operations. However, for biobanking organizations, risk mitigation is unavoidably an overly critical element of day-to-day operations. The expensive nature of irreplaceable samples/cell lines, data, and other high-value products such as cell-based drugs and biologically active pharmaceutical ingredients calls for extremely accurate planning including the full spectrum of risks. These risks can be subdivided into the following categories:

- Reputation-related risks

- Ethical and data protection risks

- Financial risks

- Operative risks

- Standard lab risks 
- Human resources risks

- Infrastructural risks

- IT risks

- Strategic risks

- Natural disasters

Risk assessments and determination are essentially rather subjective; they are very individual and are based on personal perception of an employee. Hence, it is recommended to assess the risks in a workshop involving employees from each level and field of biobanking activities such as:

- Management

- Public relation

- Human resources

- Financial officers

- Lab technicians

- Researchers

- IT specialists

- Ethics specialists

- Infrastructure specialists

- Medical doctors

- Strategy developer and network coordinator

Most risks that will be recognized in a workshop are of low probability. Years of mild weather are normal, while natural disasters are of low likelihood. Terrorism attacking biobanks is most probably also a minor aspect, except for sites that are near potential targets, such as governmental buildings and major airports. In the case of the abovementioned risks, occurrence of the damage will be irreparable. Thus, a biobank also needs an action plan for such unlikely events.

Further to evaluating the probability of a risk, the potential aftermath should also be considered in order to be able to calculate a real risk score. For example, a hurricane may be unlikely but could leave serious damage behind, including extended power outages.

If a biobank has not performed a realistic, well-researched risk assessment, then the risk mitigation strategy is based on guesswork, is not professional, and is just not acceptable compared to the efforts of collecting and storing samples and data. It is very important to have a comprehensive risk management plan in place that is up to date. It is easy to start with a well-researched and/or well-known risk assessment. 
It is crucial to define the exact steps each biobank team member needs to follow in serious cases of emergency. A periodic review, update, and "walk-through" of the risk potential assessment are pivotal, and also the action plan should be renewed periodically. One of the most known and often implemented biobanking risk actions is the duplication of critical samples and their storage in multiple locations. This can be done on-site (same biobank, different storage locations) or off-site (an extramural provider of storage in a different location).

Many biobanks are starting enthusiastically without thinking about risks and possible dangers that may occur during implementation and running of a biobank. The professional approach is not only to think about it and determine the risks but also to include risk management in the biobank budget. There is an old English saying on flyers of storage constructing companies: "Don't be penny-wise and pound-foolish.” This saying applies exactly here, when speaking about risks. Too many biobanks neglect risk management because they "do not have the funds for it." This is unacceptable and above all irresponsible, especially in public biobanks, where using the taxpayers' money too much is invested without protective mechanisms, like risk management. Admittance and maintenance of risk management not only into biobanks' daily routine but also into budget is pivotal for longevity of the given biobank initiative, as every task in the biobank requires assets and capabilities for performing the work accurate.

Cooperate, for collaborative exertion with supportive biobanks can be performed almost with every other biobank or biorepository in the world. Besides, a biobank can work with interventional research supportive organizations in their own country or area. Construct trusty collaborations with associates and encourage and promote relations, which can build up the risk vindication plan of your biobank/lab. In the event of a crisis or a disaster, it is improbable that a team of a biobank can manage and recover alone-without associates.

A respectable business managing and controlling plan comprises development and description of protection mechanisms to avoid dangers (which must be known). These risks must be predicted and managed to untroublesome issues. However, as is the case with natural disasters, not only a biobank but also any other institution is unable to always predict the future. If a biobank adopts a wide-ranging risk qualification and management plan, it can help to safeguard the protection of biobank bio specimens.

Staying with the example of off-site storage: Choosing an offsite storage facility includes asking the right questions to determine if the storage provider has the appropriate risk mitigation infrastructure in place, beginning with a realistic threat assessment of the location. The potential off-site storage provider should also provide an "emergency action plan (EAP)" in force as well as a plan for ensuring the safety of employees, for securing the facility, for addressing the media, and for notifying the relevant authorities following a disaster. Again, these plans should be written, reviewed at regular intervals independent of on-site or off-site storage solution in case changes are defensible, and tested via walk-through or table-top workouts to the extent possible and the employees trained on the procedures. Ideally, these trainings are also well documented, reviewed, reported, and repeated at least annually as well as every time if changes are made [1].

There is a list of information that should be available for emergency cases in a biobank (Figure 1).

Risk susceptible infrastructures such as biobanks should have backup capacities well in addition to the minimum requirements. Thus, this may imply to have $100 \%$ redundant storage and supply (e.g., electricity) capacity. Fully redundant working 


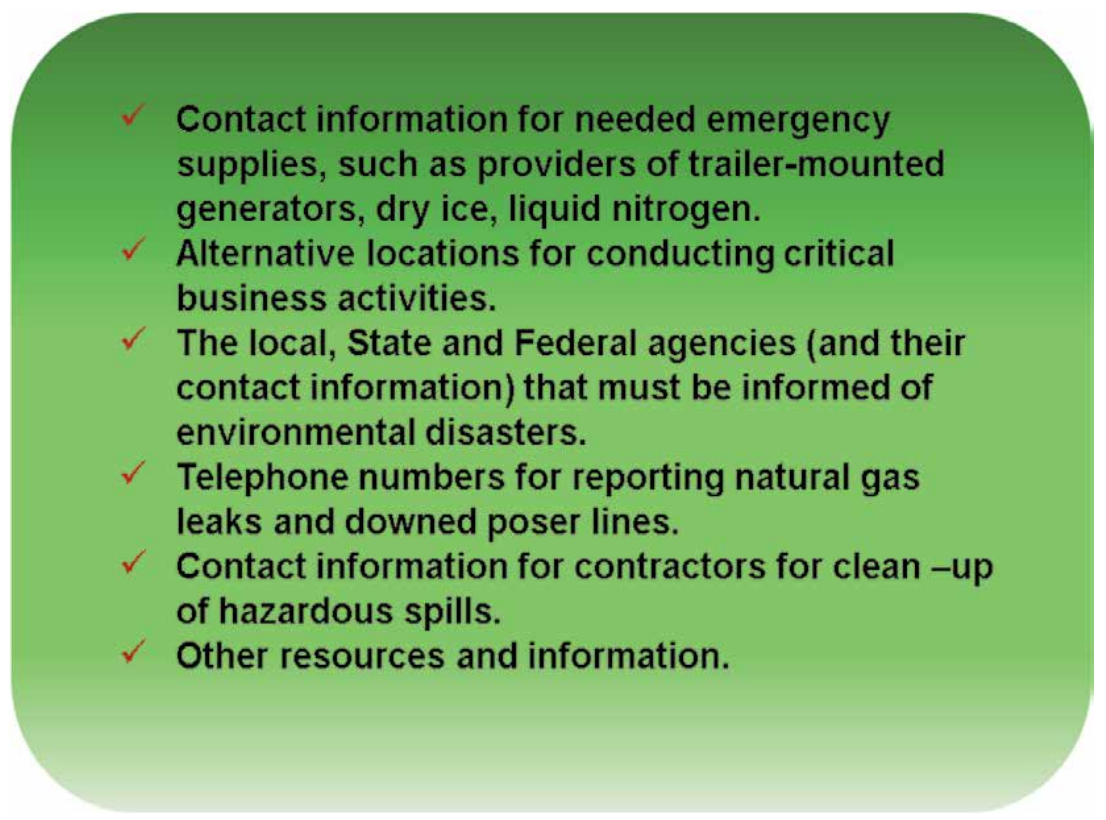

Figure 1.

Information emergency cases in a biobank. Adapted from: http://blog.fisherbioservices.com/bid/286295/ Defense-in-Depth-Off-Site-Storage-for-Biological-Specimens-and-Biopharmaceuticals-Risk-Mitigation.

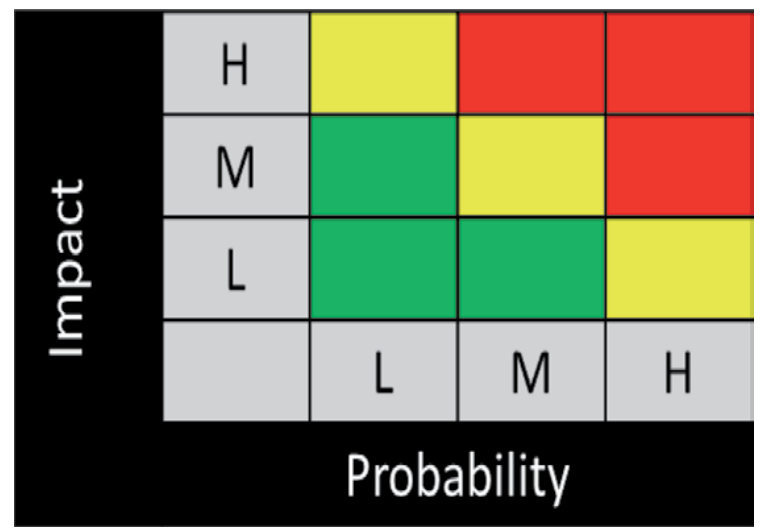

Figure 2.

Risk matrix adapted for use in qualitative risk analysis.

allows one unit to maintain accurate facility temperatures, while the other is serviced or repaired and at the same time may deliver extra cooling capacity for unexpected events [1].

Risk mitigation occurs at all levels of operations. Hence, in the following chapters, we will discuss and explore the possible risks and action strategies, if a risk occurs (Figure 2).

\section{Risk management plan}

In general a risk is an event or condition that, if it occurs, could have a negative effect on an organization. 
The direct citation of the definition is as follows: "Risk Management is the process of identifying, assessing, responding to, monitoring, and reporting risks. Therefore, a risk management plan defines how risks associated with the organization will be identified, analyzed, and managed. It outlines how risk management activities will be performed, recorded, and monitored using templates and practices for recording and prioritizing risks."

The aim of risk management is to prevent that risks become a problem or to minimize the damage, which could occur because of risks. By consistently searching and analyzing possible risks, a possible operational blindness is eliminated as well.

One of the methods that can be used when identifying risks is a Strengths and Weaknesses, Opportunities, and Threats (SWOT) analysis. When using this tool, internal factors (Strengths and Weaknesses) and external factors (Opportunities and Threats) are analyzed. As the risks for a biobank are very comprehensive, an own risk management strategy should be implemented for each biobank.

\subsection{Process}

Risks will be actively identified, analyzed, and managed periodically. They will be identified as early as possible to minimize their impact. The steps for accomplishing this are outlined in the following sections. One defined responsible person should serve as the risk manager for the organization.

\subsection{Risk identification}

Risk identification involves the management team and includes evaluation of environmental factors, organizational culture, and the strategic plan of a biobank. Careful attention needs to be given to the business plan and the stakeholder analysis cost/effort estimates, resource plans, and other key project documents.

\subsection{Risk analysis}

All recognized existing and probable risks must be evaluated in a matter of classification of the potential variety of consequences in the real case. Criterion must be implemented and discussed for definition, categorization, and regulation of risks. The recognized top risks must be followed and reacted immediately, and there will be some risks which in the given period of development can be ignored.

\subsubsection{Risk analysis}

The likelihood and influence of manifestation for individually recognized risks should be evaluated by the team of the given biobank under the moderation of risk manager. The important criteria for this consideration are probability and impact.

Probability

- High—over $<70 \%>$ likelihood of incidence

- Medium-over $<30 \%>$ but under $<70 \%>$ likelihood of incidence

- Low-under $<30 \%>$ likelihood of incidence 
Impact

- High are those risks which have the possible outcome of causing high expenses and big shifts of routine timetable or performance.

- Medium are those risks which have the possible outcome of causing slightly higher expenses and moderate shifts of routine timetable or performance.

- Low are those risks which have a possible outcome of causing some expenses and slight shifts of routine timetable or performance.

Breakdown of risk events, which are ranked by qualitative risk analysis and the consequence results, will be estimated (a numerical rating applied to each risk based on this analysis) and then documented in this section of the risk management plan.

\subsection{Planning of risk response}

For any major risk, an assignment together with responsible team/s or team member/s needs to be performed in order to monitor and to confirm the risk observation. For handling of the recognized major risks, individual tactics can be and should be carefully chosen:

- Avoid-Exclude the hazard by reducing or excluding the source

- Mitigate-Recognize ways to decrease the likelihood or the effect of the given risk

- Accept-No action needed

- Transfer-Nominate alternative party in charge for the given risk (e.g., outsourcing)

For any given risk, which will be moderated, the responsible "employee's group" needs to recognize ways to elude or as a minimum alert the risk or decrease its effect or chance of arising. This may comprise prototyping, calculations in the timetable, counting of additional resources, etc.

For any recognized major risk, which needs to be reduced or accepted, a development of action plan should be drawn for the incident of risk materialization and impact decrease.

\subsection{Monitoring, controlling, and reporting}

The level of risk needs to be followed, checked, and reported periodically. All change requests will be analyzed for their possible impact to the risk management. Management will be notified of important changes to risk status (Figure 3). To summarize, the following steps should be complied with the development of a risk management plan:

1. Identification of risks (brainstorming, cause and effect diagram, lessonslearned, analysis of documents) 


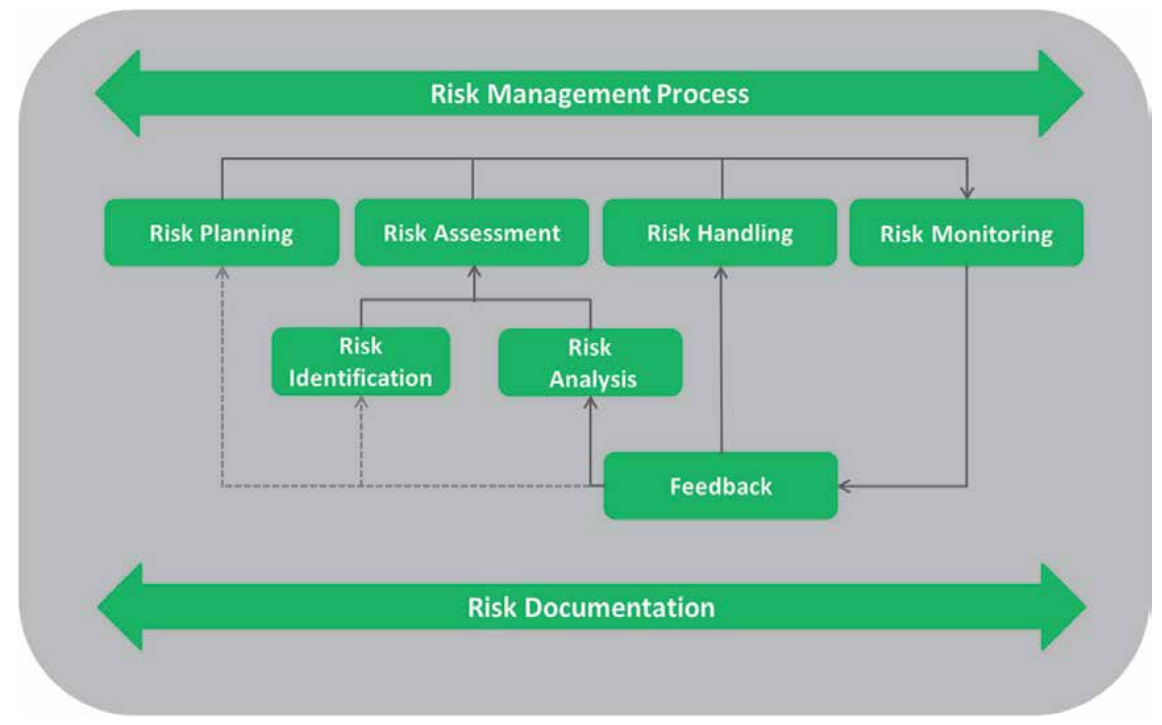

Figure 3.

Overview risk management process.

2. Analysis and evaluation of risks (development of a risk list, evaluation of probability and impact of occurrence for each identified risk)

3. Determine measures (in accordance to periodization-development of a catalogue of measures)

4. Monitoring risks (risk controlling-change of basic conditions, new risks, etc.)

\section{Adapt planning}

\section{Important risk management tools}

\subsection{Risk assessment template}

A risk assessment is a methodical technique of considering the routine and/or special work tasks, by means of thoughts on "what can go wrong." Then, it is the decision on appropriate control methods to avoid defeat, harm, or injury at the workplace. The calculation must comprise the controls, which are obligatory to exclude, decrease, or minimize the given risks.

This will depend on the organization and may vary depending on the nature of work. However, assessments must consider everyone who could be affected by that activity.

There are no unbreakable and/or reckless guidelines about how the risk assessments must be performed. Every organization, team, or department is different, so they may necessitate a somewhat diverse approach. It is nevertheless significant that risk assessments are conducted methodically and reflect all of the predictable risks. 
Risk Manager:

\begin{tabular}{ll}
\hline Address of the organization & \\
\hline Organizational unit & \\
\hline Task of the organizational unit & \\
\hline Risk owner & \\
\hline Number of employees & $\square$ Semi-annually \\
\hline Description of risk assessment & $\square$ Annually \\
\hline Risk monitoring & $\square$ \\
& XX.xx.xxxx \\
& In progress \\
Date and status & Valid until \\
& Invalid since: Xx.xx.xxxx \\
\hline Signature risk owner and date of approval: & \\
\hline
\end{tabular}

\subsection{SWOT analysis}

The direct citation of the definition is as follows

A SWOT analysis is an acronym for strengths, weaknesses, opportunities, and threats and is a structured planning method that evaluates those four elements of a projector a company. A SWOT analysis can be carried out for a company, product, place, industry, or person. It involves specifying the objective of the company or project and identifying the internal and external factors that are favourable and unfavourable to achieve that objective [2].

\subsubsection{History}

Albert Humphrey, a research manager and project leader at Stanford University between the 1960s and 1970s, invents the background of SWOT analysis method. He consumed a high amount of data from different top companies for the proof of the method. The aim was the recognition and identification of the causes of corporate planning errors. The subsequent research acknowledged a specific quantity of main areas to be addressed. The method, which is to be used to explore each life-threatening area, was named SOFT. The direct citation of the categories is as follows:

What is good in the present is Satisfactory, good in the future is an Opportunity; bad in the present is a Fault and bad in the future is a Threat.

- Strengths: characteristics of the company or project that give it an advantage over others

- Weaknesses: characteristics of the company that place the business or project at a disadvantage relative to others

- Opportunities: elements in the environment that the company or project could exploit to its advantage 
- Threats: elements in the environment that could cause trouble for the business or project

Identification of SWOTs is important because they can inform later steps in planning to achieve the objective. First, decision-makers should consider whether the objective is attainable, given the SWOTs. If the objective is not attainable, they must select a different objective and repeat the process (Figure 4) [3].

\subsubsection{A practical example for biobanking}

Within the HigherKos project "CONEKT_Cooperation, Networking and Knowhow Transfer between Austria, Kosovo, Albania in the field of Biobanking” for two biobanks of CEE countries, a SWOT analysis was performed to determine the strengths, weaknesses, opportunities, and threats of each partner (Table 1).

If specific values related to your business offerings are established within the four quadrants of SWOT analysis, a strategic plan based on the learned information could be developed.

Therefore based on the SWOT analysis, a strategy paper was developed for each country. More efficient strategies for biobanking processes and use of existing infrastructure and knowledge in research were defined (Figure 5).

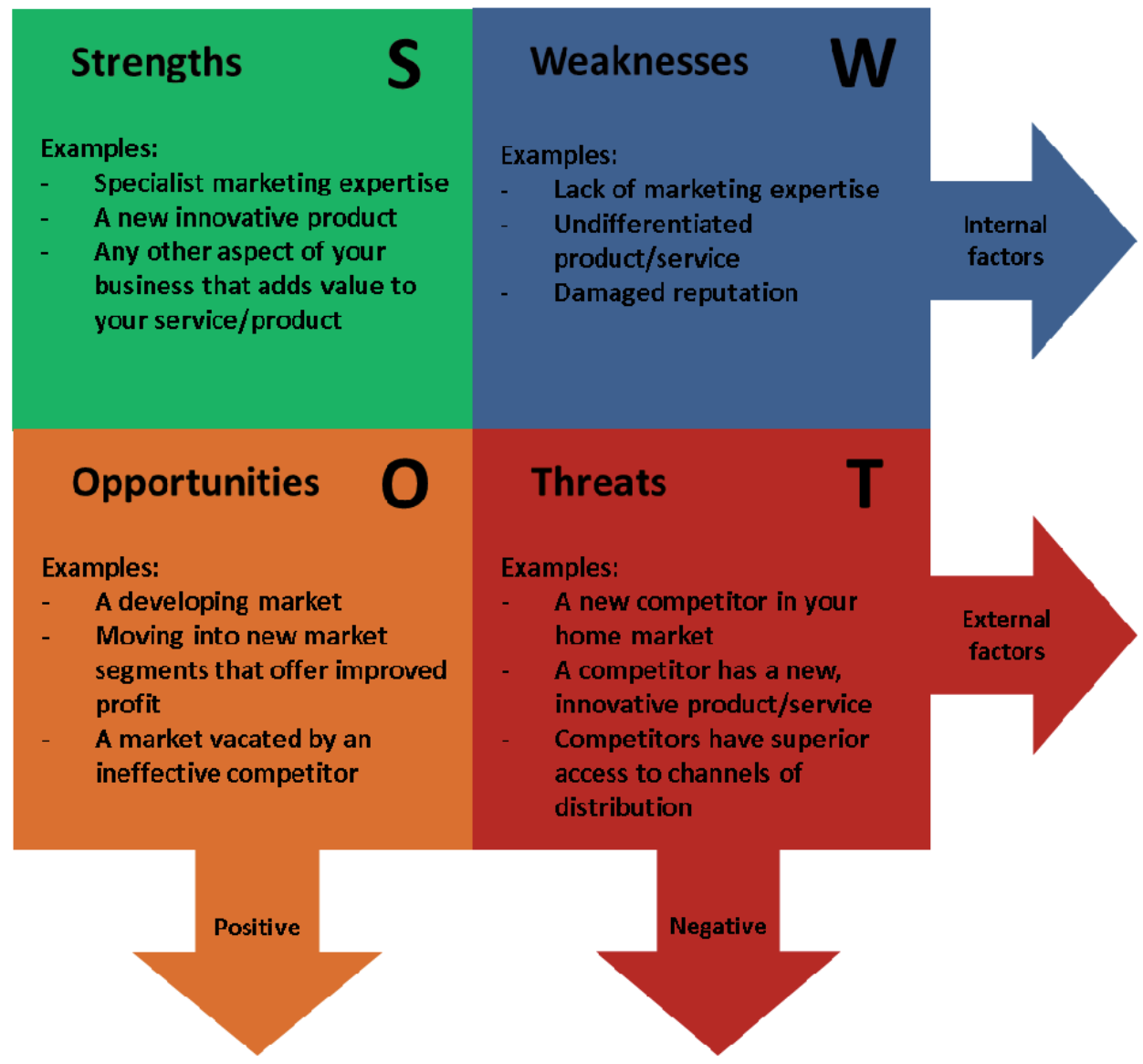

Figure 4.

Overview SWOT analysis. Adapted from source: https://conceptdraw.com/a462c3/preview-SWOT\%20ana lysis\%2omatrix. 
Strengths

- Access to focused patient collective

- Already existing sample collections (blood, liquid body fluids, tissue, microbial cultures, DNA): disease and population based

- Access to public

- Access to students

- Support by opinion leaders/key players: minister of health, chairman of the local ethical committee board, dean of medical faculty

- Unique epidemiology profile (e.g., TBC, Crimean-Congo hemorrhagic fever, brucellosis)

- Already some experience with grants and interdisciplinary collaboration

- Provided services: diagnostic, research, consulting
- Limitation of health care system (motivation, low salaries of all personnel)

- HIS status: limited access to local clinical data

- LIS status: new computer program since 05/ 2013, but no general access-only NIPH

- No standardized biobank databank for sample management

- No separate budget for pathology

- Lack of experience in biobanking

- Idea of academic career

- No dedicated personnel

- Lack of technical staff

- Undertrained technical staff

- Uncoordinated ethic landscape

- No QM system \& SOPs for sample collection and handling (e.g., unsteady formalin concentration of tissue samples

- For tissue samples: no standardized formalin concentration

- Restricted research possibilities due to sample treatment (formalin vs. fresh frozen tissue)

- Infrastructure service: Maintenance of equipment is difficult

- Lack of space

- Sample circulation to private labs \& loss of samples

- Separate sample collections at departments UCCK, Forensic medicine \& NIPHK

- No informed consent data

- Pencil-marked blocks \& slides; storage in cardboard boxes \& wooden racks)

- Suboptimal safety conditions at pathology

Opportunities Threats

- Collection opportunity potential

- International collaboration

- Interdisciplinary collaboration potential

- Academic research potential (young generation)

- European (international and private funding

- Collection of private institution
- Economic risks

- Low health care budget

- Sustainability

- Brain drain

- Legal \& ethical changes

- Weak coordination of responsible authorities

- No motivation of research and development (culture)

- No health insurance system

Table 1.

SWOT analysis_example of one of the partners (HigherKos Project-CONEKT).

\section{Implementation of a risk management plan}

As mentioned before in the planning of biobank infrastructure and processes, a specific focus should be on risk management in the case of disasters and unexpected occurrences. In the future, risk management has to be a core competency of every biobank. In order to provide structure for a risk management plan, risks need to be categorized. On the one hand, managers/directors have to ensure that there is an effective management of both, few risks that are fundamental to the organizations and many risks that impact on day-to-day activities and have a shorter time frame 


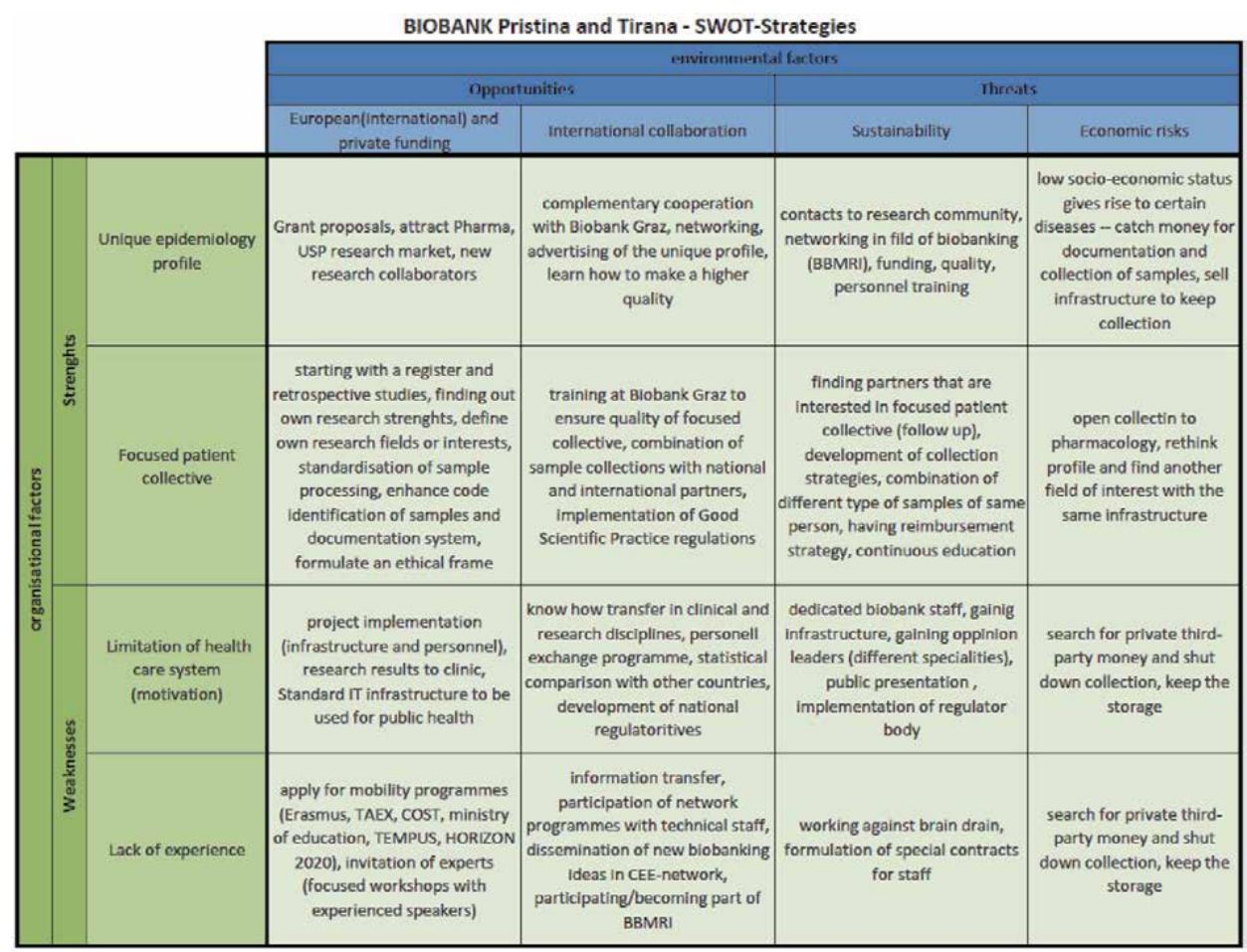

Figure 5.

SWOT strategies - practical example of two biobanks of CEE countries (HigherKos Project - CONEKT).

than longer-term strategic risks. These two types could be categorized as strategic and operational risks (Figure 6).

\subsection{Strategic risks}

Strategic risks are those that arise from fundamental decisions that managers/ directors take concerning organization's objectives.

Strategic risks are often risks that organizations may have to take in order to expand and to continue in the long term. The following section describes some strategic risks of a biobank.

\subsubsection{Unpredictable change of the strategic focus of the funding organization}

\section{Possible reasons}

- No financial support because of a small budget

- Providers of samples do not feel recognized through scientific leadership in their collection strategy — they are worried about the scientific usage.

\section{Possible consequences}

- The biobank is no longer the strategic flagship of the funding organization

- A scientific character in leading the biobank would complicate sample procuring

- Certificate extension would be in danger 


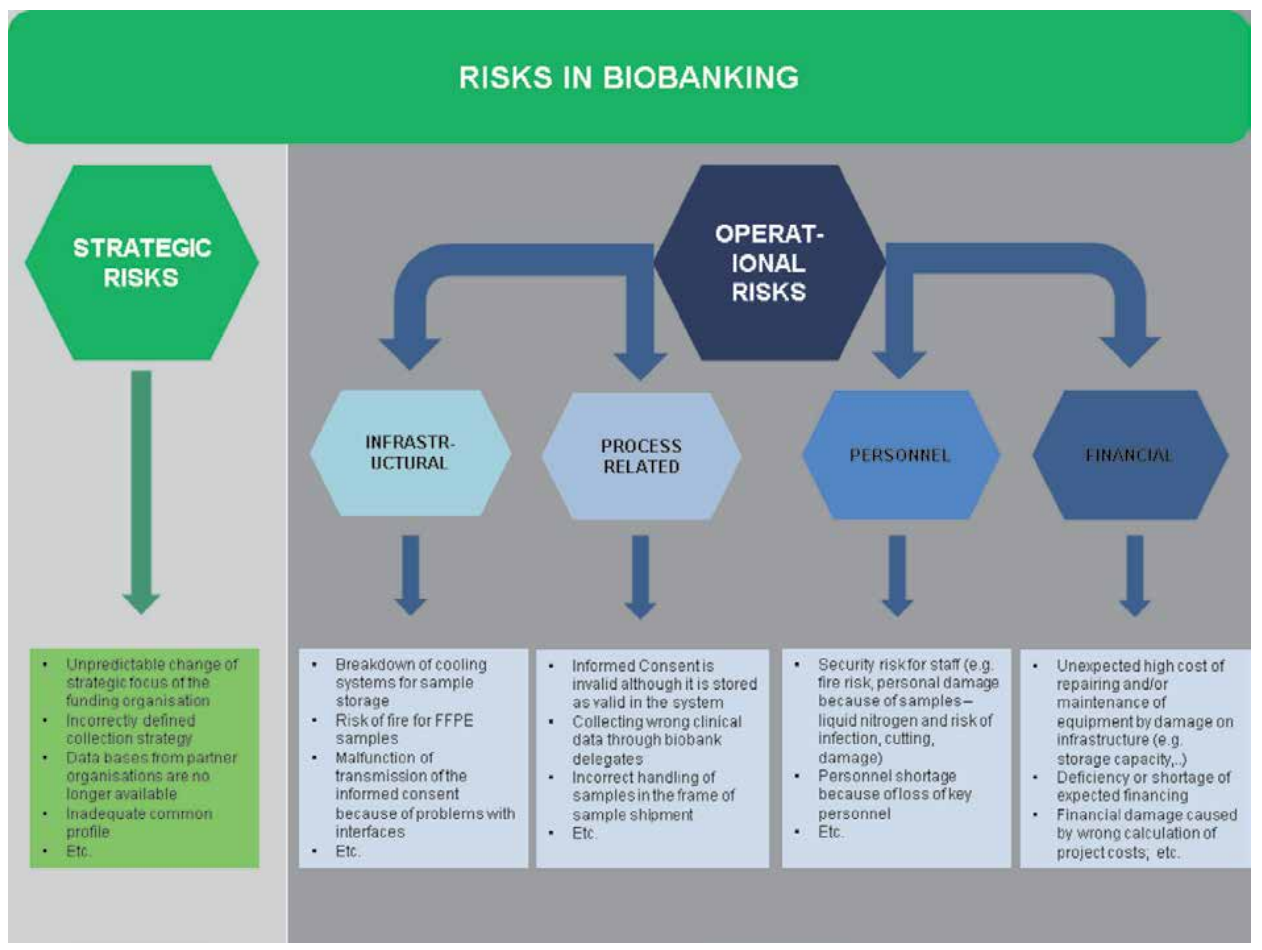

Figure 6.

Overview: risks in biobanking.

\section{Possible coping strategies}

- Regular information exchange with the funding organization and cooperative partners

- Close cooperation in establishing and implementation of the collection strategy

- Establishing a long-term strategy for financing

- Developing general conditions for collection strategies and developing rights and obligations for scientific leadership

\subsubsection{Incorrectly defined collection strategy according to bio specimens}

\section{Possible reasons}

- An insufficient adaptation of the list of collection criteria

- An insufficient trained personnel

- An insufficient infrastructure and/or instrument-qualifications for labs and storage

\section{Possible consequences}

- Samples are not used or useable in scientific projects 


\section{Possible coping strategies}

- For each cooperation an individual collection strategy will be developed, which will be defined together with the cooperation partners.

- Intensive cooperation with the areas of research of the organization.

- Specification of risks, including infrastructure, equipment and personnel (e.g. documentation of near-accident)

\subsubsection{Databases from partner organizations are no longer available}

\section{Possible reasons}

- Unclear contract situation with partner organizations

- Expiration of the cooperation contract

\section{Possible consequences}

- No access to data of the partner organization

\section{Possible coping strategy}

- Better contractual protection and control

\subsubsection{Inadequate common profile}

\section{Possible reasons}

- Lack of personnel—not enough time for PR activities

\section{Possible consequences}

- Less projects-less project requests $\rightarrow$ risk of interruption of third-party funding

\section{Possible coping strategies}

- Higher prioritization of PR activities and lobbying

- More budget for PR activities and presentations at congresses

\subsubsection{A bad strategy for public relation activities for the donors}

\section{Possible reasons}

- Inadequate information transfer to donors

- Inadequate trained medical personnel for the informed consent procedure

- A hardly comprehensible informed consent 
- Low level of awareness and transparancy (e.g. by a lack of public events and publications)

\section{Possible consequences}

- Reduced number of donors

- Increased number of withdrawals

\section{Possible coping strategies}

- Easy understandable informed consent

- More time for personnel training and informed consent procedure with donors

- Creation of visual informed consent information if possible in various languages

- Cooperation with media representatives

- Implementation of a marketing concept for specific positioning on the biobanking market

\subsubsection{Changes of legal and ethical aspects}

\section{Possible reasons}

- New national/European/international regulation

- Further development of the field in the society

- New constitution of an ethical committee/IRB

- Test cases that force the legislative organs to sharpen the law

\section{Possible consequences}

- Loss of ethical approval and stop of operation (in best case until the new approval is in place)

- Completely new development and/or sharpening of own governance

- Termination of biobank (if it is not allowed at all by law)

\section{Possible coping strategies}

- Cooperation with legislative organs on new regulation (being informed and prepared, having an influence from the beginning)

- Preparation of own approvals, applications, and governance in accordance with new regulation/law in advance

- Dialog with other biobank sand interest groups to be informed and exchange of experience about implementation 


\subsubsection{Wrong assessment of the stakeholder analysis}

\section{Possible reasons}

- Newly appointed (external) personnel without knowledge of internal/external dependencies

- Misestimating the importance of individual stakeholders

- Lack of farsightedness of operational management

\section{Possible consequences}

- Loss of possible funding by specific stakeholders

- Less favourable political standing and/or support

- Loss of sources of sample/data

- Bad image

\section{Possible coping strategies}

- Stakeholder analysis with all levels of management including carrier organization and environment

- Discussion of first results with key players internally/externally, researchers, and politics with an intention to complete the analysis

- Repeating first assessment, e.g., after 3 and 6 months, and implementing a strategy of renewal of assessment after each year

- Investigation of such analysis of comparable institutions and other local cooperation partners

\subsubsection{New strategic trends in the market of biobanking}

\section{Possible reasons}

- New research technology

- New hot topics in science

- New standards in biobanking and the pre-analytical field

- Population health-driven trends (novel infectious agents, healthy aging research and/or fertility research)

\section{Possible consequences}

- Being out of trend

- Less projects-less project requests

- Risk of interruption of third-party funding 


\section{Possible coping strategy}

- Continuing research market analysis

- High priority of congress and conference participation

- Evaluation of the requests that are not processed and implementation of strategies to close the gap (if applicable)

\subsection{Operational risks}

Not only strategic risks need to have awareness, but it is important to have an insight to "the bottom" of the organizations, e.g., if infrastructure is disturbed or key staff is leaving because of dissatisfaction, then operating the biobank may run into trouble before all new plans can be implemented. These are operational risks-risks connected with internal resources, systems, processes, and employees of the organization. The following section describes some operational risks of a biobank.

\subsubsection{Infrastructural risks}

\subsubsection{Breakdown of cooling systems for low-temperature sample storage}

\section{Possible reasons}

- Infrastructural, technical reasons

- Missing backup devices and strategies

\section{Possible consequences}

- Tissue or blood samples can be damaged (depends on temperature and duration of breakdown)

- In a worst case (duration of breakdown and period until detection of the problem), the samples are not useable any more (loss of samples)

\section{Possible coping strategy}

- Staff training in accordance to validated Standard Operation Procedures

- Define responsible staff and representatives

- Installation of backup systems

- Development of an "emergency plan" for the weekend and public holidays

- Current maintenance of cooling systems through qualified technical personnel

- Installation of monitoring systems 
- If possible-expand personnel resources

- Conclude service agreements

\subsubsection{Risk of fire for FFPE samples}

\section{Possible reasons}

- Electric spark, dust, no or defective smoke detector

\section{Possible consequences}

- Loss of samples through heat and fire

- Danger to staff

\section{Possible coping strategy}

- Regular fire protection inspections

- Installation and maintenance of fire protection systems

\subsubsection{Malfunction of transmission of the informed consent because of problems with interfaces}

\section{Possible reasons}

- Technical failure

\section{Possible consequences}

- Error is not detected $\rightarrow$ samples are not available for research

- Error is detected $\rightarrow$ additional time required for new data entry or new transmission of data

\section{Possible coping strategy}

- A second transmission of stored documents is possible

- A second scan of informed consent is possible

\subsubsection{Breakdown of backup systems}

Natural disasters such as super-storms, droughts and earthquakes must also be taken into consideration by developing the risk management plan of a biobank but also it is important to have a breakdown plan-if the case arises. Among others, the recovery after disasters can be one of the most challenging tasks of biobank management and staff. There are several examples in the literature that show the challenges of such situations. It is important to note that the staff of the given biobank have to monitor the whole infrastructure in a way that does not harm them directly, e.g., the freezers, tanks, and other storage capacities. If the breakdown 
affects also the electricity supply, there must also be a plan " $\mathrm{B}$ " for this supply, as a variety of technicians, engineers and scientists, who are usually quite familiar with standard infrastructure must act together as a team and need the electricity supply for disaster management.

\section{Possible reasons}

- Natural disasters

- Human factor

- Planning of insufficient backup capacities

- Incorrectly integrated backup systems (no jump-in in case of emergency)

- No alarm system and 24/7 monitoring

- Backup system is not functional and or outdated

\section{Possible consequences}

- Loss of samples and data

- Loss of money and time

- No new projects-no third-party money

- Obligation to pay out partners (storage services)

- No space for new samples, stop of collection of essential samples caused by storage space restrictions

\section{Possible coping strategy}

- Exact planning of backups (at least 3 times backup storages and databases)

- Regular tests and controlling of function of backups and integration systems

- Alarm systems

- 24/7 monitoring with stand-by duty

- Large local and extramural backups

\subsubsection{Hardware or software errors of productive systems}

\section{Possible reasons}

- Operational error

- Programming error

- Production error 
- Installation error

- Lack of maintenance

\section{Possible consequences}

- Faulty documentation of samples $\rightarrow$ sample-related data are difficult to find; worst case is the loss of sample-related data

- Samples cannot be used for projects

- Image loss

\section{Possible coping strategies}

- Continuous improvement of the database system

- Structured evaluation and procurement (requirement specification)

- Implementing testing periods before launching

- Demand-oriented staff training

- Regular process monitoring

\subsubsection{Process-related risks}

\subsubsection{Informed consent is invalid although it is stored as valid in the system}

\section{Possible reasons}

- Invalidity of the IC cannot be detected during scanning and monitoring and therefore is stored as valid in the system

\section{Possible consequences}

- Samples cannot be used for projects

- Image loss

\section{Possible coping strategy}

- Staff training (staff who is scanning documents)

- Follow-up of stored documents is possible

\subsubsection{Collecting wrong clinical data through biobank delegates}

\section{Possible reasons}

- Biobank delegate gets the wrong patient identification from the biobank

- Wrong documentation in the clinical subsystem 


\section{Possible consequences}

- Output of samples with wrong clinical data $\rightarrow$ cause error results

- Image loss

\section{Possible coping strategy}

- Continuous improvement of data administration

- Regular process monitoring

\subsubsection{Incorrect handling of samples in the frame of sample shipment}

\section{Possible reasons}

- Wrong or inadequate labeling for shipment

- Incorrect packaging

\section{Possible consequences}

- Samples are no longer usable

- No fulfillment of the contract

- Additional costs for the biobank

- Loss of image

\section{Possible coping strategy}

- Testing of all available shipment companies with exact documentation, for decision about a partner in shipment (including cost-service calculation)

- Continuous training of personnel involved in shipment

- Exact procedure description of labeling and packaging with easy availability for the personnel (with exact pictures and measurements)

\subsubsection{Non-traceability of samples because of wrong allocation of samples during storage}

\section{Possible reasons}

- Loss of attention while manual labeling samples

- Badly readable sample codes by poorly labeling

- Bad documentation

- No well-trained staff 
- Lack of time

- High error rate of systems for storage of samples or for input of sample-related data

\section{Possible consequences}

- Valuable samples get lost and cannot be used for projects

- Longer period to find samples

- Waste of biobank resources

\section{Possible coping strategies}

- Staff training according to Standard Operation Procedures of the biobank

- Precise working while handling with samples

- "Four-eye principle"

- Regular process monitoring

- Automated identification and process of samples

- Further development of concepts

- Expanding of personnel resources

\subsubsection{Improper handling of samples in processing}

\section{Possible reasons}

- No well-trained staff

- Lack of time

- Cryosamples may defrost (long handling time, transport, long shipping time)

- Tissue could get damaged during the freezing process

\section{Possible consequences}

- Samples are not usable for projects

- Waste of biobank resources (storage capacity, liquid nitrogen, etc.)

\section{Possible coping strategies}

- Staff training according to Standard Operation Procedures of the biobank

- Precise working 
- Careful handling of samples

- Detailed information about shipping conditions and requirements

- Expanding of personnel resources

\subsubsection{Incomplete pseudonymization and anonymization of process-related data}

\section{Possible reasons}

- Negligent breach of data protection regulations of biobank staff

- Design or implementation errors of the used pseudonymization software

\section{Possible consequences}

- Image loss

- Sanctions because of breach of data protection law

- Action of affected patients

\section{Possible coping strategies}

- Continuous scientific testing and validation of data protection measures and software components

- Regular staff training

- Externalization of parts of this risk through outsourcing of pseudonymization/ anonymization by data custodians

\subsubsection{Insufficient informed consent discussion of the medical doctor for collection of samples}

\section{Possible reasons}

- Lack of time

- Lack of staff

\section{Possible consequences}

- Complaints because of inadequate informed consent discussions

- Image loss

- Scandalization

\section{Possible coping strategies}

- Training of medical doctors according to informed consent Standard Operation procedure 
- Integration of biobank processes into clinical processes of cooperating departments

- PR that revocation of the IC is possible at any time

\subsubsection{Data protection has been violated}

\section{Possible reasons}

- Hackers

- Burglary

- Non-compliance of data protection directive

- Software error

\section{Possible consequences}

- Image loss

- Sensible data escape outside

- Extortion because of date theft

- Claims for damages

\section{Possible coping strategies}

- Appointment of a biobank data protection officer

- Data protection training for the staff

- Sensible data is not printed on paper

- Storage of data in access-protected databases

- Network security

- Externalization of parts of this risk through outsourcing of pseudonymization/ anonymization by data custodians

\subsubsection{Mix-up of samples or sample related data}

\section{Possible reasons}

- Incorrect labeling of samples

- Damaged labeling

- Direct mix-up of samples 
- Wrong documentation in the internal database system

- Lack of time

- Lack of staff

\section{Possible consequences}

- Image loss

- Worthlessness of samples

- Wrong samples used in projects $\rightarrow$ wrong results

- Project partners get lost

- Claim of the biobank

\section{Possible coping strategies}

- Staff training according to Standard Operation Procedures of the biobank

- "Four-eye principle"

- Follow-up diagnosis through pathologists

- Approval through the biobank management

- Automated identification and process of samples

- Systematic control cuts

- Expanding of personnel resources

4.2.2.10 Less or no samples because of uncooperative medical personnel of the clinical partner

\section{Possible reasons}

- Bad communication

- Lack of staff

- Image loss

- Lack of information

\section{Possible consequences}

- Lack of samples with rare entities

- Loss of samples 


\section{Possible coping strategies}

- Training of medical personnel of the clinical partners

- Integration of biobank processes into clinical processes of cooperating departments

- Problem discussions

- Information and motivation of clinical personnel

- Current presentations and reporting about the biobank

- Expanding of personnel resources

4.2.2.11 No informed consent when including samples (serum, cryo)

\section{Possible reasons}

- IC is incorrect

- IC gets lost

- IC has been withdrawn

- IC is unscannable

- IC has not been obtained

\section{Possible consequences}

- Samples are not usable for research projects

\section{Possible coping strategies}

- Training of medical personnel of clinical partners

- Integration of biobank processes into clinical processes of cooperating departments

- Process control through a traffic light system

- Comprehensive IC in all clinical departments of the hospital

4.2.2.12 The informed consent is invalid although it is marked as valid in the system

\section{Possible reasons}

- Invalidity of the informed consent cannot be detected when scanning

\section{Possible consequences}

- Samples are not usable for research projects

- Image loss 


\section{Possible coping strategies}

- Staff training (personnel who is scanning ICs)

\subsubsection{Samples are not usable or inadequate}

\section{Possible reasons}

- Long ischemia time because of long waiting period in the surgery department

- Poor communication by biobank staff

- Wrong allocation in handhelds

- Thawing of samples

\section{Possible consequences}

- Samples are not usable for projects

- Storage capacities are wasted

\section{Possible coping strategies}

- Precise working

- "Four-eye principle"

- Staff training

- Current communication with cooperating partners

\subsubsection{Project requests or project-related data get lost}

\section{Possible reasons}

- Hardware/software problems

- Accidental deletion of project data

\section{Possible consequences}

- Difficulties in re-identification of samples and related clinical data

\section{Possible coping strategies}

- Staff training

- Data backup 
4.2.2.15 External transport of samples to the biobank is too long and incorrect

\section{Possible reasons}

- Too long ischemia time because of long waiting periods in the operating room

- Poor communication between biobanking staff and clinical partners

- Wrong allocation in the handheld devices (e.g., wrong location, wrong diagnosis, etc.)

- Thawing of samples

- Staff for the transport was informed too late

\section{Possible consequences}

- Samples are not usable for projects

- Storage capacities are wasted

- Loss of value of samples

\section{Possible coping strategies}

- Rapid information transfer

\subsubsection{Personnel risks}

4.2.3.1 Security risks for staff (e.g., fire risks, personal damage because of samples (liquid nitrogen), risk of infection, cutting damage, etc.)

\section{Possible reasons}

- Careless handling

- Ignoring of safety regulations (usage of devices, chemicals, etc.)

\section{Possible consequences}

- Sick leave

- Lifelong handicap or invalidity

\section{Possible coping strategy}

- Staff training

- Security training

- Safety notes 
- Supply safety clothing and safety devices

- Documentation of near-accidents, including related adaption of processes

\subsubsection{Personnel shortages because of loss of key personnel}

\section{Possible reasons}

- Too little money and less professional prospects

- Too less education of professional personnel

\section{Possible consequences}

- Problems in execution of all processes

- Failure of IT support

- Failure of biobank management

\section{Possible coping strategies}

- Implementing representation rules

- Implementing attractive conditions and development opportunities for staff

- Expanding personnel resources

\subsubsection{Financial risks}

\subsubsection{Unexpected high costs of repairing and/or maintenance of equipment after damage of infrastructure (e.g., storage capacity)}

\section{Possible reasons}

- Incorrect or unplanned usage

- No regular maintenance

- Unexpected error

- Natural disasters

- Deterioration of old equipment

\section{Possible consequences}

- Unbudgeted repair costs-no money for other essentials (consumable, personnel, etc.)

- Unbudgeted repair costs_-no budget-loss of equipment (storage capacity, other robotics) 


\section{Possible coping strategies}

- Regular training of new and skilled personnel on correct usage of equipment

- Lab books with errors and error handling

- Regular maintenance of infrastructure with professional staff

- Replacement of old equipment in time

- Budgeting of backup funds for contingency

4.2.4.2 Financial damage caused by loss of samples (natural disasters)

\section{Possible reasons}

- Natural disasters

- Supply chain damage

\section{Possible consequences}

- Loss of samples and data, e.g., loss of money and time

- No new projects-no third-party money

- Possible: obligation to pay out partners (storage services)

- Functioning stop!

\section{Possible coping strategy}

- Extramural backup for samples and data

- Budgeted backup funds

- Insurance with reliable coverage

\subsubsection{Deficiency or shortage of expected financing}

\section{Possible reasons}

- New political orientation

- Country budget struggling

- No successful applications

- No written agreements

\section{Possible consequences}

- No budget for new investments

- No money for running costs and essentials (consumable, personnel, etc.) 


\section{Possible coping strategies}

- Budgeted backup funds

- Planned low cost run of biobank

- Collection slow down and sharpening

- Active advertisement for projects

- Acquiring of third-party funds

4.2.4.4 Financial damage caused by wrong calculation of project costs

\section{Possible reasons}

- Incomplete calculation guidelines

- Lack of training of personnel and controlling

- Underestimation of efforts and expenses

- Communication errors (internal and external)

\section{Possible consequences}

- Budget deficits

- No money for running costs and essentials (consumable, personnel, etc.)

- No recognition of real costs-customer loss

\section{Possible coping strategies}

- Regular and documented training of personnel

- Calculation guidelines proven by external professional body

- Detailed communication with project partners and customers with usage of check lists

- Timely communication about possible change of costs

\subsubsection{Financial damage caused by loss of samples in the course of a project}

\section{Possible reasons}

- Wrong or insufficient documentation

- Incomplete identification concept

- Untrained personnel

- Communication errors (internal and external) 


\section{Possible consequences}

- No money for running costs and essentials (consumable, personnel, etc.)

- Obligation to pay the expenses of project partner

\section{Possible coping strategies}

- Detailed and consequent training of personnel

- Extramural backup for samples and data

- Budgeted backup funds

- Insurance with reliable coverage

\section{Author details}

Karine Sargsyan ${ }^{1,2,3 *}$, Brigitte Jaksa ${ }^{1}$, Gabriele Hartl ${ }^{1}$ and Tanja Macheiner ${ }^{1}$

1 International Biobanking and Education (IBE), Medical University of Graz, Austria

2 Department of Genetics, Yerevan State Medical University, Armenia

3 National Medical Research Radiological Centre of the Ministry of Health of the Russian Federation, Russia

*Address all correspondence to: karine.sargsyan@medunigraz.at

\section{IntechOpen}

(C) 2020 The Author(s). Licensee IntechOpen. This chapter is distributed under the terms of the Creative Commons Attribution License (http://creativecommons.org/licenses/ by/3.0), which permits unrestricted use, distribution, and reproduction in any medium, provided the original work is properly cited. (cc) BY 


\section{References}

[1] Back-up Strategies and Risk Migration in Biobanks. Available from: https://www.thermofisher.com/blog/ biobanking/do-you-have-acomprehensive-risk-mitigation-planin-place-for-your-biobank/

[2] Humphrey AS. SWOT Analysis for Management Consulting. SRI Alumni Newsletter. SRI International; 2005

[3] History of SWOT Analysis. Available from: https://rapidbi.com/swotanalysis/ 

